\title{
How Can National Competitiveness of Less Developed Countries be Enhanced? : A Case Study of Laos
}

\author{
By \\ Phoxai Inthaboualy
}

Supervised by

Dr. Revti Raman

A thesis submitted to the Faculty of Commerce and Administration, Victoria University of Wellington in fulfilment of the requirements for the degree of Master of Commerce and Administration in International Business

Victoria University of Wellington, New Zealand 


\begin{abstract}
The current literature focuses primarily on the national competitiveness of developed or developing economies. However, minimal research exists on understanding the national competitiveness of less developed countries (LDCs) whose strengths in factor endowments, government institutions and the extent of global integration are not the same as those of developed or developing countries. This study aims to fill this research gap by exploring factors contributing to the competitiveness of Laos. Laos is a small, poor and land-locked country in Southeast Asia with rich natural resources. To achieve the study objectives, 20 semi-structured interviews were conducted with senior government officials, industrial representatives, professors and NGOs in Laos. The findings suggest three key factors are critical for enhancing Lao competitiveness: factor endowments, the role of government, and global integration. Laos' factor endowments include hydropower, mining, agriculture, garment and textile industries, and services. Laos is interacting more with the global economy as it gets set to embrace membership of the World Trade Organisation after approximately 15 years of membership of ASEAN. The government is playing a critical role by developing Lao factor endowments and developing policies required for global integration. However, the country faces challenges of value addition to the existing natural resources, developing and leveraging human capital, and further improvement in rules and regulations.
\end{abstract}

Key words: national competitiveness, globalisation, less developed countries, Laos 


\section{Acknowledgements}

After two years of study at Victoria University of Wellington, I find it incredible that I accomplished my Bachelor of Commerce and Administration with Honours in 2010 and have now, more importantly, achieved a Master of Commerce and Administration. I would like to express my deep gratitude to people around me for their great support, patience, encouragement, cooperation and assistance during my study. This support has contributed fundamentally to the completion of my thesis; without it I would have found this Master's degree impossible to finish. Therefore, I would like to take this opportunity to formally express my sincere thanks to everyone.

A Master's thesis would not have been possible without the great support, guidance, encouragement and patience of my supervisor, Dr. Revti Raman. His time, knowledge, expertise and experience have been invaluable in helping me to finish my thesis. His role as supervisor and mentor has been vital to me throughout the year, and especially during the final phase of this thesis.

I would also like to thank all the staff and lecturers of the School of Marketing and International Business (SMIB), and the Faculty of Commerce and Administration (FCA), for their support during my studies. Their input has significantly broadened my knowledge and strengthened my ability to accomplish my career in the future. More importantly, it will assist in the development of my home country, Laos.

As one of New Zealand's International Aid and Development Agency (NZAID) scholars from Laos, I would like to express my sincere thanks to the New Zealand government's Official Development Assistance Programme, and the Ministry of Foreign Affairs and Trade for its generosity in providing this invaluable opportunity to study in New Zealand. Moreover, I really hope that the New Zealand government will continue to expand and support more scholarships for Lao students to study at universities in New Zealand, in order to gain knowledge and related skills so that they can contribute to the social and economic development of the country upon their return. In addition, this contribution is considered a significant effort to develop human resource and to help the country graduate from a less developed status in alignment with the Lao government's Millennium Development Goals. 
My data collection and interviews in Laos would not have been possible without a research grant from the NZAID. Furthermore, my field work in Laos was completed successfully because of the considerable assistance I received from government officials, private sectors, international organisations, universities and institutes. Their consultation and guidance helped me to gather my data productively and on time. I would also like to thank all the research participants immensely for providing the information for this thesis. I really appreciate their time, expertise and effort.

Another important source of tremendous support was the Student Learning Support Service (SLSS), who provided professional feedback and reviewing services, especially at the end of this project. I benefited from and appreciated their insightful suggestions.

Personally, I am greatly indebted to my parents, sister and brother in China, Australia and Laos for their encouragement and inspiration. And, most importantly, I thank my lovely wifeKhonesavanh, who was always there with me. She has given me so much by taking care of me and sharing every moment with me to enable me to get this far in my academic studies. I thank them all for their words of encouragement, kind support and love throughout the year I was writing this thesis.

Many thanks also to the Lao community in Wellington for sharing love, encouragement, friendship and laughter. I felt like I was living at home when I was there. Their ongoing support has always ensured that I was in the best study environment. 


\section{Table of Contents}

ABSTRACT.

. .1

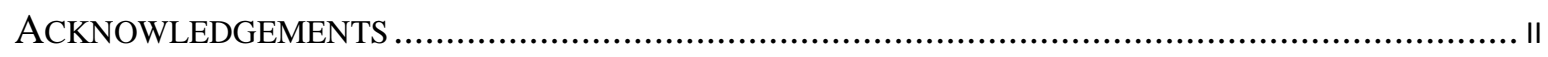

LIST OF ABBREVIATIONS AND ACRONYMS …..........................................................III

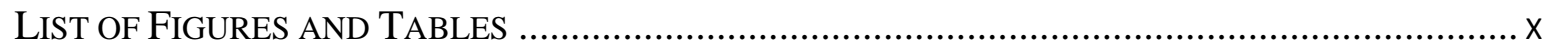

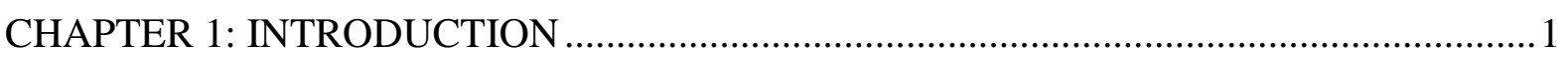

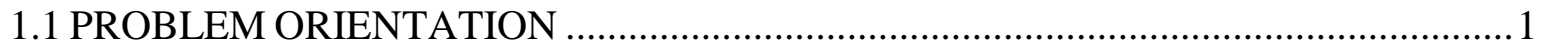

1.2 LAOS - A SOUTHEAST ASIAN LESS DEVELOPED COUNTRY ….........................

1.3 RESEARCH OBJECTIVES AND METHODOLOGY ...............................................

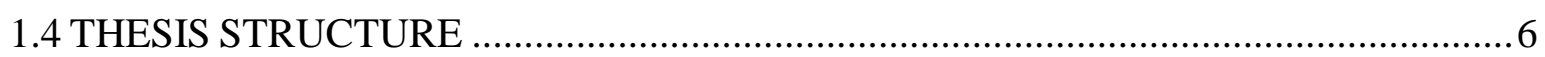

CHAPTER 2: AN OVERVIEW OF THE LAOS BUSINESS EVIRONMENT ..................... 8

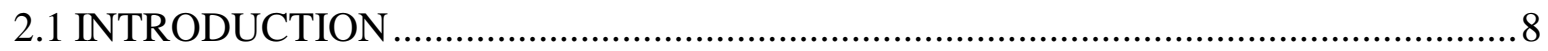

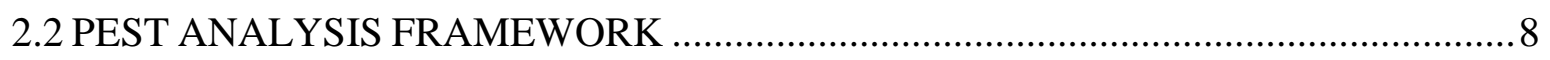

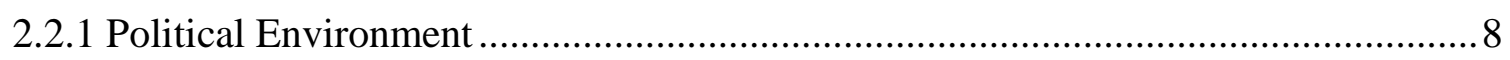

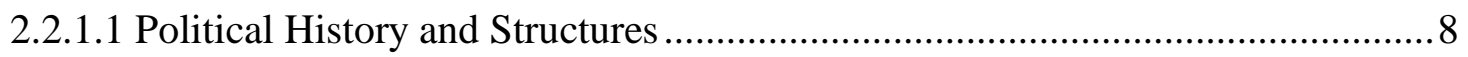

2.2.1.2 International Trade Policies........................................................................... 9

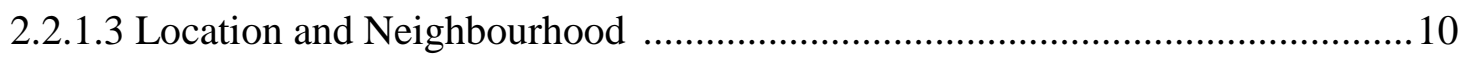

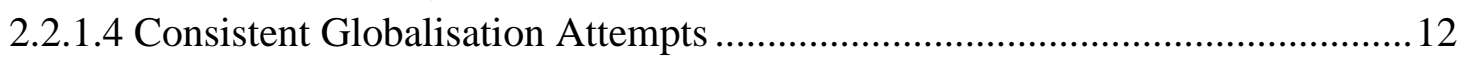

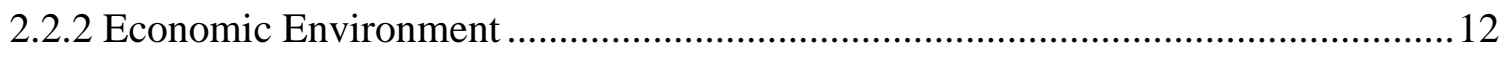

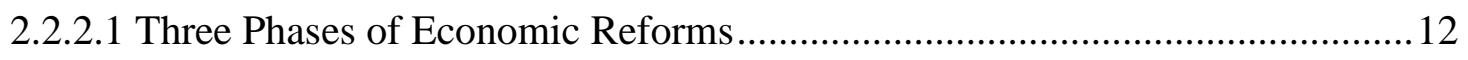

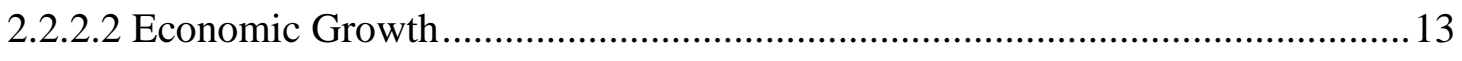

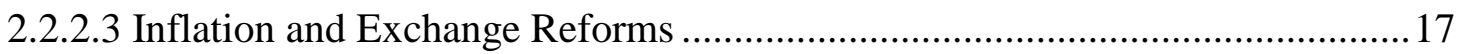

2.2.2.4 Constraints of Lao Economic Development................................................... 18

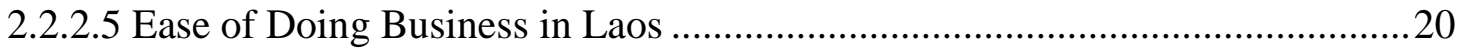

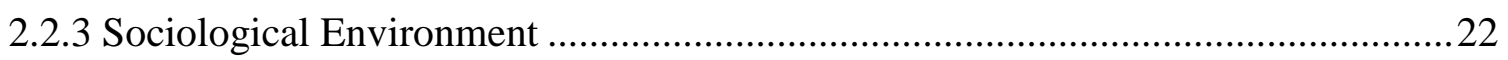

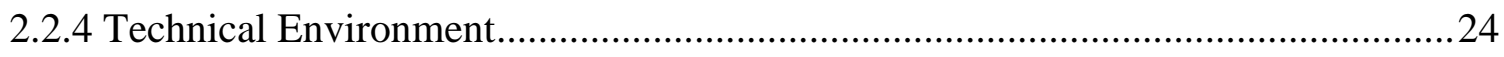

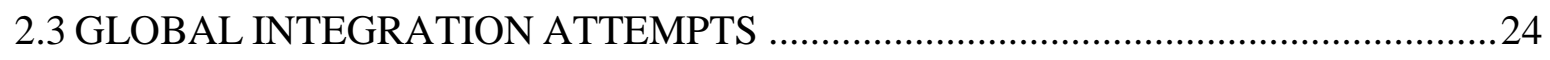

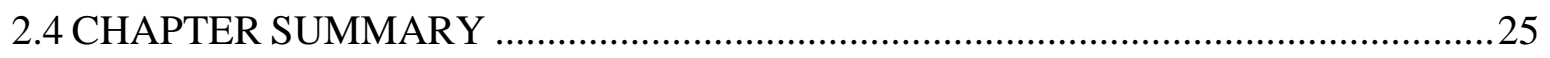

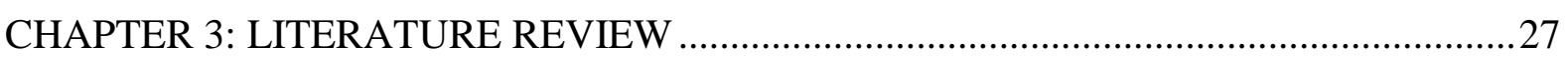

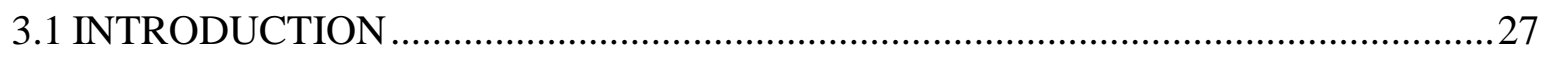

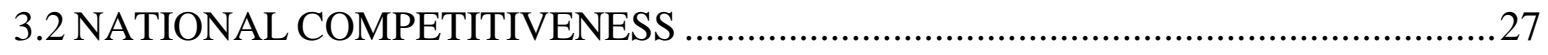

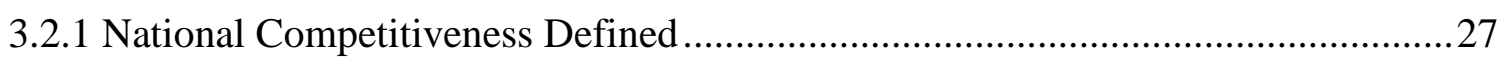

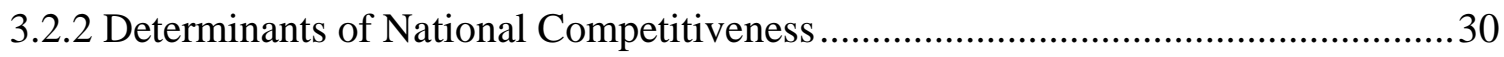

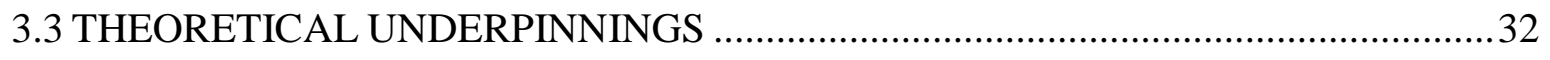

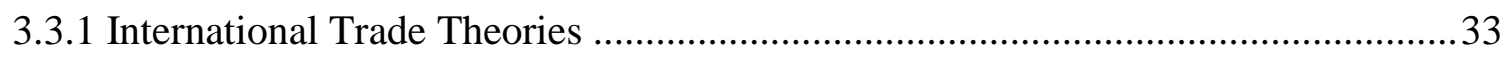




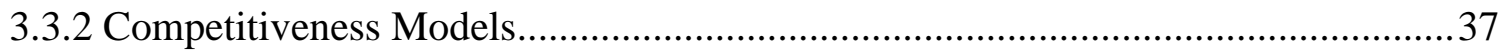

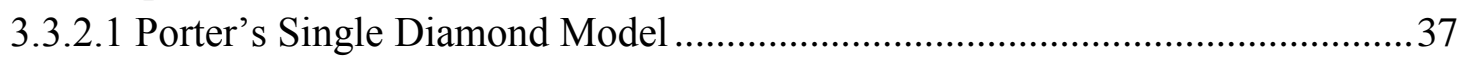

3.3.2.2 Extensions of Porter's Single Diamond Model .............................................. 40

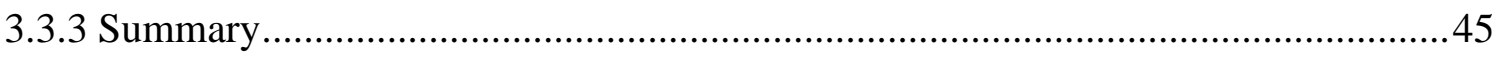

3.4 TRADE LIBERALISATION AND NATIONAL COMPETITIVENESS .....................45

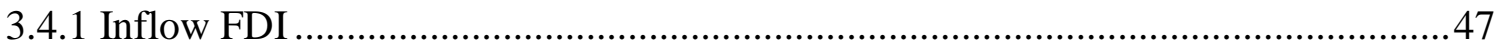

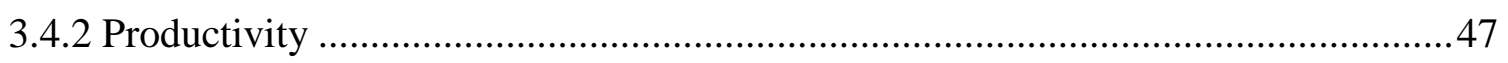

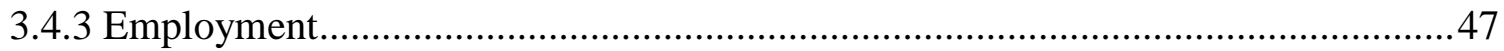

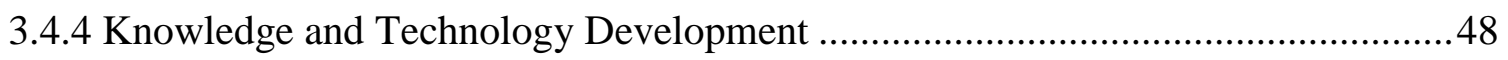

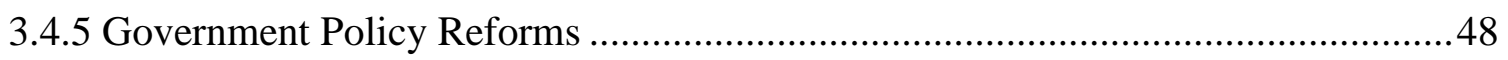

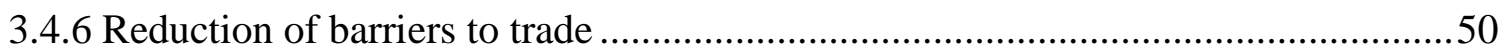

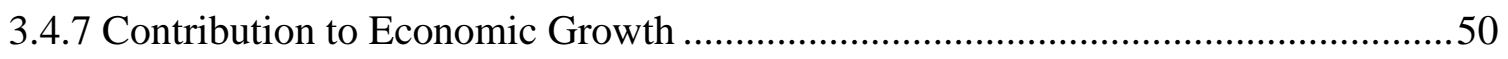

3.5 COMPETITIVENESS OF LESS DEVELOPED COUNTRIES …..............................50

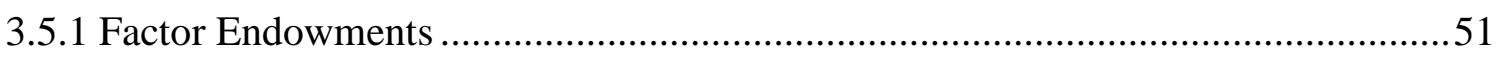

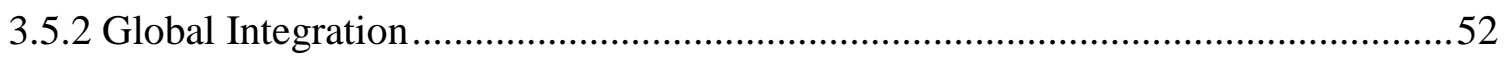

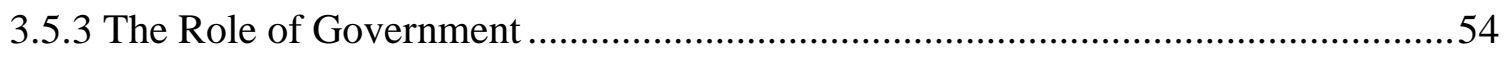

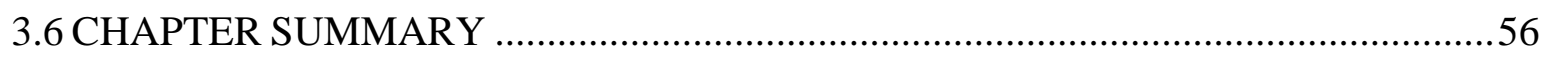

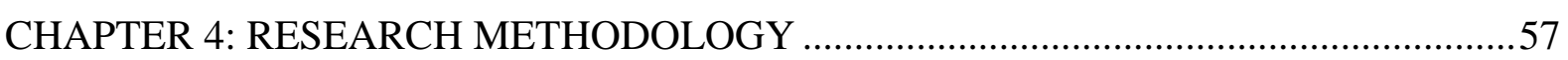

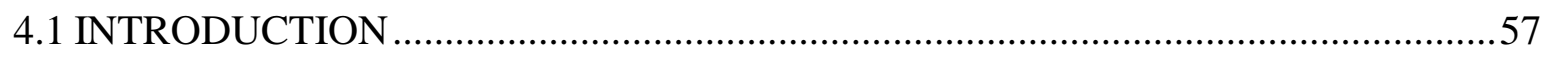

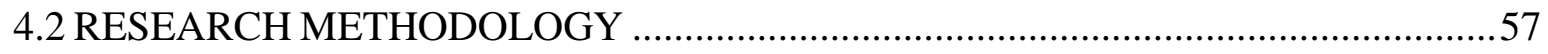

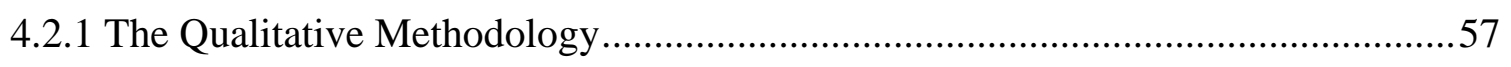

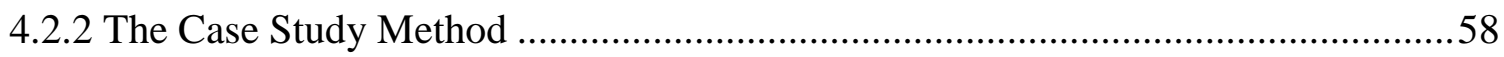

4.2.3 The Single versus Multiple Case Studies ............................................................59

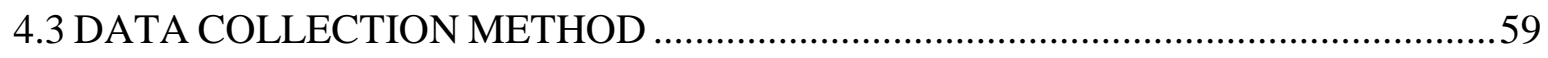

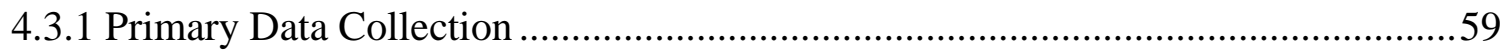

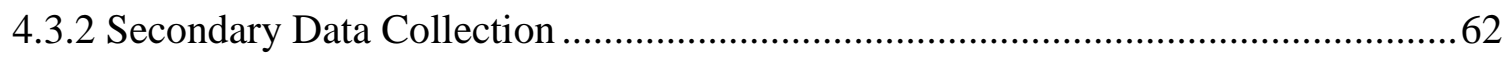

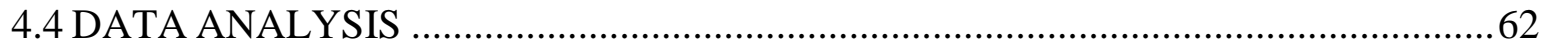

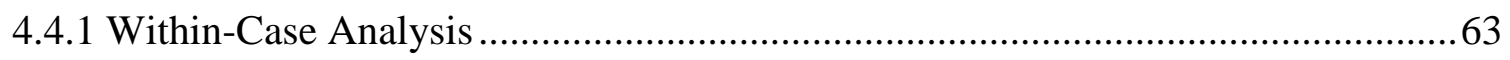

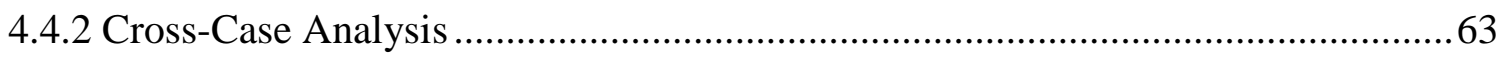

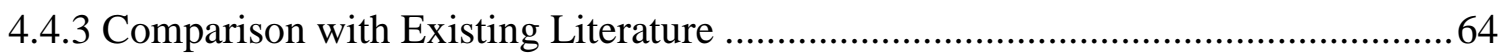

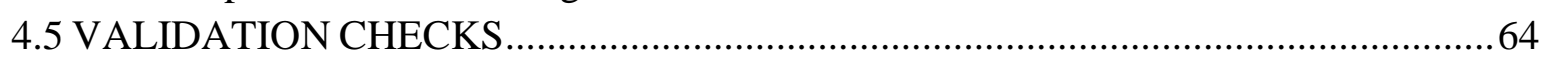

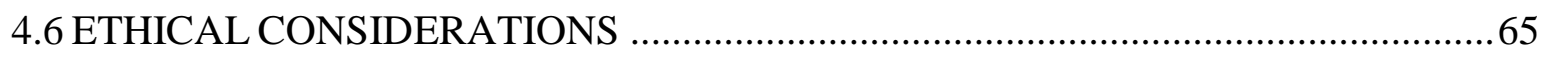

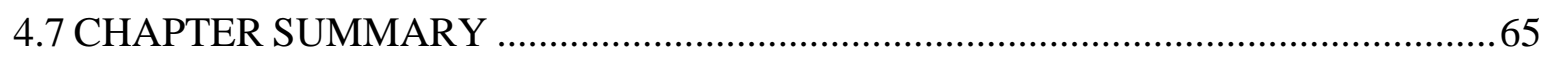

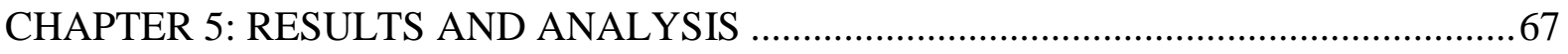

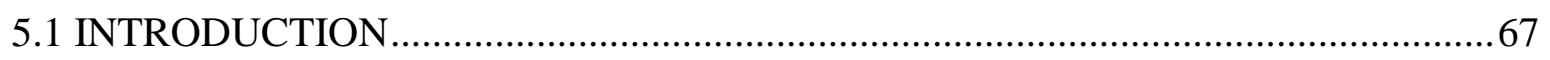

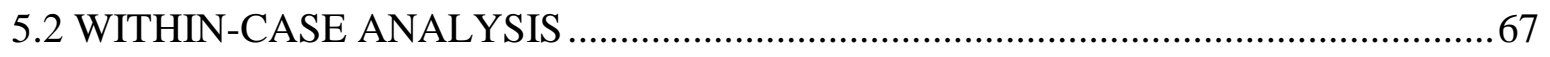

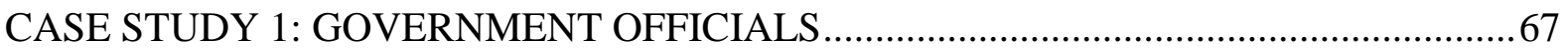

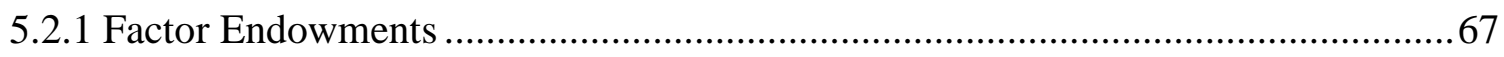




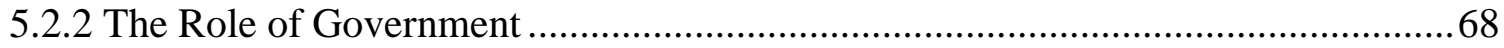

5.2.3 Regional and Global Integration Issues ............................................................... 70

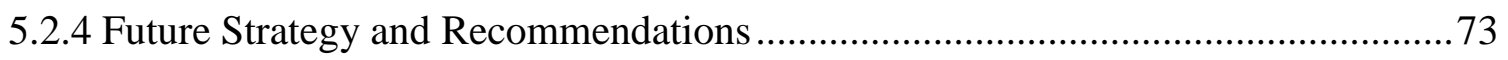

CASE STUDY 2: INDUSTRIES AND ENTREPRENEURS …........................................... 75

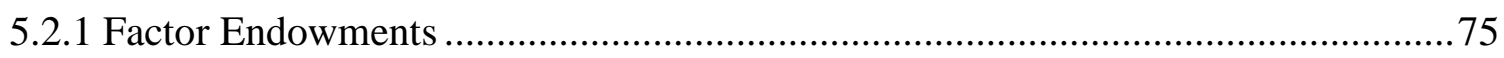

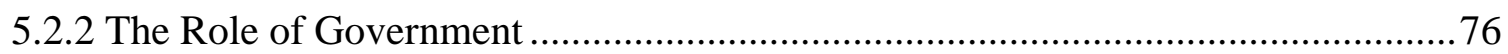

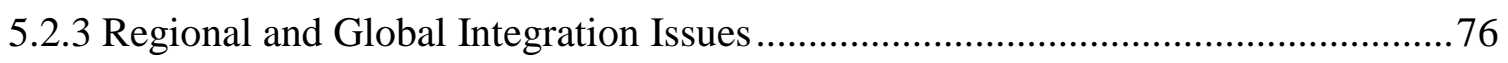

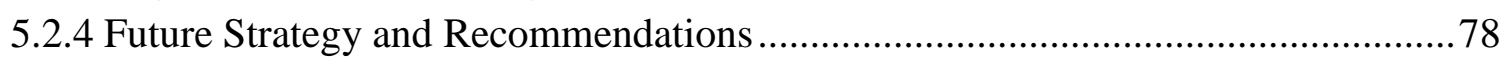

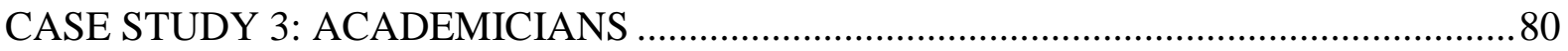

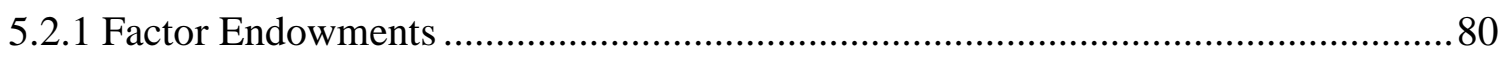

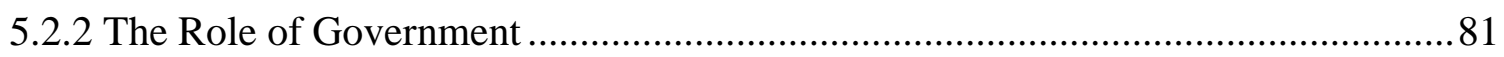

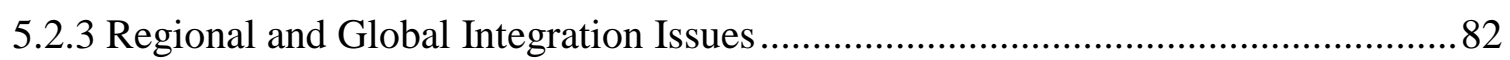

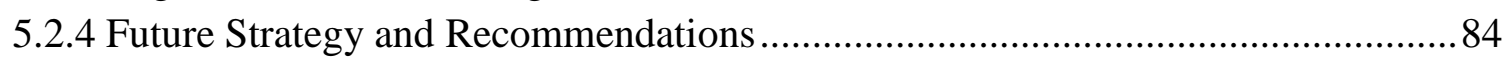

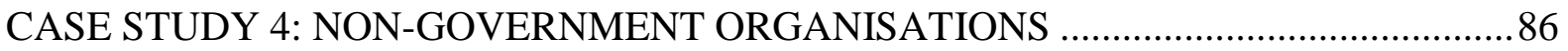

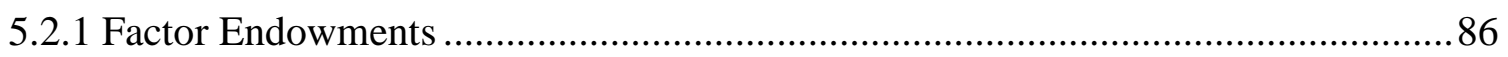

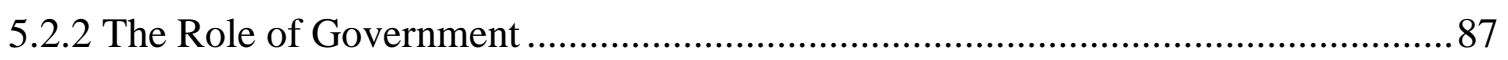

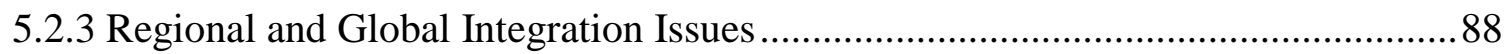

5.2.4 Future Strategy and Recommendations ........................................................ 90

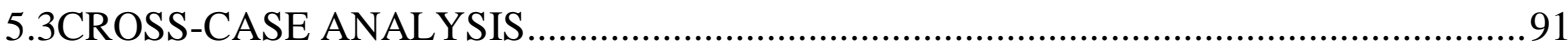

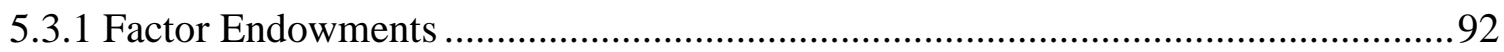

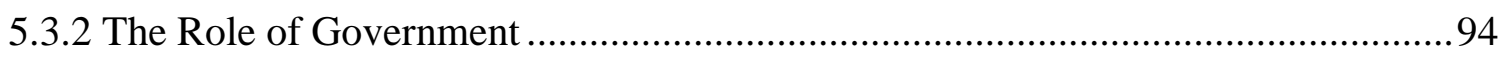

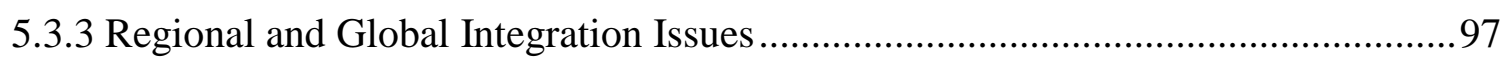

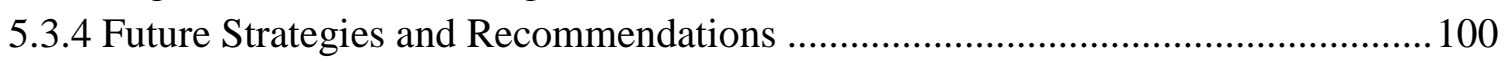

5.4 PROPOSED COMPETITIVENESS MODEL AND DISCUSSION ............................. 103

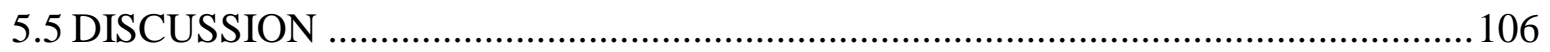

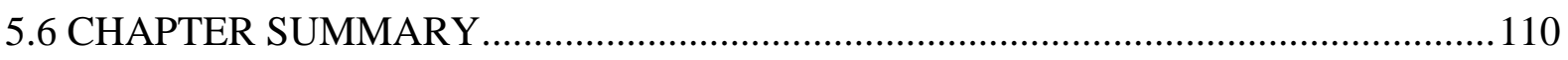

CHAPTER 6: SUMMARY, CONCLUSION AND IMPLICATIONS ................................111

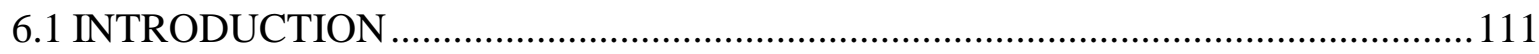

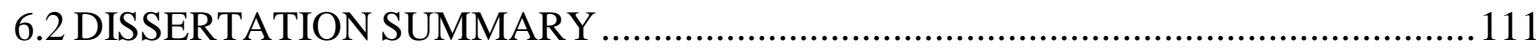

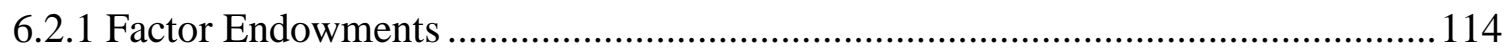

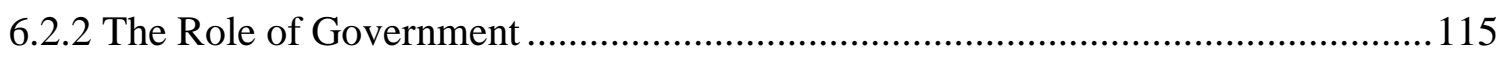

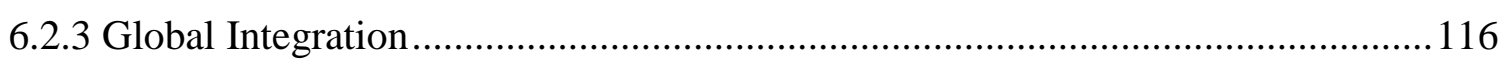

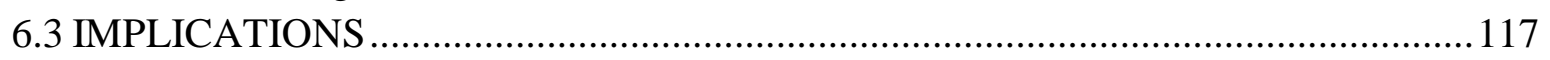

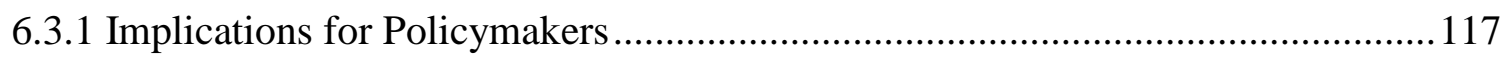

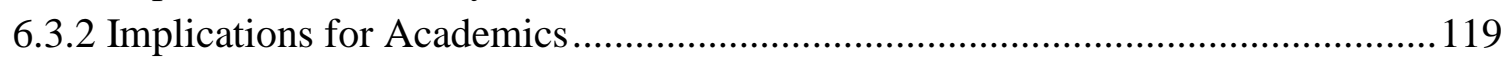

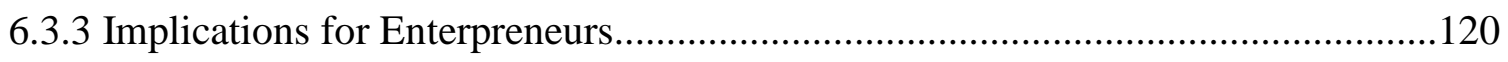

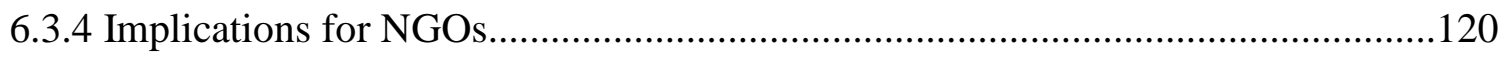


APPENDICES 124

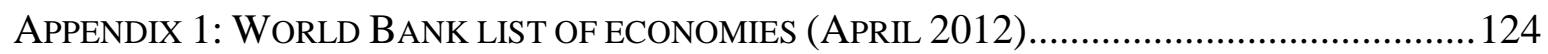

APPENDIX 2: LDCS AND WTO MEMBERSHIP (52 COUNTRIES) ....................................... 125

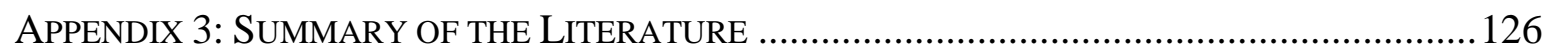

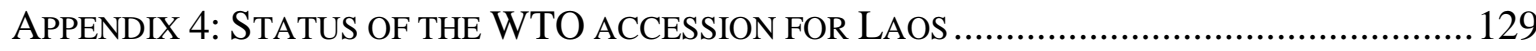

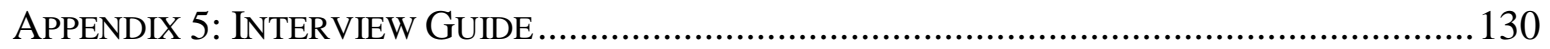

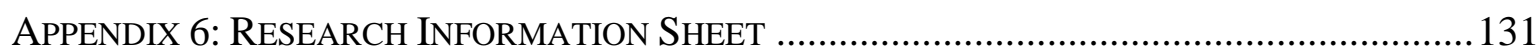

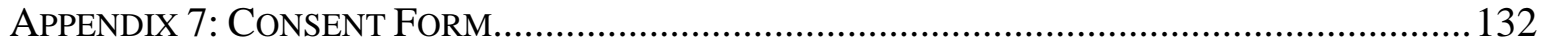

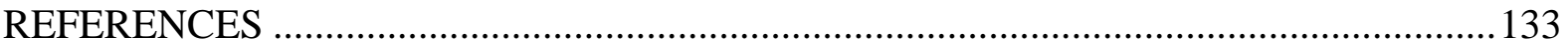




\section{List of Abbreviations and Acronyms}

ADB Asian Development Bank

AFTA ASEAN Free Trade Area

ASEAN Association of Southeast Asian Nations

CEPT Common Affective Preferential Tariffs

CLMV Cambodia, Laos, Myanmar and Vietnam

CSA Country-Specific Advantage

CSR Cooperate Social Responsibility

DDD Double Dual Diamond

DTIS Diagnostic Trade Integrated Study

EU European Union

FDI Foreign Direct Investment

GCI Global Competitiveness Index

GDD Generalised Double Diamond

GDP Gross Domestic Product

GMS Greater Mekong Sub-region

GNI Gross National Income

GSP Generalised System Preferential

HDI Human Development Index

HRD Human Resource Development

ICT Information and Communication Technology

IFC International Financial Cooperation

IF $\quad$ Integrated Framework

IMD International Institute for Management and Development

IMF International Monetary Fund

Lao PDR Lao People's Democratic Republic

LPRP Lao People's Revolutionary party

LDCs Less Developed Countries

MDG Millennium Development Goal

MFN Most Favoured Nation

MNEs Multinational Enterprises

NC National Competitiveness

NEM National Economic Mechanism 
NGOs Non-Government Organisations

NPEP National Poverty Eradication Programme

NSEDP National Social and Economic Development Plan

OECD Organisation of Economic Co-operation and Development

PEST Political, Economic, Social and Technology

R\&D Research and Development

SMEs $\quad$ Small and Medium Enterprises

S\&T Science and Technology

TFP Total Factors Productivity

UN United Nations

UNDP United Nations for Development

UNCTAD United Nations Conference on Trade and Development

UNIDO United Nations Industrial Development Organisation

WEF World Economic Forum

WB World Bank

WTO World Trade Organisation 


\section{List of Figures and Tables}

Figure 1: Lao People's Democratic Republic Map ...........................................................11

Figure 2: Lao Economic Growth from 1993-2011 …......................................................15

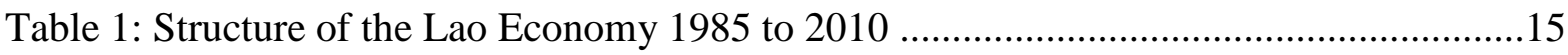

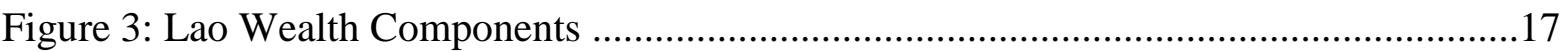

Table 2: Costs for the Lao Business Community to Trade across Borders ...........................20

Table 3: Summary of Indicators of Doing Business Environment in Laos 2012-2004 .........21

Table 4: Human Development Index of Laos 1990-2011 …............................................23

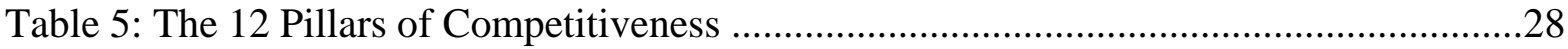

Figure 4: Evolution from Trade Theory to Competitiveness Theory ....................................36

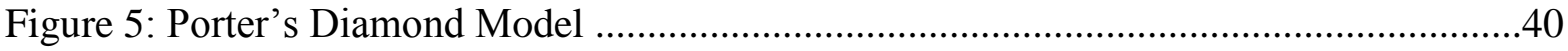

Figure 6: Porter's Diamond Model and Its Extension Models.............................................42

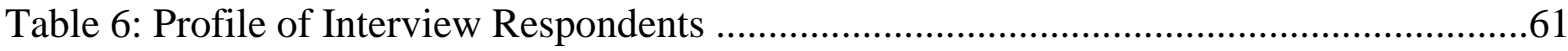

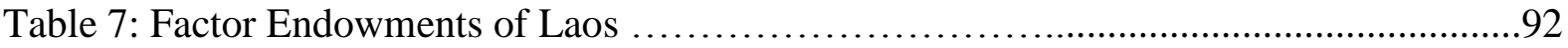

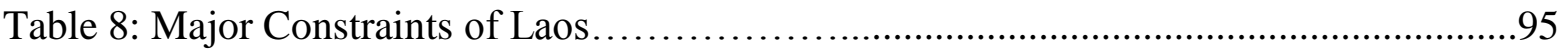

Table 9: Major Constraints of Regional Integration of Laos ............................................99

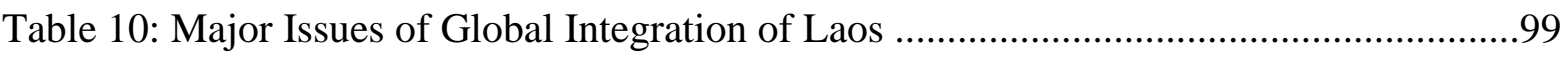

Table 11: Strategies and Recommendations for Lao Competitiveness ................................101

Figure 7: Conceptual Model of the National Competitiveness of Laos ..............................105

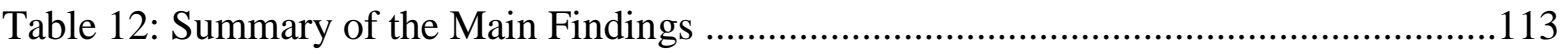




\section{CHAPTER 1: INTRODUCTION}

\subsection{PROBLEM ORIENTATION}

One-third of the countries in the world have achieved a high level of national competitiveness (NC), while many are lagging behind (WEF, 2011) (see Appendix 1). The highly competitive and developed countries are members of the Organisation of Economic Co-operation and Development (OECD). These comprise the world's most advanced economies including North and South America, Europe and some countries in the Asia-Pacific region. The main reasons for the high economic performance and NC are sophisticated human capital, a high level of industrialisation, sufficient government roles, infrastructures, science and technology (S\&T) development, research and development (R\&D) and innovation (Garelli, 2003; WEF, 2011). The rest, however, in particular less developed countries (LDCs), are still lacking in many of the important components above, which results in less NC (Lall, 1999, 2001; Lin, Hsieh, Yuok, Savary, \& Sum, 2004; van Wyk, 2010). The nature of LDCs' factor endowments is basic and not well-integrated globally. Evidence of the high level of countries' economic development is derived from high performance during trade liberalisation, and is an important way for countries to maintain economic growth and enhance NC (Winters, 2004; Winters, McCulloch, \& McKay, 2004). In addition, relatively few economic variables of LDCs have been identified throughout the process of enhancing $\mathrm{NC}$ in the literature, compared with other more advanced economies (Berger \& Bristow, 2009; Cho \& Moon, 2005; Lall, 2001; Lin, et al., 2004; Thompson, 2004). As a result, even though some LDCs are rich in natural resources, the relatively low performance of their economies, including S\&T and R\&D development, affects their productivity and NC (van Wyk, 2010).

According to the criteria set by the United Nations Development Program (UNDP), LDCs are defined as countries with less than US $\$ 1,000$ of income per capita per year, a low level of human development index (HDI) and a vulnerable economic development (UNDP, 2006). There are wide-ranging reasons for the poverty of LDCs, including persistent civil wars, political conflicts, insufficient governance, epidemic diseases, drought, economic turmoil and geographical difficulties. However, poverty reduction and sustained economic growth goals can be achieved through the increase of national economic performance through trade liberalisation (Easterly, 2005). Therefore, global integration is one of the tools LDCs can use 
to achieve a high economic performance and increase their NC. The recent trends show a continuous rise in the number of regional trade blocks and the number of LDCs joining organisations such as the World Trade Organisation (WTO) (Evenett \& Braga, 2005) (see Appendix 2). The WTO is based on the principles of free trade, non-tariff barriers, and nondiscrimination among the members, with several priorities such as a period of implementation, technical assistance and flexibility, which allows LDCs to gain benefits from the membership (WTO, 2012).

However, LDCs seem to have fewer benefits in regional economic integration (Menon, 1999). Smaller countries with less bargaining power, in particular, are pushed by larger trading partners to comply with excessive policies when joining regional and international trade agreements (Bhagwati, Krueger, \& Ebrary, 1995; Helleiner, 1996). Moreover, while the countries' trade processes are opening, the gaps between rich and poor countries are widening (Dollar \& Kraay, 2004; Stokey, 1991). Evidence shows that trade liberalisation increases foreign direct investment (FDI), the exploitation of natural resources, the labour market and government policies with favourable conditions for attracting FDI to the countries, and does not directly benefit poor people as it should (Dollar \& Kraay, 2004). Therefore, governments need to play a critical role in managing and enhancing NC.

As a generalisation, governments play important roles in both improving factor endowments and enhancing the global integration process to increase the $\mathrm{NC}$ of countries. According to Porter (1990) and Porter, Takeuchi, \& Sakakibara (2000), governments are the main actor in developing all essential infrastructures and other advanced factors such as S\&T, R\&D and innovation to facilitate business environments, which are considered essential for increasing the productivity of industries. The findings of Hodgetts (1993) and Moon, Rugman \& Verbeke (1998) suggested that all four determinants of NC can be improved through the appropriate roles of governments. In addition, transparent government institutions affect industries' levels of productivity through clear policies (Winters, 2004). Furthermore, regional and international integrations need significant input from home governments in order to improve existing rules and regulations, in line not only with other members and dialogue partners, but also with countries that are transitioning to market economies (Winters, 2004; Wu, 2006). 
Even though many trade theories, economic models and studies have been developed and discussed in order to gain a clear picture of the NC of different countries, no model can be used as the ideal measurement (Berger \& Bristow, 2009; Giedre Staskeviciute, 2010). These models also have limitations in varying degrees, especially when these are applied to the NC of LDCs, due to the differences of economic variables. For instance, the Single Diamond model by Porter (1990) and other following models, including the Generalised Double Diamond (GDD) model (Moon, Rugman, \& Verbeke, 1995; Moon, et al., 1998), the NineFactors model (Cho \& Moon, 2000) and the Double Dual Diamond (DDD) model (Cho, Moon, \& Kim, 2009) can be used only among the OECD countries, but not among LDCs whose domestic and international economic variables are not fully developed. Thus, there is a need to explore the NC of LDCs.

Most of the research on NC relates to advanced economies, while the perspectives of LDCs are less well understood. Several organisations (WEF, IMD, OECD) (Garelli, 2003; OECD, 1998; WEF, 2011), trade theories and studies focused on assessing the NC of advanced economies by using several basic and sophisticated indicators to measure NC factors (Cho, 1994; Cho \& Moon, 2005; Cho, et al., 2009; Cho \& Moon, 2000; Kao et al., 2008; Moon, et al., 1998; Porter, 1990, 1998; Porter, et al., 2000; Rugman \& D'Cruz, 1993). On the other hand, even though LDCs have an abundance of natural resources, poor agriculture, poor infrastructures, low HDI and weak government roles have negative effects on the degree of social and economic performance (van Wyk, 2010). Hence, this study aims to provide insights into understanding the NC of LDCs. The main motivations for the research are summarised below:

1. LDCs' $\mathrm{NC}$ is less well understood, as most of the literature is on advanced economies with more advanced economic variables (see Appendix 3).

2. LDCs' sources of NC are likely to be different, as the nature of factor endowments are basic, with fewer benefits of global integration and government roles that are not active and transparent. Therefore, existing NC models may not explain the NC of LDCs.

3. The nature of LDCs' competitiveness (Laos, in this case) depends heavily on natural sectors (hydropower and mining) with no value-added and other important activities. Thus, the economic development is not considered sustainable in the long term. 
4. Even though LDCs are actively integrating into the global economy with the aim of enhancing economic performance, they are still poor. Therefore, it is essential to find out the reasons behind the lower rate of competitiveness.

5. Despite global integration pushing LDCs' governments to move forward by providing technical and physical assistance, most of them still cannot exploit this potential to enhance NC.

\subsection{LAOS - A SOUTHEAST ASIAN LESS DEVELOPEDCOUNTRY}

Lao People's Democratic Republic (Lao PDR) or Laos is a small, land-locked and less developed country in Southeast Asia, therefore, enhancing NC particularly during the period of global economic integration, has become one of the most focused issues of the government. The Millennium Development Goals (MDG) of the Lao government are to achieve social and economic development and poverty reduction by 2020 (NSEDP, 2010). Consequently, Laos became a member of the Association of Southeast Asia Nations (ASEAN) in 1997 and at present Laos is attempting to join the World Trade Organisation (WTO) (see Appendix 4). In addition, the East and Southeast Asian regions are considered to have the fastest economic growth in the world; with a GDP of US\$700 billion the "Asian miracle" is attracting a significant inflow of FDI (Kao, et al., 2008; Ku, 2002). Furthermore, the WTO is considered to be a comprehensive global framework for trade and tariff issues, which can provide more opportunities for Laos to access international markets. As a result of open policies, particularly in exports from natural resource sectors and the garment industry, Laos has one of the fastest growing economies in the region, with an average growth of $7.8 \%$ over a decade.

However, Laos has an inadequate capacity to be able to fully commit to such a high level of external demand during the process of global integration. As is the case with many LDCs, basic and sophisticated factors, particularly infrastructures, S\&T, R\&D and the quality of human capital, are still far behind other developed and developing countries. In addition, a lack of access to the sea and insufficient internal transport routes connecting the national borders are major problems hindering Laos from integrating into international markets. The land-locked issue isolates Laos from any international trade activities and contributes 
negatively to in-land transport costs for import and export activities (Ghemawat, 2001; Lewis, 2008; Mbekeani, 2007; WB, 2006). In addition, only a few countries in the world have the same land-locked issues as Laos.

Generally, a high level of productivity determines the competitiveness of industries and countries. While many countries have established national institutions to deal with the NC issue over many decades, the Lao government has only just started paying more attention to the issue. Annual world competitiveness reports from the World Economic Forum (WEF), the International Institute for Management Development (IMD), OECD and the Institute for Strategy and Competitiveness at Harvard Business School were published so that policymakers and practitioners could gain a better understanding of the competitiveness position of their industries and countries. These reports not only identify the competitiveness ranks for countries with several economic indicators, but also help to diagnose the strengths and weaknesses of the economic structures of countries and deliver useful recommendations and solutions for improvements. Laos, however, is still missing from those reports. Despite the fact that many studies and economic models have discussed and developed a comprehensive dimension of competitiveness at both industry and country level over a long period of time, little attention has been paid to LDCs.

\subsection{RESEARCH OBJECTIVES AND METHODOLOGY}

The main research question in this study investigates is: 'How can the national competitiveness of LDCs be enhanced?' Because of a lack of data within trade theories, economic models and studies to explain and measure the NC of LDCs, the purpose of this research project is to explore the factors contributing to the NC of LDCs by undertaking a case study of Laos - an LDC. Several questions are asked in order to explore various aspects of the NC of Laos: 1) 'What are the main competitive forces of Laos?'; 2) 'Why has Laos not developed as fast as other countries?'; 3) 'What effect does the role of government have on productivity and NC?'; and 4) 'To what extent do regional (ASEAN) and international economic integrations (WTO) help the country to increase competitiveness?' Finally, the researcher offers policy recommendations, and initiates further strategies and implications of $\mathrm{NC}$ for policy-makers and practitioners in this field. 
There are many reasons why the researcher has chosen qualitative methods as the most appropriate tool of enquiry for this study. In order to address the research questions of this research project (see section 1.3), the researcher used a qualitative approach as the most appropriate method of enquiry, aiming to fill the current gaps in the literature. More details of this research can be found in Chapter 4. Firstly, the NC of LDCs is not well-researched and understood; most research looks at competitiveness from the point of view of advanced countries. Research projects by international institutes focus on specific industrial and manufacturing sectors of LDCs; however, none of them focuses on the economy as a whole. Secondly, there are not only economic aspects to this topic, but also social aspects, and these should be explained in various ways. Finally, most studies use several sophisticated economic indicators to measure the level of competitiveness of countries, whereas the nature of LDCs' economic factors is basic and undeveloped. The present study aims to provide understanding of the NC of LDCs and explores, through a qualitative approach, determinants of the NC of Laos.

\subsection{THESIS STRUCTURE}

The structure of this thesis is divided into six chapters.

Chapter 1 introduces the overview of this research project, as well as its research objectives, research gaps and contributions.

Chapter 2 presents background information and an overview of the Lao economic environment, the current national economic situation, and the competitiveness of Laos, to obtain an overall picture of the Lao economy.

Chapter 3 provides a literature review of related issues, including different definitions and measurements of $\mathrm{NC}$, and debates and extensions of trade theories and competitiveness models, in order to provide an explanation for the $\mathrm{NC}$ of specific industries and countries. The well-known economic models that have been developed from the Single Diamond model by Porter (1990), are then discussed. This chapter also examines the impact of globalisation on the NC of countries and analyses the impact of regional and international economic integrations within the different categories of status: developed countries, developing countries and LDCs. 
Chapter 4 focuses on the reasoning behind the qualitative methods that were employed to meet the research objectives. In addition, research design, data collection methods, research procedures, data analysis, validation checks, ethical considerations and a chapter summary of are presented alongside the research using the qualitative methods.

Chapter 5analyses the data by undertaking within-case and cross-case analysis across the four clusters interviewed. A detailed conceptual model is proposed and discussion of the NC of Laos is provided. After comparing and contrasting the interview responses on the key endowment factors of Lao $\mathrm{NC}$, the role of government, and regional and international economic integration, the findings of this research in cross-case analysis show similar and differing results. Further strategies and recommendations are proposed in the discussion section. This section is also supplemented by existing literature on NC.

Chapter 6 provides a dissertation summary and discusses the implications, recommendations, further research, contribution and limitations of this study. 


\section{CHAPTER 2: AN OVERVIEW OF THE LAOS BUSINESS EVIRONMENT}

\subsection{INTRODUCTION}

This chapter provides an overview of the Lao business environment by using the PEST analysis framework. The main purpose of this chapter is to provide an understanding of the context i.e. the business environment of Laos. The PEST framework is used to discuss the political, economic, social and technological environments of countries. The next section summarises the PEST framework, followed by one section each on the PEST dimensions. The next section provides an historical perspective of Lao's globalisation attempts. The chapter is summarised in the last section.

\subsection{PEST ANALYSIS FRAMEWORK}

The PEST analysis framework has been widely used by policy-makers and practitioners to examine the business environment of countries in order to provide knowledge to guide accurate, strategic decision-making (Peng \& Nunes, 2009; Ward, 2005). PEST stands for Political, Economic, Sociological and Technological environment, which influences the overall business environment of a country. These factors help to review its current environment and calculate potential changes in its business environment, including those of its competitors. They also provide a bigger picture, giving a greater understanding of the environment in which a country is operating. Furthermore, the four elements are useful tools for evaluating expansion and decline in association with goods and services, as well as the position, propositions, potential and direction of an individual country.

\subsubsection{Political Environment}

\subsubsection{Political History and Structures}

After the communist victory in 1975, the country was ruled as a single-party state by the Lao People's Revolutionary Party (LPRP), which brought relative peace and political stability to Laos. There are two significant revolutionary eras in Lao history in the nineteenth century, namely the French colonial era (1945), and the withdrawal of the American military forces 
and the abolishment of the monarchy (1975). As a result, the country turned from a monarchy system into a socialist republic, with a president as head of state. However, it is worth noting that even though Laos had secured relative peace and political stability, this did not translate into sustained economic performance and a developed HDI in the first decade (Rosser, 2006). Laos still maintains a very stable political system compared with other countries in the region (Bird \& Hill, 2010). The basic principle of the constitution is sovereignty; power is established by the people and all decision-making is authorised by the people (Jönsson, 2000). Laos consists of more than 47 different ethnic minority groups throughout the country with non-discrimination, equal rights and treatment, free religion and beliefs and unity (Jönsson, 2000).

Under the leadership of the LPRP since 1975, Lao has maintained a stable political system and has not been involved in any major conflicts. As in any socialist system, the Lao National Assembly has the supreme role of managing the legislative power, the People's Court, and the People's Prosecutors administer the law (Jönsson, 2000). All executive power is held by the central government; the Party leads and manages the people as the masters of the nation, with four levels of top-down administration, namely central government, provincial, district, and village.

In addition, while the 6th National Social and Economic Development Plan (NSEDP) and the National Poverty Eradication Programme (NPEP) were implemented between 2006-2010, the 7th NSEDP 2010-2015 focuses on the improvement of public sectors, particularly in macroeconomic policy, public financial management and government expenditure on propoor strategy (IMF, 2011). This strategic framework identified the national development policy and aimed to address poverty through a combination of broad-based economic growth and focused policy interventions. The four strategic intervention areas of the plan are: i) human development and private sector-driven economic growth; ii) competitiveness, trade and regional integration; iii) social development and targeted poverty reduction interventions; and iv) good governance (NSEDP, 2010). Apart from the key priorities of intervention areas, the NSEDP provides the overall enabling environment for the evolution of the Lao economy towards a system where the private sector can play a leading role, with step-by-step modernised governance, while keeping a strong focus on human and social development. 


\subsubsection{International Trade Policies}

Laos has changed from a central planned economy and engaged in a market economy with an aim of liberalising trade policies in order to be consistent with regional and international trade after the economic reforms or the New Economic Mechanism (NEM) in 1986. With regard to trade reform policies, Laos has liberalised its trade regime by reducing import duties, removing import quota, quantitative restrictions and export tax on primary products (Bourdet, 2000). However, a certain number of sensitive lists and binding tariffs under the ASEANFree Trade Area (AFTA) have remained high because they are considered an important source of government revenue. For example, vehicles and other luxury products have a very high volume of tariffs. Despite the AFTA helping Laos to accelerate the trade liberalisation process and contribute to the WTO accession in the coming years, the full integration of Lao trade policies into this agreement would take longer than expected due to the insufficient resources of the Lao government.

\subsubsection{Location and Neighbourhood}

Laos is situated in the middle of the Indochina peninsula and shares borders with countries with large population densities, fast economic growth and LDCs, including China in the north, Cambodia in the south, Thailand and Myanmar in the east and Vietnam in the west (see Figure 1). Being land-locked forces Laos to be dependent on neighbouring countries' infrastructures, particularly Thailand and Vietnam, in order to access international markets by seaport (Andersson, Engvall, \& Kokko, 2007). Laos has a particularly close and comprehensive political, social and economic cooperation with Vietnam and China. Under this cooperation, thousands of students and government officials are sent to study and train in universities and institutes in Vietnam and China every year. Consequently, the Lao political, social and economic systems are influenced by these neighbouring countries, especially Vietnam. Despite Lao and Thai languages being similar, however, only economic cooperation has been enhanced due to the differences in political regimes and the history of conflicts between the countries. In contrast, Cambodia and Myanmar are the same size in terms of economic development, but they have no influence on any aspect of the country's economy. 
Figure 1: The Lao People's Democratic Republic Map

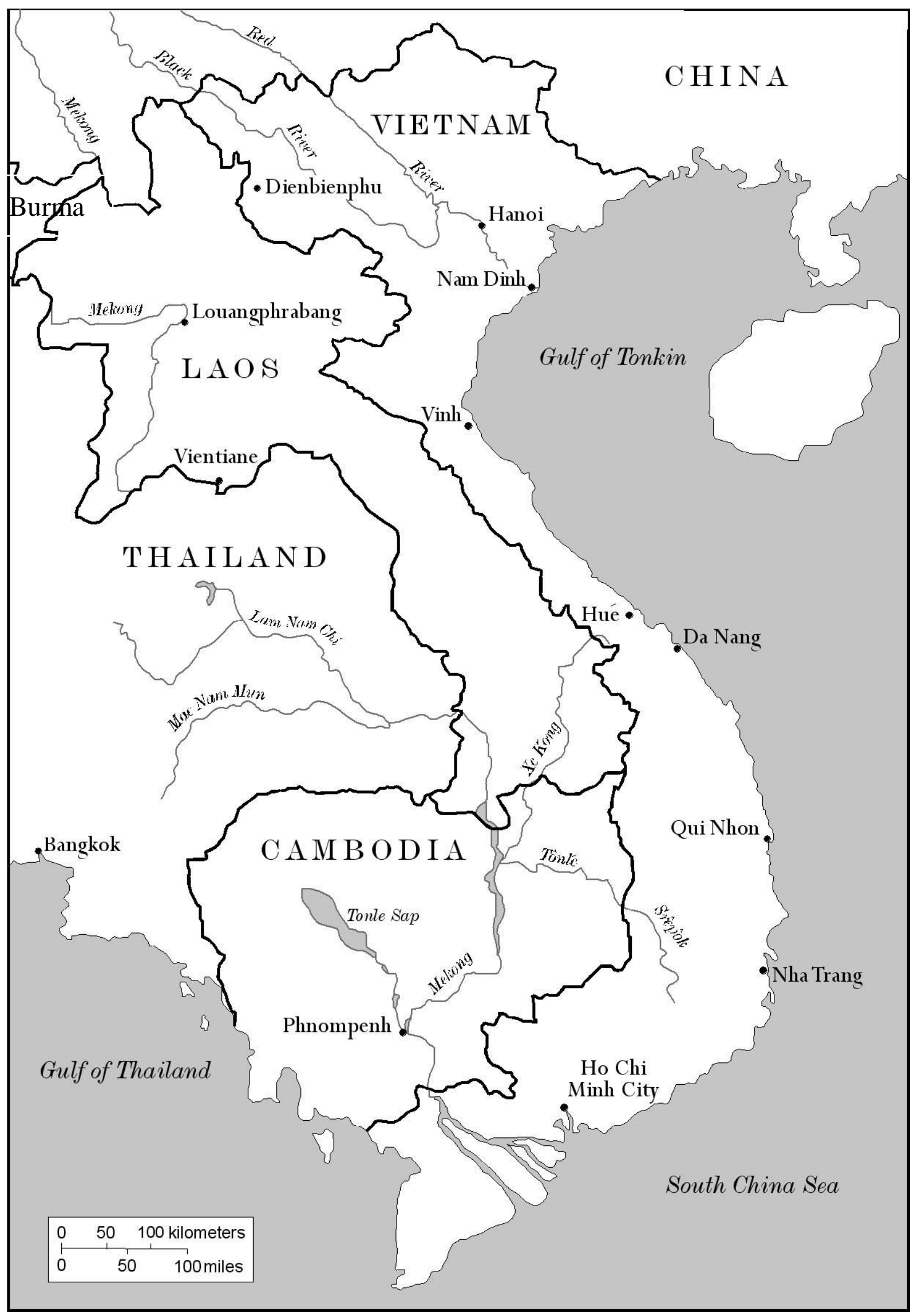




\subsubsection{Consistent Globalisation Attempts}

The Lao government has played an active role in improving rules and regulations to comply with regional and international agreements and has created transparent environment, clarity and fairness for business. For example, after becoming an ASEAN member in 1997, the Lao government introduced formal tariff heading system codes and the tariffication of non-tariff barriers, in accordance with the ASEAN-FTA framework, with maximum tariffs 0-5\% (ASEAN, 2009). Recently, the government has also adjusted the category of goods and services from prohibited to controlled and controlled to general lists to comply with the ASEAN Common Effective Preferential Tariffs (CEPT) agreement (ASEAN, 2009). As a result, the state controls over quantitative restrictions on imports have been removed and the free flows of trade and investment have been enhanced significantly. This also marked equal treatment and non-discrimination between state-owned enterprises, domestic and foreign firms. With regard to inflow FDI, the government has approved the investment laws to accommodate the needs of foreign investors with various favourable conditions such as tax incentives, tax holidays and exceptions for the projects that specialise in the prioritised sectors of agriculture, infrastructure development and services. In addition, as Laos prepares for the WTO accession, the further aspects of trade distortions are gradually being eliminated.

\subsubsection{Economic Environment}

\subsubsection{Three Phases of Economic Reforms}

The consistent economic reforms of Laos have been made across the three phases (Bird \& Hill, 2010; Phouphet, 2009). In the first phase (1986-1999), the Lao government introduced the NEM in 1986 to begin the economic transition from a centrally-planned to a marketoriented economy. However, the Lao trade policy still remained restrictive, with no protection law for private sectors and non-transparency in the nature of market economy implementation. Quantitative restriction on imports, various taxes, fees and tariff structures were complicated (Bourdet, 2000; WB, 2006). At this stage, the state-owned enterprises had been reduced significantly and the size of the private sector had increased slightly. The main focus of economic development depended heavily on agriculture and forestry, with relatively low productivity.

The second phase (1990-2005) revealed more comprehensive trade and tariff reforms. This significant reform was caused by the East Asian economic crisis, which affected the 
government's macroeconomic control, high inflation and currency depreciation (Bird \& Hill, 2010). As Laos became a member of ASEAN in 1997 and other multilateral initiatives, several burdens on trade and tariff were removed in order to be fully integrated into the regional and international trade frameworks. Step by step, the trade reforms continued and the state-owned enterprises were also re-regulated (Bourdet, 2000).

The third phase began in 2005, with macroeconomic instability and structural reforms that focused on natural resources (Bird \& Hill, 2010). This phase emphasised further market oriented reform and required Laos to reduce tariffs on intra-regional trade to below 5-0\%.As a result, during the 2000 s the exploitation of foreign investment on natural resources accounted for $78 \%$, compared with $37 \%$ in the 1990s (Bird \& Hill, 2010). In addition, regulations on simplification and harmonisation of foreign investment law and trade liberalisation have included both import and export activities. Furthermore, this step was also considered the significant achievement of Laos in the trade agreements within ASEAN and with dialogue partners. For example, the Early Harvest Program between ASEAN and China has reduced Chinese import tariffs on many agricultural products under the ASEAN-ChinaFTA, which came into effect for the old ASEAN members in 2010 and will come into effect for Laos in 2015 (Andersson, Engvall, \& Kokko, 2009).

As a result, the three phases of economic reform and liberalisation have brought about a dramatic economic transformation in Laos including: i) price controls and import quotas were progressively eliminated; ii) the government's monopoly on goods and services was removed; iii) the financial system, for example the exchange rate, was unified and inflation remained low; iv) the number of state-owned enterprises was dramatically reduced and the establishment of private firms was enhanced (Bird \& Hill, 2010). Thus, openness and outward orientation were the central government objectives for economic growth, which has also contributed to more transparency in the business environment (Andersson, et al., 2009).

\subsubsection{Economic Growth}

Figure 2 highlights two points of the economic performance of Laos throughout three phases of the reforms. Firstly, the persistent Lao trade deficit remains critical. A higher volume of goods and services have been imported than exported. Secondly, import and export activities 
have increased constantly in the past two decades, particularly after regional economic integration such as ASEAN and ASEAN-FTA in the 1997 period. Even though a trade deficit is foreseen, the Lao economy is still considered to have made significant progress since the early 1990s.

While the main export destinations are Thailand, Vietnam, Malaysia, China and Europe, as well as Australia and Taiwan, the primary imports are industrial and capital products, petroleum, food, and other consumer goods from the main import destinations including Thailand, Vietnam, China, Japan, India, and South Korea (UNCTAD, 2010). In addition, the regional financial crisis marked a slight slowdown of the Lao economy, particularly for imports; however, it recovered slightly after 2000 and increased rapidly throughout a decade. As the third phase of the economic reforms, the period of 2000s illustrates a significant increase in import and export activities, particularly in the top priority sectors such as hydropower, mining, the garment industry and tourism.

Furthermore, the significant contribution of the investment boom in Laos is related to FDI inflows. Figure 2 illustrates the increased inflow net of FDI over almost two decades. Despite Laos experiencing remarkable economic growth between 1993 and 1997, the Asian crisis highlighted the slump of the inflow net of FDI to nearly 0\% at the end of 2002 after signs of recovery in early 2003 and a dramatic growth in early 2005, and continued to reach over 900 million in 2011. Particularly in the third phase of economic reform, Figure 2 also indicates the significant growth of the GDP of Laos. GDP has risen rapidly with an average growth of $7 \%$ per annum, which is the second highest growth rate in the region.

Table 1 shows the changes in percentage of the Lao economic components from 1985-2010 through the three phases of economic reforms with three major areas: agriculture-forestry, industry-handicrafts and services. While the overall trend illustrates a decline of agriculture and forestry roles (from $70.7 \%$ in 1985 these have become almost halved at only at 35\% in 2010), industry-handicrafts and services continue to grow, from nearly $11 \%$ and $18.4 \%$ for services in 1985 to 27 and $37 \%$ respectively. As a result of the growth of service and industry-handicraft sectors in 2010, agriculture became slightly less important to the structure of the Lao economy and remains only $35.6 \%$. 
Figure 2: Lao Economic Growth from 1993-2011 (billion USD)

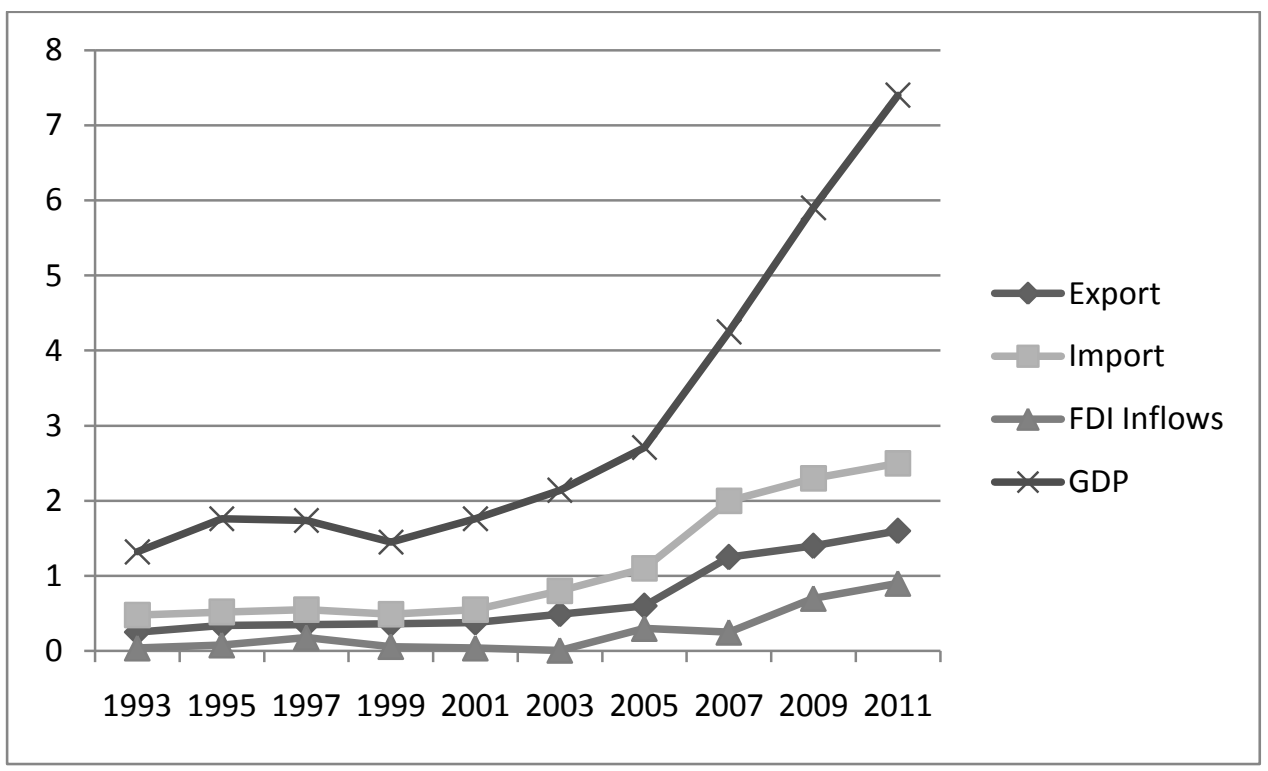

Source: Adapted from the Ministry of Industry and Commerce (MOIC, 2012) and the Ministry of Planning and Investment of Laos (MOPI, 2012)

Table 1: Structure of the Lao Economy 1985 to 2010

\begin{tabular}{|l|l|l|l|l|l|l|}
\hline \multirow{2}{*}{ Sector } & \multicolumn{2}{|l|}{ Structure (\%) } \\
\cline { 2 - 8 } & $\mathbf{1 9 8 5}$ & $\mathbf{1 9 9 0}$ & $\mathbf{1 9 9 5}$ & $\mathbf{2 0 0 0}$ & $\mathbf{2 0 0 5}$ & $\mathbf{2 0 1 0}$ \\
\hline Agriculture - Forestry & 70.7 & 60.7 & 54.3 & 51.3 & 41.2 & 35.6 \\
\hline Industry - Handicrafts & 10.9 & 14.6 & 18.8 & 18.8 & 24.4 & 27.2 \\
\hline Services & 18.4 & 24.7 & 26.9 & 26.9 & 34.4 & 37.2 \\
\hline Total & 100 & 100 & 100 & 100 & 100 & 100 \\
\hline
\end{tabular}

Adapted from: UNIDO (2003) and UNCTAD (2010)

The share of agriculture has declined as the country's economy continues to perform well, which emphasises the significant growth of industry and service sectors (Perkins, Radelet, \& Lindauer, 2006). With a total area of $236,800 \mathrm{~km}^{2}$, the majority of land is covered by mountain and tropical forest; as a result, only $5 \%$ is suitable for agriculture, which accounts for $70 \%$ of the total workforce. The annual GDP growth rate increased to $7.3 \%$ in 2006, and was projected to maintain at $8.2 \%$ through 2010 (ADB, 2008; Onphanhdala \& Suruga, 2007). 
Even though agriculture is the backbone of the Lao economy, its contribution to the economy has significantly declined recently due to the new trend of economic mechanism in industrial goods and services. For instance, in 2008, the agricultural sector accounted for only $31 \%$ of the total GDP and contributed to $70 \%$ of the labour force, industry was over $26 \%$, and service was about 38\% (UNCTAD, 2010). A slight decrease on the agricultural role in the economy, minerals accounted for more than $60 \%$ of total Lao exports, with the remaining exports consisting of hydro-electric power, garments, food processing, agricultural and forest products. In addition, industry and service sectors continued to grow and contribute to GDP growth: nearly $70 \%$ in 2009 (UNCTAD, 2010).

Figure 3 illustrates over $54 \%$ of Lao wealth is based on the potential of natural endowments including hydro-electric power potential, land for agriculture, and forests and mining sectors (WB, 2010). In contrast, physical factors such as infrastructure, machinery and equipment, housing etc. accounts for only $9 \%$ of the total wealth factors. This figure indicates the limitations of crucial infrastructures for growth and is even lower than the average lowincome countries (17\%) and East Asia Pacific (28\%) (WB, 2010). In addition, human capital including unskilled workers, entrepreneurs, politicians and professors remains $37 \%$ of the total wealth. 


\section{Figure 3: Lao Wealth Components}

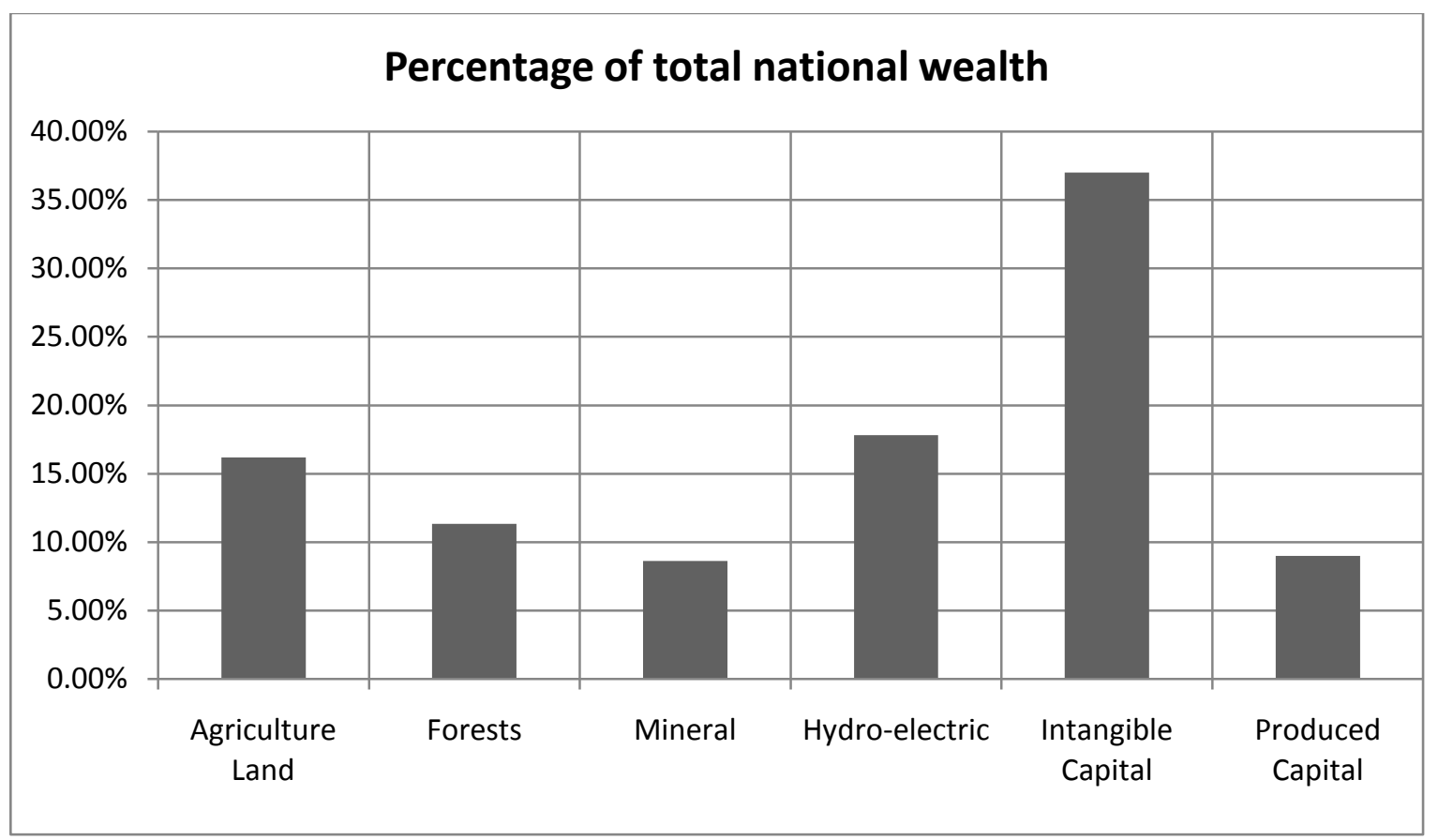

Adapted from: The World Bank report 2010

\subsubsection{Inflation and Exchange Rates}

With limited resources, the Lao economy has been affected significantly by regional and global financial crises; for example, the Asian financial crisis in 1997. This was not only linked to the regional financial crisis, but also to poor economic management by the government (Bourdet, 2000). Between 1997-1998 the kip (Lao currency) depreciated about 70\% against the US dollar and the inflation rate hit a record 150\% in 1999 (Phouphet, 2009). In addition, the global financial crisis marked a decline of real GDP growth in 2009 to about 6.4\%. As a result, export commodity, FDI inflows, remittance income and non-resource exports, especially agriculture, slowed down in comparison with the previous decades (see Figure 2) (WB, 2009).

Achieving significant economic growth has driven the country's inflation rate in the past decade. The annual average GDP growth of approximately 7\% per annum (IMF, 2011) marks a consistent growth of the economy. In addition, the gross national income (GNI) stands over US\$1,000 in 2012, attaining the category of the lower middle-income countries. As the result of economic growth, the inflation rate has been maintained at single digits since 2005 and the kip has appreciated slightly against hard currencies (UNCTAD, 2010; WB, 2008). 
However, the Lao policy setting on exchange rate is complicated, even in the period of the transition economy. Despite the government's monetary policy of focusing on managing the exchange rate against the Thai baht and US dollar, widespread use of foreign currencies in the domestic market still exists. The central bank of Laos cannot control the extensive use of foreign currencies (Thai baht and US dollar) in the exchange market and even estimates the precise value of Vietnamese dong and Chinese Yuan against the kip, particularly transactions at border checkpoints. However, a stable Lao kip has been achieved against the US dollar in the past few years. In addition, only $50 \%$ of Lao currency circulates in the domestic market, while $60 \%$ of bank deposits are in dollars and baht (Menon, 2008). Experts have revealed both the advantages and disadvantages of the Lao financial market when assessing the competitiveness of countries with small and open economies.

\subsubsection{Constraints of Lao Economic Development}

The overall goal of the Lao government is to strengthen economic development and graduate from the LDC status by the year 2020 (NSEDP, 2010), however many constraints have been seen as less competitive factors for the Lao economy. Firstly, Laos is a small country with weak economic structures, relatively low management skills, poor human capital development, poor agriculture, insufficient information technology development and basic level of industries (ADB, 2009; Andersson, et al., 2007; Bird \& Hill, 2010; Bourdet, 2000; Lewis, 2008; Rigg, 2005). As a result, a degree of adding value particularly in natural resource sectors is still lower than other countries in the region. Secondly, the land-locked issue is a physical barrier that the country must contend with in order to compete with other countries with regard to transport costs, and contributes negatively to import and export activities (Menon, 1999). Thirdly, the country is highly dependent on the assistance of donor communities and other neighbouring countries, rather than being self-sufficient, as are other countries (Bourdet, 2000). Therefore, this impacts negatively on the level of self-creation of the country. Furthermore, doing business in Laos, particularly import and export, takes four times longer than in advanced countries, which is not considered attractive to investors.

Despite much progress in terms of economic development being made in the past few decades, the export performance of private sectors continues to lag behind expectations. The private sector still faces significant disadvantages in doing business, including poor 
infrastructure, cumbersome regulations, discretionary taxation, limited access to finance, and limited access to essential information and business support services. A study by the World Bank (2010) shows that domestic exporters face a higher regulatory burden than nonexporters. This issue is explained by land tenure issues, no added value on agricultural products and natural sectors, lack of markets, insufficient market information, poor irrigation systems, livestock diseases, poor healthcare and educational systems, poor technical ability, difficult access to credit, environmental degradation, biodiversity losses, lack of environmental awareness, lack of significant leadership skills, and weak governance structure (UNIDO, 2003).

Another reason for the constraints of the Lao economic development is that the country suffered heavily after the Indochina War from persistent government external debts. More than three million tons of unexploded ordnance still remains underground throughout the country, which is considered a significant threat to economic development potential. As a result, Laos is well-known for having the world's largest stock of unexploded ordnance per capita, which has not yet been cleared (Bird \& Hill, 2010). Furthermore, Laos is not only a poor country, but has high external debt accounting for $92 \%$ of GDP. Three-quarters of this debt is in the public sector, with low interest rates from international financial institutes such as the Asian Development Bank (ADB) and the World Bank (WB) (Bird \& Hill, 2010).

Furthermore, according to annual surveys by the World Bank on the business climate, the result shows that the difficulties of transport and the logistics of exporting from Laos across international borders requiring significant amounts of documentation, is time consuming, requires customs clearance and costs more for the Lao business community than elsewhere in the region and in advanced economies (see Table 2). The result shows that the cost of consignments from Laos to other countries is double that of other countries. For instance, to export a standard container from Laos to Los Angeles (USA) takes twice the time and is 50\% more expensive than exporting the same container from Bangkok (WB, 2010). 
Table 2: Costs for the Lao Business Community to Trade across Borders

\begin{tabular}{|l|l|l|l|}
\hline Indicator & Laos & Region & OECD \\
\hline Documents for export (number) & 9 & 6.7 & 4.5 \\
\hline Time for export (days) & 44 & 23.3 & 10.7 \\
\hline Cost to export (US\$ per container) & 1,880 & 902 & 1,069 \\
\hline Documents for import (number) & 10 & 7.1 & 5.1 \\
\hline Time for import (days) & 46 & 24.5 & 11.4 \\
\hline Cost to import (US\$ per container) & 2,035 & 949 & 1,133 \\
\hline
\end{tabular}

Source: Doing Business Survey 2012, retrieved 20 March 2012 (www.doingbusiness.org)

\subsubsection{Ease of Doing Business in Laos}

Table 3 illustrates the small fluctuation of the Lao doing business ranking in comparison with 183 economies, from the World Bank annual reports of 2004 to 2012. These consist of several economic indicators and sub-indicators to measure the country's doing business environment. Despite the GDP per capita showing the consistent improvement of the Lao economy in the past eight years, the doing business ranking is still unimpressive for both government and foreign investors. In particular, obtaining credit, protecting investors, trading across borders and resolving insolvency indicators seem to lag far behind other countries, negatively shaping the competitiveness of the economy. Furthermore, some data in the current year is still missing from the reports and affecting their accuracy. The rank of 165 out of 183 in 2012 indicates that factors impacting negatively on the business environment such as numerous procedures, time constraints and related costs of the doing business process, are always considered as uncompetitive factors for economic growth. 
Table 3: Summary of Indicators of Doing Business Environment in Laos 2012-2004

\begin{tabular}{|c|c|c|c|c|c|c|c|c|c|}
\hline Ease of doing business & 2012 & 2011 & 2010 & 2009 & 2008 & 2007 & 2006 & 2005 & 2004 \\
\hline Rank of Lao PDR out of 183 countries & 165 & 163 & 171 & 165 & 164 & 159 & 147 & --- & $-\cdots$ \\
\hline GNI per capita: (US\$) & 1,010 & 880 & 740 & 580 & 500 & 440 & 390 & 320 & 300 \\
\hline Population (million): & 6.4 & 6.3 & 6.2 & 5.9 & 5.8 & 5.9 & 5.7 & 5.7 & 5.6 \\
\hline Starting a business (rank) & 89 & 93 & 89 & 92 & 78 & 73 & --- & --- & --- \\
\hline Procedures (number) & 7 & 7 & 7 & 8 & 8 & 8 & 9 & 9 & 9 \\
\hline Time (days) & 93 & 93 & 93 & 103 & 103 & 163 & 198 & 198 & 198 \\
\hline Cost (\% of income per capita) & 7.6 & 11.3 & 12.3 & 14.1 & 16.5 & 17.3 & 15.1 & 18.5 & 19.5 \\
\hline Minimum capital (\% income per capita) & 0.0 & 0.0 & 0.0 & 0.0 & 0.0 & 0.0 & 23.4 & 28.5 & 150 \\
\hline Dealing with construction permits (rank) & 80 & 78 & 115 & 110 & 111 & 130 & --- & --- & --- \\
\hline Procedures (number) & 23 & 24 & 24 & 24 & 24 & 24 & 24 & --- & --- \\
\hline Time (days) & 108 & 108 & 108 & 172 & 172 & 192 & 208 & --- & --- \\
\hline Cost (\% of income per capita) & 52.4 & 131 & 144 & 172 & 202 & 204 & 224 & --- & --- \\
\hline Getting electricity (rank) & 138 & 139 & 140 & --- & --- & --- & --- & --- & --- \\
\hline Procedures (number) & 5 & 5 & 5 & --- & --- & --- & --- & --- & --- \\
\hline Time (days) & 134 & 134 & 134 & --- & --- & --- & --- & --- & --- \\
\hline Cost (\% of income per capita) & 2,381 & 2,734 & 2,245 & --- & --- & --- & --- & --- & --- \\
\hline Registering property (rank) & 72 & 163 & 161 & 159 & 149 & 148 & 148 & 148 & $\begin{array}{c}-- \\
\end{array}$ \\
\hline Procedures (number) & 5 & 5 & 9 & 9 & 9 & 9 & 9 & 9 & --- \\
\hline Time (days) & 98 & 98 & 135 & 135 & 135 & 135 & 135 & 135 & --- \\
\hline Cost ( $\%$ of property value) & 1.1 & 1.1 & 4.1 & 4.1 & 4.2 & 4.2 & 4.2 & 4.2 & --- \\
\hline Getting credit (rank) & 166 & 152 & 150 & 145 & 170 & 173 & 173 & 173 & --- \\
\hline Strength of legal rights index $(0-10)$ & 4 & 4 & 4 & 4 & 2 & 2 & 2 & 2 & --- \\
\hline Depth of credit information index $(0-6)$ & 0 & 0 & 0 & 0 & 0 & 0 & 0 & 0 & --- \\
\hline Public registry coverage ( $\%$ of adults) & 0.0 & 0.0 & 0.0 & 0.0 & 0.0 & 0.0 & 0.0 & 0.0 & --- \\
\hline Private bureau coverage ( $\%$ of adults) & 0.0 & 0.0 & 0.0 & 0.0 & 0.0 & 0.0 & 0.0 & 0.0 & --- \\
\hline Protecting investors (rank) & 182 & 182 & 182 & 180 & 176 & 170 & --- & --- & --- \\
\hline Extent of disclosure index $(0-10)$ & 2 & 2 & 2 & 0 & 0 & 0 & 4 & 1 & --- \\
\hline Extent of director liability index $(0-10)$ & 1 & 1 & 1 & 3 & 3 & 3 & 2 & 1 & --- \\
\hline Ease of shareholder suits index $(0-10)$ & 2 & 2 & 2 & 2 & 2 & 3 & 4 & 2 & --- \\
\hline Strength of investor protection index $(0-10)$ & 1.7 & 1.7 & 1.7 & 1.7 & 1.7 & 2.0 & 3.3 & 1.7 & --- \\
\hline Paying taxes (rank) & 123 & 116 & 113 & 113 & 114 & 36 & --- & --- & --- \\
\hline Payments (number per year) & 34 & 34 & 34 & 34 & 34 & 31 & 31 & 34 & --- \\
\hline Time (hours per year) & 362 & 362 & 362 & 560 & 672 & 180 & 180 & --- & --- \\
\hline Total tax rate (\% of profit) & 33.3 & 33.7 & 33.7 & 33.7 & 35.5 & 32.5 & 24.7 & 35.5 & --- \\
\hline Trading across borders (rank) & 168 & 170 & 168 & 165 & 158 & 161 & 161 & 163 & --- \\
\hline Documents to export (number) & 9 & 9 & 9 & 9 & 9 & 12 & 12 & 11 & --- \\
\hline Time of export (days) & 44 & 48 & 50 & 50 & 50 & 66 & 66 & 66 & --- \\
\hline Cost to export (US\$ per container) & 1,880 & 1,860 & 1,860 & 1860 & 1750 & 1420 & 1420 & 1420 & --- \\
\hline Documents to import (number) & 10 & 10 & 10 & 10 & 10 & 16 & 16 & 15 & --- \\
\hline Time to import (days) & 46 & 50 & 50 & 50 & 50 & 78 & 78 & 78 & --- \\
\hline Cost to import (US\$ per container) & 2,035 & 2,040 & 2,040 & 2040 & 1930 & 1690 & 1690 & 1690 & --- \\
\hline Enforcing contracts (rank) & 110 & 109 & 111 & 111 & 111 & 146 & 146 & 146 & --- \\
\hline Procedures (number) & 42 & 42 & 42 & 42 & 42 & 53 & 53 & 53 & 42 \\
\hline Time (days) & 443 & 443 & 443 & 443 & 443 & 443 & 443 & 443 & 571 \\
\hline Cost (\% of claim) & 31.6 & 31.6 & 31.6 & 31.6 & 31.6 & 30.3 & 30.3 & 30.3 & 31.6 \\
\hline Resolving insolvency (rank) & 183 & 183 & 183 & 181 & 178 & 151 & 151 & 151 & --- \\
\hline Time (years) & N/A & N/A & N/A & N/A & N/A & 5.0 & 5.0 & 5.0 & --- \\
\hline Cost (\% of estate) & N/A & N/A & N/A & N/A & N/A & 76 & 76 & 76 & --- \\
\hline Recovery rate (cents on the dollar) & 0.0 & 0.0 & 0.0 & 0.0 & 0.0 & 0.0 & 0.0 & 0.0 & --- \\
\hline
\end{tabular}

Source: Adapted from The Ease of Doing Business Report 2012, retrieved 20 March 2012 (www.doingbusiness.org) 


\subsubsection{Sociological Environment}

With a total area of 236,800 square kilometres, the total population of Laos was around 6.4 million in 2011, with an average growth of $2 \%$ per annum and a density of 25 people per square kilometre: the lowest numbers in the region in all aspects (IMF, 2011). The majority of the country is covered by tropical forest and mountains, with a hot and humid climate. According to the Human Development Report of the UNDP in 2011, Laos ranked 138 out of 187 countries (UNDP, 2011). In addition, about $70 \%$ of the population was estimated to be living on under US\$1 per day (UNDP, 2006). As the result of a better healthcare and education system, the literacy and primary school enrolment rates have risen considerably, from $63 \%$ in 1990 to $84 \%$ in 2005 , and a higher percentage of the population in the rural areas now have access to clean water supplies (Bird \& Hill, 2010). In addition, due to higher rice production and an improved transport infrastructure, nutritional intake has increased significantly.

Table 4 shows the slight increase of Lao HDI from 1990 to 2011. The implementation of three phases of reform has marked a significant improvement of several social indicators and Laos is now on the right track to meet poverty alleviation under the MDG in 2020 (NSEDP, 2010). Consequently, this achievement has contributed to a decline in poverty line figures from $45 \%$ in the early 1990s to less than 25\% in 2011 (Fane, 2006; IMF, 2011). However, Laos still lags behind in many significant social indicators and has a very low GDP (US $\$ 1080$ in 2011) and HDI (0.524 in 2011), as ranked by UNDP. Nevertheless, The government, together with international donors, have invested more capital in order to improve the healthcare system throughout the country; as a result, life expectancy at birth has improved by almost half since the 1990s (Bird \& Hill, 2010). In addition, aside from the relatively strong economic growth, this progress also indicates an improvement in human capital and the absence of internal and external violence and conflicts since the declaration on the neutrality of Laos in 1975 (Rosser, 2006). 
Table 4: Human Development Index of Laos1990-2011

\begin{tabular}{|c|r|r|r|r|}
\hline Year & Lao PDR & Medium human development & East Asia and the Pacific & World \\
\hline 2011 & 0.524 & 0.630 & 0.671 & 0.682 \\
\hline 2010 & 0.520 & 0.625 & 0.666 & 0.679 \\
\hline 2009 & 0.514 & 0.618 & 0.658 & 0.676 \\
\hline 2008 & 0.507 & 0.612 & 0.651 & 0.674 \\
\hline 2007 & 0.500 & 0.605 & 0.642 & 0.670 \\
\hline 2006 & 0.491 & 0.595 & 0.631 & 0.664 \\
\hline 2005 & 0.484 & 0.587 & 0.622 & 0.660 \\
\hline 2000 & 0.448 & 0.548 & 0.581 & 0.634 \\
\hline 1995 & 0.411 & 0.517 & 0.544 & 0.613 \\
\hline 1990 & 0.376 & 0.480 & 0.498 & 0.594 \\
\hline
\end{tabular}

Source: Adapted from Bird and Hill (2010) and UNDP (2011)

Despite healthcare and education systems having improved considerably in the past decades, several issues have been highlighted during the process of poverty reduction including land tenure, low quality and price of agricultural products, lack of markets, market information, inadequate and poor transport infrastructure, lack of irrigation systems, livestock disease control, poor health and education conditions, a shortage of technical abilities, difficult access to credit, the threat of environment degradation due to low awareness of people, lack of leadership in the rural communities, management skills and weak governance structure (UNIDO, 2003). Particularly in the education sector, government expenditure on improving the quality of the education system has been very low: only 1\% in the 1990s and $8 \%$ in the 2000s (Onphanhdala \& Suruga, 2007). These issues are considered to be contained problems for the National Poverty Eradication Program, however, that should be addressed by the year 2020. Furthermore, a large social constraint for Laos is the quality and availability of the healthcare system, particularly in regard to preventive and curative services in rural areas, which are still relatively limited (UNDP, 2006).

Laos, together with Cambodia, Myanmar, and Timor Leste are classified by the United Nations (UN) as LDCs. The United Nations Development Programme (UNDP) defines an LDC as a country that has low levels of per capita income (less than US $\$ 1,000$ per year), low levels of HRD, and a lack of economic diversification (UNDP, 2006). More than $50 \%$ of the population is dependent on poor agriculture, with less being dependent on industries and services (ADB, 2009). In addition, lack of adequate transport routes and access to sea ports 
are common problems hindering Laos from integrating into the world markets (Andersson, et al., 2007; WB, 2010). This factor makes Laos more isolated from international trade activities and also contributes negatively to transportation costs across international borders (Lewis, 2008; WB, 2010).

\subsubsection{Technical Environment}

No science and technology initiatives, R\&D or innovation transfer existed in Laos until 2003 (UNIDO, 2003). The National Plan for the Development of Science and Technology (NPDST) was prepared by a government agency and submitted to the government in 2002. The national development plans were divided into three phases of implementation from 2001 to 2020. In addition, the $7^{\text {th }}$ Party Congress advocated R\&D as a tool for the transfer and development of new technologies for social and economic advancement in order to tackle poverty alleviation. However, due to various constraints such as human capital and resources, these initiatives to industrialise the country and increase employment opportunities have been implemented only slowly, one step at a time. The first step of this endeavour, by the Science, Technology and Environment Agency under the Prime Minister's Office, was to send researchers and professors for training abroad; the intention being that they will then return to train the local staff. This initial development plan revealed not only the deficiency in policy and management capabilities to deal with the issues, but also focused on the existing strengths of the country in order to build up capacities.

\subsection{GLOBAL INTEGRATION ATTEMPTS}

The Lao government considers regional and international economic integration as the two main driving forces of economic development and poverty reduction (NSEDP, 2010). Laos has integrated into the regional framework (ASEAN in July 1997). The results of the implementation of regional integrations over a decade in the ASEAN-FTA Common Effective Preferential Tariffs (CEPT) show that Lao imports and export volumes have increased significantly (see Figure 2). The fundamental principles of ASEAN are based on the Treaty of Amity and Cooperation in Southeast Asia (1976). This agreement placed more weight on the social and political aspects of ASEAN members, instead of being based solely on the economic goals of the region (Bird \& Hill, 2010). 
In addition, Laos is the only country in Southeast Asia which, to date, has not been a member of the World Trade Organisation (WTO). Laos submitted an application to be a member on 19 February, 1998. A memorandum on the foreign trade regime was circulated to the WTO Accession Committee and members in March 2001 and a revised offer on trade in goods and services is now underway (WTO, 2012) (see Appendix 4). Several enquiries have been resolved by line ministries, organisations and related sectors with regard to agriculture, sanitary and phytosanitary measures, technical barriers to trade, services and intellectual property (Lewis, 2008). However, the Lao WTO accession remains challenged because of its specific requirements on the adjustment of internal rules and regulations, as well as the difficulties of a land-locked country seeking to accomplish integration into global trading systems (ADB, 2009; Lewis, 2008). Economists and policy-makers are struggling to establish how Laos can gain suitable benefits from these integrations in the short, mid and long term.

In addition to comprehensive regional economic cooperation, Laos also considers global economic integration as significant for economic growth. After applying for WTO membership in 1998, Laos joined the Integrated Framework (IF) process in 2004 and undertook a Diagnostic Trade Integration Study (DTIS) in 2006 in order to diagnose the main constraints of the economy and improve trade performance. Based on the DTIS "Action Matrix", the government is now working more systematically to address these constraints, including institutional capacity building, and simplification and streamlining of the regulatory environment for trading activities (WB, 2006). This also enhances the effectiveness of government institutions in the preparation of the WTO accession process. Furthermore, the Greater Mekong Sub-region (GMS), with the support of the Asian Development Bank (ADB) and other donors, helps to improve inadequate transport infrastructures (Andersson, et al., 2007).

\subsection{CHAPTER SUMMARY}

To sum up, the Lao economic environment has improved significantly after a great deal of effort and the implementation of government reform policies throughout the three phases of economic reform. Laos still relies heavily on natural abundance, neighbouring countries and international donations, however, rather than the development of advanced economic factors, 
as in developed and developing countries. That notwithstanding, there have been several achievements boosting economic performance in the past few decades, indicating a steady rise in economic growth within this time. ASEAN regional economic integration also shows the sustained growth and rapid recovery of the Lao economy from regional and global financial crises. Nevertheless, domestic, human and physical factors still force Laos to lag behind other countries and hinder its real competitive potential. Despite significant effort to become a member of the WTO, Laos still has to work harder in order to maintain its economic growth and to reduce any negative impacts to the economy in the future. 


\section{CHAPTER 3: LITERATURE REVIEW}

\subsection{INTRODUCTION}

This chapter reviews literature on NC and trade liberalisation. Section 1 defines NC. Section 2 reviews theoretical and empirical literature on NC. Section 3 discusses the impact of globalisation on NC and the need for studying less-developed countries (LDCs). The last section provides the chapter summary.

\subsection{NATIONAL COMPETITIVENESS}

\subsubsection{National Competitiveness Defined}

$\mathrm{NC}$ is a multidimensional and relative term. $\mathrm{NC}$ is a country's ability to create and sustain national wealth, living standards (Garelli, 2003; Moon, et al., 1998; Scott \& Lodge, 1985) and productivity levels (Porter, 1990; WEF, 2011).

According to the World Economic Forum (WEF), NC is defined as "the set of institutions, policies, and factors that determine the level of productivity of a country" (WEF, 2011, p. 4). The WEF report is based on secondary data sources and a primary survey of the various micro and macro-economic dimensions of the 12 pillars of competitiveness: institutions, infrastructure, macroeconomic environment, health and primary education, higher education and training, goods market efficiency, labour market efficiency, financial market development, technological readiness, market size, business sophistication and innovation with several proxies (see Table 5) (WEF, 2011). However, the criteria have been criticised because of analytical, methodological and quantitative weaknesses and lack of a strong theoretical framework basis, as they do not provide accurate directions for policy-makers and practitioners to achieve productivity and prosperity, particularly for countries with smaller economic variables (Berger \& Bristow, 2009; Cho \& Moon, 2005; Lall, 2001; Lin, et al., 2004; Thompson, 2004). Furthermore, The results of the reports were overwhelming by the policy-makers and practitioners particularly for smaller economies, which can lead to overconfidence and misleading policies (Lall, 2001). 


\section{Table 5: The 12 Pillars of Competitiveness}

\begin{tabular}{|c|c|}
\hline Basic requirements & \\
- Institutions & Key for factor-driven economies \\
- Infrastructure & \\
- Macroeconomic environment & \\
- Health and primary education & \\
\hline Efficiency enhancers & \\
- Higher education and training & Key for efficiency-driven economies \\
- Labour market efficiency & \\
- Financial market development & \\
- Technological readiness & Key for innovation-driven economies \\
- Market size & \\
\hline Innovation and sophisticated factors & Business sophistication \\
\hline
\end{tabular}

Source: The Global Competitiveness Report 2010-2011, WEF (WEF, 2011, p. 9)

According to Scott and Lodge (1985), the NC of a country is its ability to create value from existing resources in goods and services to compete with international trade and improve people's standard of living. Garelli (2003, p. 740) defines NC as "the ability of a country to create added value and thus increase national wealth". Another view on NC is that it is "the degree to which a country generates, while being and remaining exposed to international, relatively high factor income and factor employment levels" (Farra, Burgio, \& Cernov, 2011, p. 11). The abundance of natural resources and cheap labour are no longer considered the advantage of countries, but instead the level of productivity (Porter, 1990). Thus, science and technology development and R\&D are the first priorities, which create competitiveness over time (Porter, 1980, 1990). Moon, Rugman \& Verbeke (1998, p. 139) defined competitiveness as "the ability of firms in value-added activities in a specific industry in a particular country to sustain this value-add over long periods of time in spite of international competition". 
Thus, increases in productivity, national income and exchange rate are key indicators of defining NC.

In the modern world, productivity is widely used by economists and policy-makers to understand the nature of NC. Porter's Single Diamond home-based model used productivity to explain why some countries perform well in certain industries, but others fall behind (Porter, 1990). He stated that "a nation's prosperity is created, not inherited"; productivity is how productively the country can make use of its existing endowments to create prosperity beyond the capacity of others. This model reflects the relationship between firms as the actual actors in microeconomic activities and government as the controller of the entire country's economic policy decisions. In his later study, Porter also added that "the only meaningful concept of competitiveness at the national level is productivity" (Porter, 1998, p. 160). Similarly, national wealth is only created by productivity and has nothing to do with NC (Krugman, 1994).

According to the yearbook of global competitiveness reports by the IMD and WEF, GDP is a crucial proxy to measure the national competitive ranks. GDP is also regarded as an accurate measurement and is widely used by both economists and decision-makers to identify the standard level of living (Garelli, 2003; WEF, 2011). GDP per capita or a market value of final goods and services produced by a country in a period of time is widely used to help policy-makers or investors assess the growth of a country's economy (Garelli, 2003; Greenaway, Morgan, \& Wright, 2002; Porter, 1990; WEF, 2011). In contrast, it is not an effective measurement to explain the comprehensive social and economic sustainability and wellbeing of people as a whole (Krugman, 1994; Lall, 2001; Wilson, 2008).

A stable exchange rate is important for internal and external trade transactions and has an impact on exporting activities. In contrast, currency depreciation usually affects international trade activities, with a low exchange rate leading to a decrease in domestic income (Boltho, 1996). Empirical evidence shows that during and after the Asian financial crisis in 1997, a depreciation of the currency against both the US dollar and their major trading partners' currencies weakened Asian economies and their current account positions (Zhuang \& Dowling, 2002). Indeed, the depreciation of exchange rates against the US dollar results in the reduction of oil prices, particularly for oil-exporting countries (Lee, 2010). 


\subsubsection{Determinants of National Competitiveness}

According to Smith (1937), the wealth of nations is determined by the abundance of natural resources, labour and capital. He also found that the competitiveness of each country is similar. In contrast, a highly competitive country depends on how productive labour is per unit, compared with labour in the same industries in different countries (Porter, 1990). This is why some countries can achieve higher economic performance than others. The competitiveness of nations does not depend only on those three abundance factors, however, but also on the degree of differentiation of labour's productivity influenced by technology development (Porter, 1980). The following are the key determinants of NC as discussed in the literature.

Inflow FDI: It is well accepted that FDI promotes economic growth over time (Farra, et al., 2011; Hsiao \& Hsiao, 2006; Rugman \& D'Cruz, 1993). Inwards FDI does not only help to improve domestic infrastructure, but also human capital and technology development (Gugler \& Brunner, 2007; Hsiao \& Shen, 2003; Kneller \& Pisu, 2007; Liu \& Song, 1997; Qi, 2007; Rugman \& D'Cruz, 1993). The impact of FDI on competitiveness has also been established for small economies (Cartwright, 1993; Grant, 1991). For instance, the evidence of East and Southeast Asian from 1986 to 2004 indicated the correlation between FDI inflows and the rapid economic growth of China, South Korea, Taiwan, Hong Kong, Singapore, Malaysia, the Philippines and Thailand (Hsiao \& Hsiao, 2006). Generally, FDI is not only a key driver of the improvement of domestic manufacturers in developing countries, but also helps developing countries to catch up with the economic growth level of industrialised economies (Yao \& Wei, 2007). FDI helps development through technological spillover (Rugman \& D'Cruz, 1993). According to Dunning (1993, p. 108), “inward FDI is likely to bring new resources and technologies into a nation. Indeed, a foreign investor might import advantages from his or her base and some of its assets could contain ownership specific advantages". In addition, because different countries have different objectives for attracting FDI based on their potential and capacity, it is logical, therefore, that if some countries receive more, the rest are likely to have less. It is interesting to note that even though all countries have promoted an attractive environment for FDI, they still receive a differing number of investments (Yao \& Wei, 2007).

Infrastructure development: A degree of infrastructure development is a primary indicator for determining the competitiveness of nations. Apparently, this factor is used by the 
International Institute for Management and Development (IMD), WEF, the Organisation of Economic Cooperation and Development (OECD) and many economic models for assessing the productivity and competitiveness of nations. For the IMD and WEF, infrastructure is a significant factor for identifying the basic level of technological, scientific, healthcare, environment and education, satisfying the needs of business with 94 different indicators (Dzeng \& Wang, 2008). The reports were conducted by using both quantitative and qualitative approaches to measure each infrastructure indicator and advise policy-makers of the areas that need to be improved most to enhance a NC. In addition, Dunning (1993) and Ghemawat (2001) argued that a poor cross-border transport system in the host countries results in a disinclination by MNEs to make decisions around entry into a foreign market. Furthermore, most Central Asia countries are land-locked and double land-locked, therefore, the development of transport corridors helps to boost trade and economic cooperation in the region (Farra, et al., 2011).

Innovation, knowledge and technology development: The literature suggests a strong relationship between innovation and NC. Innovation is defined as "the knowledge and ability to produce goods and services of higher or better quality per unit price" (Narula, 1993, p. 90). Technical advancements provide high returns for $R \& D$ and thus contribute to competitiveness (Clark \& Guy, 1998). According to Porter (1990), innovation is essential for countries to upgrade competitiveness, particularly if they are at the stage of industrialising development to exploit their capacity and move into the innovation competitiveness phase. For example, while the EU spent $2 \%$ of GDP on innovation and R\&D, Japan and the US invest $1 \%$ more than the EU; as a result, Japan and the US are more sophisticated in technology than the EU (Clark \& Guy, 1998). In addition, a wider scope of innovation should combine the variety of technological fields through information and communication technology (ICT) in order to increase more innovation activities (Cantwell, 2005).

Furthermore, the combination of multinational enterprises (MNEs) and the preparation of human capital with higher education enhance a country's competitiveness. Because of the roles of MNEs involved in international trade activities such as knowledge-embedded and technological transfer to host countries, the roles of MNEs have contributed to the NC of the host countries (Dunning, 1993; Rugman \& D'Cruz, 1993). In addition, due to a lack of internal competitive know-how and the incompetency of human capital, the host countries are 
unlikely to absorb knowledge and increase technology, precluding them from becoming a network of the MNEs (Dunning \& Narula, 2004; Gugler \& Brunner, 2007; Lall, 2001).

Government institutions: Efficiency of government institutions and organisations are found to be a critical determinant of NC (Gugler \& Brunner, 2007; Lee, 2008; Lee, 2010; Liu \& Hsu, 2009; Moon, et al., 1998; Porter, 1990). It is necessary to differentiate between government institutions and organisations (North, 1990). According to North, institution means "rules of the game" and organisation refers to "players". While organisations are responsible for microeconomic activities, government institutions are in charge of macroeconomic development plans. Krugman (1994) found that a country's competitiveness is not only defined by the productivity of the firms, but also depends heavily on the effectiveness of government institutions. For example, governments regulate and deploy economic plans in accordance with the nature of domestic and international economic structures, particularly in emerging economies; therefore, any changes in institutional structures affect the level of industries' competitiveness (Luo, 2001).

Moreover, governments are responsible for investments of human capital and infrastructures for economic productivity to enhance NC. The findings by Barro (1991) confirmed that education systems provided by governments help to improve the productivity of workers. This means a diversification in education has contributed to an improvement in workers' skills, which is considered a significant factor for higher productivity. In addition, infrastructure development has been regarded as a crucial factor for competitiveness because it facilitates all variables of economic activities (Easterly, 2001). For instance, roads, ports, railways and airports are required to transport goods and services within and across countries in perfect condition and in a minimum amount of time.

\subsection{THEORETICAL UNDERPINNINGS}

Many theories have emerged over time to explain the competitiveness of countries (see Figure 4). The figure shows the evolution from international trade theories to Porter's Single Diamond model, and debates and extensions on competitiveness theories. 


\subsubsection{International Trade Theories}

Absolute Advantage: The absolute advantage theory, as devised by Smith, is based on the presumption that trade is a positive way in which all players can benefit through its abundant factors. This absolute advantage consists of three determinant factors: land, labour and capital, which are considered major forces that constitute the economic growth of countries (Myint, 1977; Smith, 1937). However, the focus is on absolute advantage and not on comparative costs, which affects the production costs (Myint, 1977). According to Smith, the main determinant of domestic economic development is labour's productivity, which helps to increase productivity and economic growth and explains why some countries are richer, while others are lagging behind. However, this theory has been criticised by subsequent economists because at the time Smith was working the roles of international trade and multinational activities did not exist; therefore, all findings were based on the facts of that time.

Comparative Advantage: The absolute advantage theory was extended by Ricardo (1817) and discovered the theory of the law of comparative advantage, which identified the role of relative productivity in determining trade patterns. Both efficient and inefficient countries, with or without absolute advantage, can still benefit from trade-offs due to their most specific and comparative advantage in international trade (Cho \& Moon, 2000). Even though some countries may not have absolute advantage in any goods, international trade can still bring benefits to a country. However, the comparative advantage only can be achieved if a country can produce goods at relatively lower production costs compared with others. Productivity of labour is influenced by technology application in the production process, which creates differences of comparative advantage. However, the Ricardian theory does not adequately explain why the comparative advantages of different countries vary (Cho \& Moon, 2000).

Factor Endowments: A century later, Hecksher and Ohlin (HO), two Swedish economists, explained in their factor endowments theory why comparative advantages differ between countries, particularly labour and capital to produce goods and services (Ohlin, 1933). The factor endowments include four major factors: natural resources, labour, capital and entrepreneurships of the countries, which are used to create comparative advantages. The HO theory also explained how a country used its abundant factors intensively to produce and 
export in order to increase economic growth. As a result, a country with high factor endowments is likely to perform better than one with limited factor endowments; however, it is interesting to note how countries exploit the potential benefits of their endowment factors to enhance economic growth (Sokoloff \& Engerman, 2000). Hecksher and Ohlin criticised the Ricardian theory that comparative advantages of countries are different because of their unique comparative advantages in particular products; for example, countries whose strength is based on exporting and importing products can overcome their poor endowment factors. However, this finding was criticised for a lack of evidence and for insufficient research from different sources, so was not applicable to the complex diversity of international trade variables (Hämäläinen, 2003).

Leontief Paradox: The factor endowments theory was not without its challenges for long. In 1953, Wassily Leontief tested the HO theory by using input-output analysis, and then proposed the Leontief Paradox theory. For example, while agriculture is a labour-intensive sector in many LDCs and developing countries, it is a capital-intensive sector in the US (Hämäläinen, 2003). Therefore, if the US imports agricultural products, this means they are importing capital-intensive products. The reverse applies for LDCs and developing countries when they import products from the US. In addition, the key challenge to the previous trade theory suggested that some countries with poor factor endowments still can achieve a high level of comparative advantages (Hämäläinen, 2003). In fact, international trade and globalisation facilitates the free flow of trade among similar and different countries with different factor endowments.

Country Similarity: A country with similarities to others in domestic market conditions seems to have the same level of international competitiveness. This theory found that sophisticated domestic demand (Moon, et al., 1998; Porter, 1990) is essential for export, which leads to the success of firms acting in international markets. This implies that if domestic customers are more educated, advanced products and services within internal markets will also be enhanced, and will subsequently meet international markets. A similar view also provided by Porter (1990) is that the sophisticated and similar demand characteristics of local consumers can result in the international expansion of products. This finding also implies that knowledge embedded in new products in a firm in one country can also benefit the consumers in other countries with similar tastes. 
Product Life Cycle: Local market conditions facilitate firms' technological advantages through export (Vernon, 1966). This finding also emphasised the importance of product innovation. As importing countries developed their own domestic advantages, production that was already available in these countries was shifted to the rest of the world. Despite the theory addressing the two issues of production and innovation, it did not provide strong evidence as to why technology was embedded from developed to less developed and developing countries, but not between developed countries (Hämäläinen, 2003). In addition, Vernon was unable to provide a reason why advanced countries tend to export and differentiate products and services in international trade activities.

Imperfect Competition and Economies of Scale: These two theories are the driving force of trade among countries with similar and different characteristics. The theories attempted to demonstrate why intra-industry trade flows are crucial for countries with a similar level of development, and why inter-industry trade flows are important among countries that maintain differences in factor endowments. This explains why countries with different or fewer factor endowments gain solutions from international trade. Krugman also found that when production costs per unit fall and markets enlarge, profits increase spontaneously. In addition, Krugman also argued that because of economies of scale, imperfect markets drive growth for countries, regardless of the amount of international trade. 
Figure 4: Evolution from Trade Theory to Competitiveness Theory

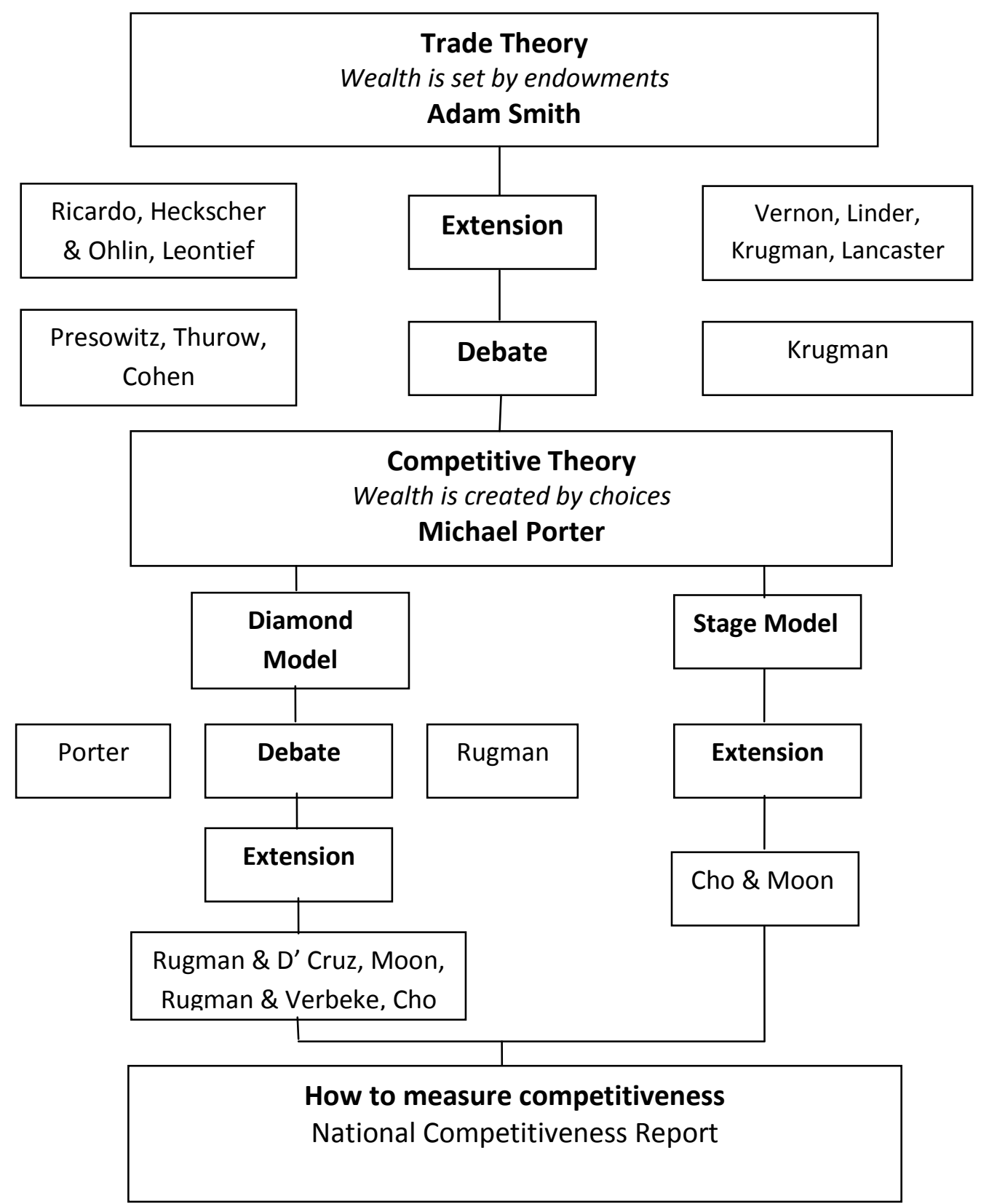

\section{Pioneer/year}

Smith, 1937 (1776)

Ricardo, 1971 (1817)

Heckscher, 1949 (1919); Ohlin, 1933

Leontief, 1953

Linder, 1961

Vernon, 1966

Krugman, 1979; Lancaster, 1979

\section{Theories}

Absolute Advantage

Comparative Advantage

Factor Endowments

Leontief Paradox

Country Similarity

Product Life Cycle

Economies of Scale

Source: Cho \& Moon, (2000, p. 17) 


\subsubsection{Competitiveness Models}

\subsubsection{Porter's Single Diamond Model}

A widely-used framework is the competitiveness of nations in Porter's Single Diamond model (see Figure 5). This model consists of two major, independent variables: endogenous and exogenous factors that identify productivity and competitive advantages of nations. The endogenous factor comprises of four determinants: factor conditions, demand conditions, related and supporting industries, and firm strategy; while structure and rivalry, government and chance are considered exogenous factors (Porter, 1990).

Porter (1990) considered NC as a dependent variable in his diamond model, which consists of endogenous and exogenous independent variables justifying competitiveness of nations. Nations are likely to achieve high performance in industries or industry segments and contribute to NC if all the major determinants are improved (Porter, 1990). Figure 5 shows all significant determinants affecting competitiveness of countries. In addition, according to Porter, "no nation will fit a stage exactly" (Porter, 1990, p. 545). However, the following attributes imply a very comprehensive tool and provide the necessary requirements for competitiveness between nations.

Factor conditions includes both basic and advanced fundamental factors, which are crucial inputs for production and considered basic for competition. However, Porter argued that advanced factors are considered an important source for comparative advantage. According to him, advanced factors such as know-how, capital and infrastructure facilitate export and increase outbound FDI. In addition, advanced factors are considered to be competitive advantages of industries and countries in order to generate global competitiveness and productivity.

Basic factors:

- Human resources: the number of skilled and unskilled workers, the value of personnel (management and development skills) and how productive the workers are in standard working hours and per unit

- Natural resources: "the abundance, quality, accessibility, and cost of the nation's land, water, mineral, or timber deposits, hydroelectric power sources, fishing grounds, and other physical traits" (Porter, 1990, p. 74). In addition, geographical 
difficulties that increases transportation costs, and time zone differences, which can be considered both an advantage and a disadvantage to NC.

Advanced factors:

- Knowledge resources: market information and structure (particularly in goods and services), scientific and technical knowledge, research institutions in both the government and private sectors

- Capital resources: structure and stock of capital in banking and financial systems to serve local and foreign industries

- Infrastructure: quality and cost of all transportation, communication, healthcare, education, and so on, that is available to create a competitive advantage for both domestic and foreign firms in the country.

Demand conditions refers to a demand from local customers. Porter (1990) emphasised home demand conditions in his work based on three general characteristics: the basic needs of local buyers, the anticipation of size and potential growth of domestic demand, and the local demand for products and services that can be transferred into foreign markets. In addition, Porter also placed emphasis on sophisticated domestic consumers who increase the level of product differentiations and competition to meet with international demands. Furthermore, he also highlighted that improvements in education can increase the potential for sophisticated demand from consumers over time, which helps to increase the technological development of domestic firms and compete with global demand.

Related and supporting industries consists of all elements of the input and supply chain among manufacturers, service suppliers and distributors, which always affects the competitive advantage of domestic and international industries. Porter (1990) argued that if domestic suppliers and related industries are able to compete internationally, these competitions provide as much innovation, $\mathrm{R} \& \mathrm{D}$, information flow and shared technology development as the advantages of industries. In addition, industry success depends on countries' competencies in related and supporting industries. Furthermore, a number of scientists and institutions for innovation and $R \& D$ enhance the performance of domestic and foreign firms. For example, the success of the Italian ski boot industry internationally relies on the quality of domestic leather suppliers (Porter, 1990). 
Firm strategy, structure, and rivalry is based on all three determinants above. In reality, firms rely on their competitive advantage and focus on solving their less competitive issues. As Porter stated, "vigorous local and global competition not only sharpens advantages at home but pressures domestic firms to sell abroad in order to grow" (Porter, 1998, p. 199). This illustrates that domestic rivalry encourages firms to develop improved productive strategies and structures, and consequently strengthens NC. For instance, domestic rivalry within American and Japanese industries helped them to achieve higher industry competitiveness than before (Krugman, 1994).

Alongside the four endogenous determinants of this model, competitiveness between nations also depends on exogenous factors as follows:

Government imposes rules, regulations and policies in order to facilitate or protect industry activities and increase a firm's productivity and a country's competitiveness. These are consistent with creating wealth and a standard of living for people, as well as achieving economic, political stability and other social benefits (Porter, 1998). Apparently, government plays an important role in constructing a national competitive advantage throughout all four endogenous factors, either positively or negatively. In addition, solid and competent economic policies can determine success and strengthen competitiveness. For example, strict government regulations increase $\mathrm{NC}$ if they are consistent with the trend of economic development within the countries (Porter, 1990). Government can particularly influence all indicators of factor conditions. In contrast, any inconsistency in government policies may both directly and indirectly affect the ability of domestic industries to compete with global markets (Grant, 1991; Porter, 1990; Rugman \& Verbeke, 1990).

Chance means any unpredictable events that are not controlled by firms or governments. These circumstances also affect the performances of industries and NC. Generally, the situations are due to shortages of input, technological breakthroughs, new inventions, outbreaks of war, economic crises, natural disasters, epidemic diseases, energy crises, sharp fluctuations of foreign exchange in the international financial market and other capital commodities price increases; all of which have a direct or indirect impact on global market demand. Consequently, firms have made efforts through the promotion of innovation and the improvement of technologies to mitigate the potential threats of chance events. 
Figure 5: Porter's Single Diamond Model

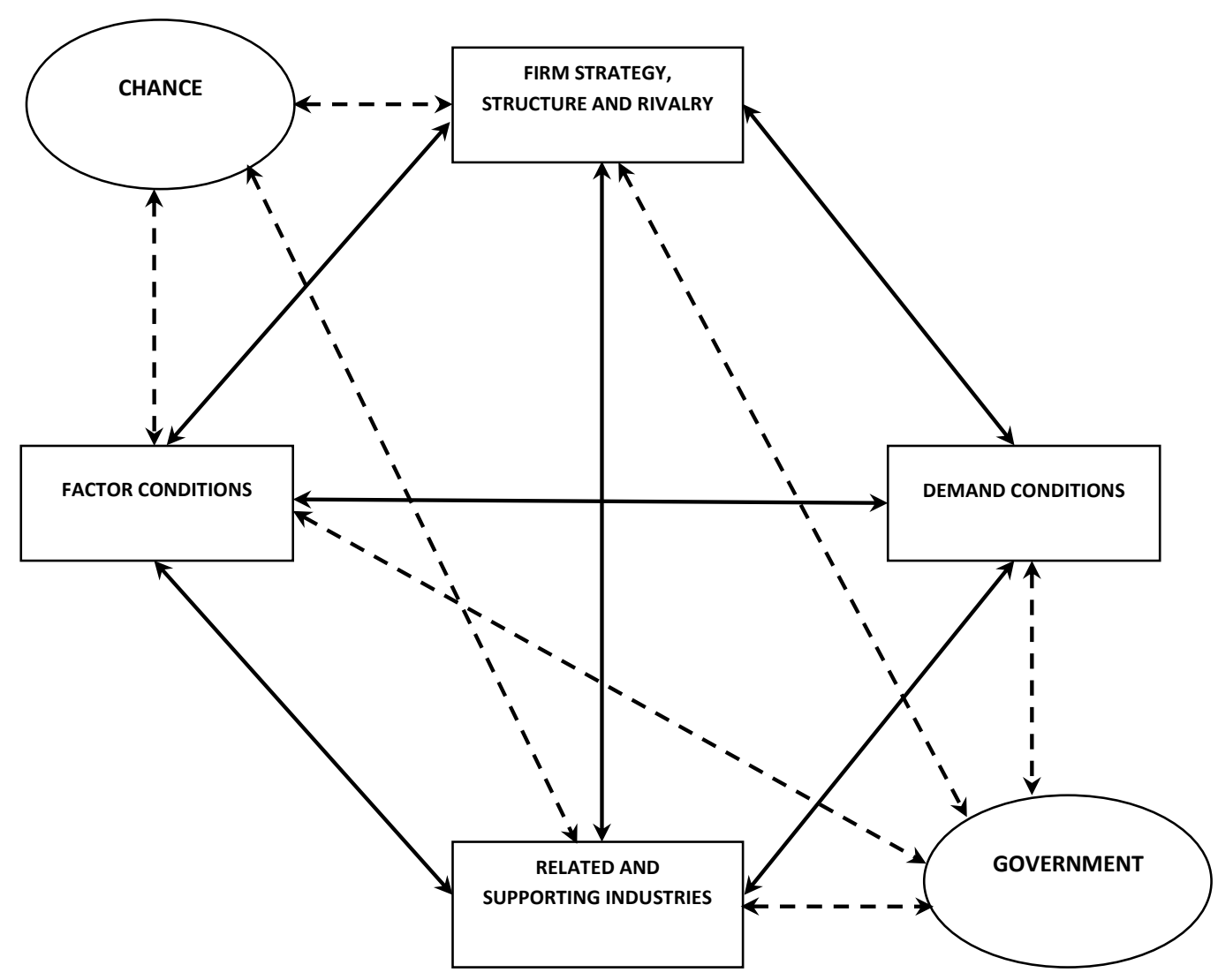

Source: Porter, (1990, p. 76)

\subsubsection{Extensions of Porter's Single Diamond Model}

Competitiveness in each country is unique due to the level of economic development and cultural differences, therefore, different countries need suitable models to achieve competitiveness (Giedre Staskeviciute, 2010). Several researchers have developed and extended NC models from Porter's Single Diamond model (see Figure 5) to make them suitable for the nature of different industries or countries (Cartwright, 1993; Cho \& Moon, 2005; Cho, et al., 2009; Dunning, 1993; Grant, 1991; Hodgetts, 1993; Krugman, 1994; Moon, et al., 1995, 1998; Narula, 1993; Rugman \& D'Cruz, 1993). Evidence given by Hodgetts (1993), Cho (1994), Lin et al. (2004), and Cho et al. (2009) showed that due to the small domestic variables of smaller countries, Porter's Single Diamond model would not provide a sufficiently comprehensive explanation for the productivity and competitiveness of LDCs and other developing countries. 
Countries are not only different in size and level of economic development, but also have distinctive strengths and weaknesses in their economic structures. Therefore, a modification of Porter's Single Diamond and other models should be considered (Cho, et al., 2009; Hodgetts, 1993). In addition, contrary to Porter, inbound foreign investment is essential for LDCs to strengthen NC. For example, innovation and R\&D are the two main benefits of FDI that foreign investors always bring along with them. Furthermore, natural resources are sources of comparative advantage in many LDCs, developing countries or even developed countries, and accumulate national wealth and as well as firm-specific advantages. In addition, regional and international trade agreements create more opportunities for countries to overcome their disadvantages within Porter's four attributes on competitiveness (Feinberg \& Weymouth, 2011).

Small and open economies become competitive through internationalisation under regional and international trade agreements. According to Ku (2002) and Farra et al. (2011), many Asian countries have liberalised trade since the 1980s within the regions and with the rest of the world and supplied important resources. As a result, the Asian economy has grown rapidly and contributed to global economic growth. This factor also helps the economic structures become more dynamic and attractive to FDI. Consequently, inward FDI is important for small and open economies (Rugman \& D'Cruz, 1993), contrary to Porter's statement that "inward FDI is not entirely healthy" (Porter, 1990, p. 671). The roles of international activities have not been covered adequately in Porter's Single Diamond model. Therefore, the majority of countries identify NC by models other than Porter's (Cho, 1994; Cho \& Moon, 2005; Moon, et al., 1998; Moon, 2006; Rugman \& D'Cruz, 1993).

Furthermore, the Single Diamond model did not cover international and multinational activities (Rugman \& D'Cruz, 1993). Dunning (1993) further developed this model and paid more attention to international factors when analysing a country's competitiveness. According to Rugman \& D' Cruz (1993) and Lall (2001), the original diamond model should include international and multinational activities to obtain a precise understanding of the competitiveness of nations. For example, while many countries' competitiveness relies on global sourcing, New Zealand has developed multinational links with trading partners because it is an export-dependent nation (Cartwright, 1993). This implies that countries 
should not only focus on internal physical factors, but also international factors such as FDI, international network and global standard.

Figure 6: Porter's Single Diamond Model and Its Extension Models

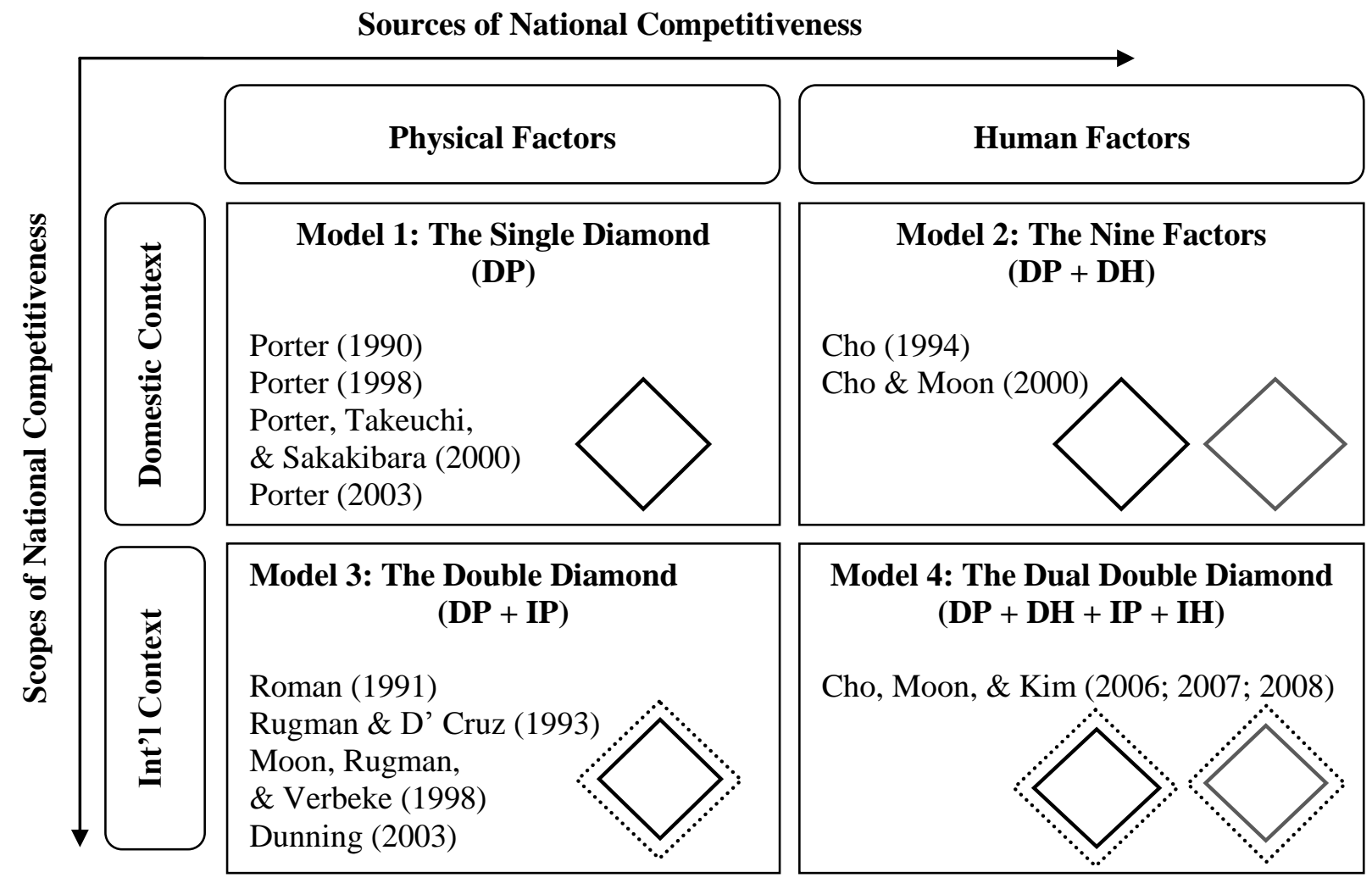

Note: DP: Domestic Physical factors, HD: Human Domestic factors, IP: International Physical factors, IH: International Human factors.

Source: Cho et al. (2009, p. 88)

\section{The Generalised Double Diamond (GDD) model}

The GDD model was developed to tackle the existing competitiveness of small and open economies, which includes international physical factors (Moon, et al., 1995, 1998). Grant (1991) argued that Porter's Single Diamond model (1990) should take not only domestic factors but also multinational activities into account in order to assess NC. LDCs and some developing countries are heavily reliant on inward net FDI, and international physical factors such as capital, knowledge and new technologies also make a vital economic contribution towards strengthening their competitiveness regionally and globally (Moon, et al., 1995, 1998; Rugman \& D'Cruz, 1993). 
The most controversial issue identified by Porter (1990) is whether or not to incorporate international variables into the diamond model. The GDD model, based on Porter's model, integrates the international variables as parameters to obtain accurate results from a smaller country's point of view. This model uses the breakdown factors from the IMD, the Growth Competitiveness Index (GCI) and the WEF reports as indicators to help measure the competitiveness of nations. This model has been used by several researchers to examine the international competitiveness of Mexico, New Zealand, Canada, Singapore, Hong Kong, China, Taiwan, South Korea and other small and open economies in Africa (Cartwright, 1993; Hodgetts, 1993; Jin \& Moon, 2006; Liu \& Hsu, 2009; Moon, et al., 1998; Narula, 1993; Rugman \& Verbeke, 1993; Tummala, Lee, \& Yam, 2000; van Wyk, 2010).

The inner diamond of the GDD model (see Figure 6) represents domestic competitiveness and the outer diamond represents international competitiveness. The small dotted lines between the domestic and international diamonds show the NC level of the countries in accordance with these two diamonds. The GDD model places an emphasis on international physical factors that affect NC. Dunning (1992) found that Porter's model should include treating multinational activities as an exogenous variable, in addition to government and chance. Consistent with this finding, Cho \& Moon (2000) contend that international activities are a crucial factor in the modern world that influence $\mathrm{NC}$ and should be included in factor conditions, rather than as an exogenous factor. In addition, the GDD model by Moon et al. (1995, 1998) suggested that sustainable value-added activities in specific industries in particular countries are derived from the performance of both domestic and international firms. Moreover, this model puts an emphasis on both the inbound and outbound FDI of multinational activities, which are suitable for small and open economies.

\section{The Nine-Factor model}

Although, Porter's Single Diamond model includes all the crucial indigenous basic and advanced domestic factors of productivity to measure the competitive advantage of nations, Cho \& Moon (2000) added domestic human factors and developed the Nine-Factor model (see Figure 6), which consists of two main aspects different from Porter's model (Cho, 1998) as follows:

Physical factors: The four physical factors are endowed resources, business environment, related and supporting industries, and domestic demand. These factors are mainly concerned 
with domestic conditions at the firm, industry and national levels. Without the physical factors, it is impossible for competitiveness to exist. Thus, it is necessary for countries to overcome all limitations of these fundamental factors to enhance competitiveness.

Human factors: These consist of four groups of people, namely workers who drive all production activities, politicians and bureaucrats who regulate and implement rules or regulations on economic development plans, entrepreneurs who run business in accordance with government policy, and professional managers and engineers who manage businesses and develop new technologies. These groups of people are not only essential for production quality and quantity; they are also considered the backbone of a country's economy. There is no doubt that a country with a sophisticated level of education, high motivation and dedication is more likely to succeed than others, despite the lack of necessary physical factors; for example, Singapore, South Korea and Taiwan (Liu \& Hsu, 2009; Moon, et al., 1998). In addition, human factor roles are considered the most important factor in explaining the competitiveness of nations (Cho, et al., 2009; Moon, et al., 1998; Porter, 1990).

\section{The Double Dual Diamond (DDD) model}

Cho, Moon \& Kim (2009) proposed the DDD model to analyse country-specific advantages (CSAs), which integrate international human factors into one single diamond model to analyse the competitiveness of countries. Despite the fact that the GDD model and the NineFactor model have integrated all international contexts and domestic human factors to explain country-specific advantages better than the single diamond model, it is necessary to incorporate international human factors in order to obtain a comprehensive model of NC (Cho, et al., 2009). The DDD model integrates all four determinants in order to have a complete understanding of NC: physical and human factors in domestic and international contexts (Cho, et al., 2009).

Unlike the existing GDD and Nine-Factor model, the DDD model analysed both the domestic and international aspects of the human factor in relation to NC. For example, countries with high international connectivity and high international human factor dependency, such as Switzerland, Belgium, Hong Kong, United Kingdom and Taiwan, experience an increasing ranking in global competitiveness (Cho, et al., 2009). To sum up, the DDD model is very important for the MNCs' decision-making on the basis of CSAs, which can help them to expand an efficient global strategy. However, the DDD model is only applicable for 
sophisticated countries with strong and various economic variables. Thus, it may not apply for LDCs based on the evidence of Hodgetts (1993); Lin et al. (2004) and Cho et al.(2009).

\subsubsection{Summary}

Despite Porter's Single Diamond model being considered the comprehensive tool to assess the NC of countries and industries, several debates and extensions continue to develop, with the aim of tackling the nature of NC in different countries. This model is more suitable for industrialised and advanced economies instead of the status of LDCs and other developing countries (Rugman \& D'Cruz, 1993). Due to the differences in the number of variables of the countries' economic structures, specific models should be taken into account when identifying the NC of smaller countries. Another limitation is the significant contribution of inbound FDI, particularly for LDCs and developing countries, as it is considered the driving force of economic growth because of the difficulties of internal financial supports. Furthermore, the role of multinational enterprises is crucial during the period of knowledge and technology transmission to host countries and beneficial to local industries that always contribute to NC.

\subsection{TRADE LIBERALISATION AND NATIONAL COMPETITIVENESS}

The impact of trade liberalisation on the competitiveness of countries has been discussed and analysed over two decades (Frankel \& Romer, 1999; Greenaway, 1998; Greenaway, Leybourne, \& Sapsford, 1997; Greenaway, et al., 2002; Greenaway \& Sapsford, 1994; Krugman, 1994; Sachs \& Warner, 1995). These studies found that international trade activities through regional and international economic integrations enhance the government efficiency, improve the human capital, knowledge, technology, and the productivity of countries over time. Trade liberalisation increases the growth of both imports and exports, and also improves living standards (Edwards, 1993; Greenaway, et al., 2002; Greenaway \& Sapsford, 1994; Winters, 2004; Winters, et al., 2004). As a result, removing trade barriers and unnecessary import and export regulations have contributed to economic growth. The OECD (1998) asserted that economies that are more open and outward-oriented consistently perform better than economies with restrictive trade and foreign investment regimes. Trade liberalisation is strongly associated with per-capita income growth (Stiglitz, 1998). Moreover, the only way for countries to grow is by integrating into the world economy (Fischer, 2000). 
This is because trade liberalisation helps to reduce trade distortions among countries (Lee, 1993).

Trade liberalisation is a tool to reduce the costs of trade, technology transfers, financial flows and capital movements between countries (Crafts, 2004). Frankel \& Romer (1999) found that the increased ratio of trade contributed to a higher level of income and economic growth between 1960 to 1985 and helped the countries to overcome geographic constraints. PostWorld War II, 40-50\% of the trade barriers still existed among industrial nations; after the 1990s this figure had reduced to 4-5\%. Similar to Dollar \& Kraay (2004), liberalised countries performed better on the basis of trade policy than non-liberalised countries during the post-1980s period. For example, after South Korea, Taiwan, Hong Kong and Singapore liberalised the trade regime by removing import substitution and implementing outer-oriented trade strategies in the early 1960s, their economies grew significantly (Krueger, 1998). However, Greenaway \& Sapsford (1994) and Greenaway et al. (2002) suggested that after implementing trade liberalisation, country growth could be known as a "J curve", which divided the different impact of trade liberalisation into three different phases: small growth and difficulties, recovery in the medium term, and high growth in the long term.

Liberalised trade countries are likely to grow faster than countries with trade distortions (Dollar \& Kraay, 2004; Edwards, 1992; Greenaway \& Sapsford, 1994; Krueger, 1997; Sachs $\&$ Warner, 1995). There is a positive relationship between trade liberalisation and economic growth (Greenaway, et al., 2002). In contrast, trade restriction policies are considered to reduce the supply chain of intermediate goods and lower the productivity of economies (Romer, 1994). Krueger (1997) and Harrison (1996) found that there is a positive correlation between trade liberalisation, exports and GDP growth. According to Dollar \& Kraay (2004), there was a significant increase in GDP in the 1990s during trade liberalisation; while developed countries gained $2.2 \%$, developing countries achieved 5\% from liberalisation. Furthermore, openness and trade reform policies facilitated the importing of foreign capital and intermediate goods into the domestic markets (Foster, 2008), which, in turn, raised productivity to a level that was higher than before and led to economic growth. Growth of exports contributes to GDP growth and both are highly correlated (SGreenaway, 1998). For instance, an increase of 1\% GDP results in a 1.5\% income level (Crafts, 2004). However, income may be influenced not only by the amount of foreign trade, but also by the domestic 
trade (Frankel \& Romer, 1999). Trade liberalisation influences NC in many ways as discussed below.

\subsubsection{Inflow FDI}

It is well-accepted that trade is an engine of growth. Free flow of trade increases opportunities for FDI flows, then FDI helps countries to accumulate capital formation, technology transfers and development, and improve domestic entrepreneurial skills, high domestic and international competitions, and the ability to access markets. Rodrik (1994, 1997) and $\mathrm{Ku}$ (2002) noted that because of strong incentives on FDI, Asia was considered the most popular destination for foreign investors during the decades of the 1990s and 2000s. However, openness does not drive prices down due to high expectation on returns in large markets (Bhagwati \& Srinivasan, 1999). In addition, the issues of property rights, peace and financial depth are determinant factors for an effectiveness of openness to attract FDI, which should be carefully considered by policy-makers (Winters, 2004).

\subsubsection{Productivity}

Promoting trade liberalisation increases the level of productivity (Ferreira \& Rossi, 2003). According to Winters (2004), removing unnecessary barriers to trade enhances productivity, and import competition is the key for a significant productivity growth of manufacturing products. Empirical evidence shows that increasing import competition leads to productivity, because most of the apparent total factor productivity (TFP) is due to openness (Winters, 2004). For example, Hay (2001) and Ferriera and Rossi (2003) on Brazil, Jonsson and Subramanian (2000) on South Africa, Lee (1996) and Kim (2000) on South Korea found that import competition through trade liberalisation promoted a significant improvement in technological efficiency to industries, which helped to improve productivity.

\subsubsection{Employment}

Employment in developing countries, particularly the wages of skilled workers, increases through trade liberalisation (Santos Paulino \& Thirlwall, 2004). This finding also showed that a more liberalised trade regime reduces import and export duties, which leads to a positive growth of imports rather than exports. According to Hanson \& Harrison (1999), while there was an increase in wages and employment of skilled workers after Mexico adopted trade liberalisation, there was no change in wages for unskilled workers. On the other hand, entrylevel countries in the mid-1980s such as China, India, Bangladesh, Pakistan and Indonesia 
with a high level of unskilled labour had more difficulty in income equality (Davis, 1996; Wood, 1997). The findings also supported that given the oversupply of unskilled labour for production goods, these countries have less of a comparative advantage in wages. Furthermore, evidence by Milner and Wright (1998) showed trade liberalisation increases the wages of women and unskilled labour in association with export sectors. Wages and employment have been significantly improved as LDCs liberalise their FDI policies. After joining trade liberalisation, particularly for LDCs, demand for labour-intensive production increases, therefore, both wages and employment also increase (Winters, et al., 2004).

\subsubsection{Knowledge and Technology Development}

Trade liberalisation increases the spillover of knowledge and technology within and outside industries. Evidence shows that exporters from developing countries need to strengthen knowledge by interactions with international markets (Krueger, 1998). Apparently, after experiencing international buyers, productivity is likely to be higher. Exporters from developing countries are learning by doing and are able to adapt to a highly competitive environment among domestic and international firms. For instance, while the growth of 28 countries rose after 0-5 years after liberalisation, 35 countries were found to have grown after 5-10 years (Kneller, Morgan, \& Kanchanahatakij, 2008). In addition, they also added that openness also increases advanced technology transfers to countries. At the same time, new technological adaption is also an advantage, rather than the low wage of labour.

\subsubsection{Government Policy Reforms}

Trade policy reform is an essential tool for ensuring the benefits of trade liberalisation in long-term economic growth (Edwards, 1998; Greenaway, 1998; Lee, 1993; Rodriguez \& Rodrik, 2001; Winters, 2004). Any inconsistent supplementary policies through trade reforms reduce the potential benefits of trade liberalisation (Bolaky \& Freund, 2005). There is a strong relationship between trade policy reform and economic growth (Kneller, et al., 2008). This study used the sample of 37 liberalised countries and found that the countries that achieved high economic performances in the period of post-liberalisation were relatively more successful than pre-liberalisation (Lee, 1993). The study also found that there is a correlation between political regime changes and structural changes of economy. In addition, most liberalised countries rely on imports to enhance domestic productivity, thus, any trade distortion policies imposed by the government such as quantitative restrictions, import tariffs, quotas and exchange control are considered as barriers to growth (Lee, 1993). 
Transparency is an important dimension for reducing corruption and facilitating trade liberalisation (Winters, 2004). A low degree of openness and a passive industry policy by government is a sign of corruption (Ades \& Di Tella, 1997, 1999). As a result, corruption reduces investment flows and economic growth opportunities. Conversely, however, Wei (2000) found that more open countries have more corruption than less open countries. He also pointed out two issues of concern. Firstly, over-favourable conditions for FDI in natural resources allow more corruption in the public sector. Secondly, governments in open countries focus on administration and pay their civil servants better, which also leads to corruption.

Over the past 20 years, trade liberalisation has increased economic growth in many developing countries (Greenaway, et al., 2002) by removing trade barriers through trade policy reform, which enhanced the export and import of products, the inflow of foreign capital, and FDI (Kawai, 1994). In addition, a free flow of trade and FDI policies led to higher productivity; as a result, domestic market size, sophisticated product demand and income distribution also rose (Levine \& Renelt, 1992). Moreover, most countries benefitting from trade liberalisation were those that had low levels of trade barriers (taxes), imported competitions and sophisticated human capital (Kneller, et al., 2008). However, most countries experienced long-term benefits by implementing long-term trade liberalisation policies rather than short-term processes.

Governments in many developing countries have adopted new economic mechanisms through trade liberalisation to stabilise international economies. During the 1970s and 1980s, developing countries initiated new economic mechanisms and reform policies, including trade liberalisation by deregulating financial and capital markets, as well as regulations on production and workforce (Arbache, Dickerson, \& Green, 2004). As a result, there were many dramatic changes in protected industries, which led to technological change, innovations and income generation. Furthermore, developing countries such as Brazil, China, India and South Korea received large amounts of both quality and quantity of inflows FDI, which contributed to productivity and enhanced modern technology (Arbache, et al., 2004). 


\subsubsection{Reduction of barriers to trade}

Many developing countries tend to decrease tariff barriers through trade liberalisation to achieve a higher performance in international trade. For example, the recent two decades have witnessed a rapidly growing number of WTO member countries. This is because WTO membership enhances opportunities for countries to engage in international trade activities, while removing burdensome aspects of tariffs and trade distortions (WTO, 2012), which can be crucial for countries' economic development in the current trade liberalisation context. On the other hand, having said that reducing unnecessary barriers to trade promotes openness, there is no strong evidence supporting the idea that trade liberalisation increases countries' productivity (Rodriguez \& Rodrik, 2001; Rose, 2004). A notable phenomenon is that since 1986, after the Uruguay Round, more LDCs and developing countries expressed their willingness to join WTO (Evenett \& Braga, 2005). As a result, in 2011 more than two thirds of WTO members are LDCs and developing countries.

\subsubsection{Contribution to Economic Growth}

Trade liberalisation is a tool for economic growth for two reasons. Firstly, competition between domestic and international firms always results in high productivity (Melitz \& Ottaviano, 2008). A high degree of competition drives domestic firms to improve their efficiency by reducing production costs, as well as forcing firms to concentrate on their core competency products, focus on risk management, generate profits and raise innovation to compete with external threats (Topalova \& Khandelwal, 2004). Secondly, superior inputs and technology are the determinant for technological efficiency (Melitz \& Ottaviano, 2008). Because insufficient input affects technological changes, particularly for developing countries, an adequate and sufficient input of technology is needed for economic growth.

\subsection{COMPETITIVENESS OF LESS DEVELOPED COUNTRIES}

Most of the studies on the impact of trade liberalisation on NC relate to developed and developing countries, with only few studies focusing on LDCs (see Appendix 3). Research suggests that the impact of trade liberalisation on economic growth, particularly from the point of view of small countries, remains lower than expected (Greenaway, et al., 2002; Rodriguez \& Rodrik, 2001; Winters, 2004). Small countries are promoting openness to achieve higher economic performance and greater productivity growth (Dollar, 1992; 
Edwards, 1998; Frankel \& Romer, 1999; Sachs \& Warner, 1995; Winters, 2004). However, there is little evidence to support which direction trade policy changes via openness should take (Greenaway, et al., 2002; Rodriguez \& Rodrik, 2001; Tybout, 1992; Winters, 2004). Despite the percentage of small countries involved in international export manufacturing increasing by $10.6 \%$ to $26.5 \%$ from the 1980 s to the $1990 \mathrm{~s}$, their value-added activities slumped to $23.8 \%$ (UNCTAD, 2002). Trade liberalisation also reduces domestic protectionism, which results in diversification of products, quality, prices and global standard (Foster, 2008). Also, while trade liberalisation may contribute to economic growth, it does not necessarily increase the standard of living (Rodriguez \& Rodrik, 2001).

Human resource development (HRD) is the main priority for LDCs, rather than many sophisticated factors as is the case in developed countries. Increasing skills and qualifications of human capital are associated with an increase in output and productivity (Porter, 1990; Rugman \& D'Cruz, 1993). Generally, education plays a very crucial role in accelerating effective openness to improve both the health of workers and to assist them to absorb new technologies more quickly (Winters, 2004). Winters also stated that there is a strong relationship between openness and sophisticated education systems, such as the import of better techniques, technologies, and equipment, as well as education abroad for students.

LDCs define the benefits of trade liberalisation differently from developed countries. While developed countries' economic variables take a very comprehensive approach to measuring $\mathrm{NC}$, there are few economic variables found in the context of LDCs. In fact, only a few elements may be used to assess NC for LDCs, namely factor endowments, the impact of trade liberalisation (global integration) and the role of government, which are all considered critical for their competitiveness, as discussed below.

\subsubsection{Factor Endowments}

The majority of trade and competitiveness theories confirm that the development of basic and advanced factor endowments are considered to be a significant source of NC (Cho, et al., 2009; Cho \& Moon, 2000; Kao, et al., 2008; Moon, et al., 1998; Moon, Rugman, \& Verbeke, 1995; Ohlin, 1933; Porter, 1990; Rugman \& D'Cruz, 1993; Smith, 1937). In contrast, while basic factors of $\mathrm{NC}$, such as natural sectors, are being exploited, sophisticated factors including S\&T, R\&D and innovation activities are not well developed in LDCs, which results in reduced competitiveness. At the same time, these finding also argue that even though some countries have fewer basic factor endowments, they still obtain the greatest economic 
performance through the development of advanced factor endowments, for example South Korea, Singapore and Taiwan (Moon, et al., 1998; Rodrik, 1994). Thus it is worth noting how LDCs develop and exploit the potential of endowment factors and why the majority are still considered less competitive compared with countries with fewer resources.

Particularly for LDCs, turning the abundance of natural resources into potential economic development would not be considered as sustainable development (Lin, et al., 2004; van Wyk, 2010; WB, 2010). It is important that LDCs choose the right projects and undertake them in the right way. Poverty reduction needs not only proactive policies, but also the ability of the government to identify risks and deal with them effectively (WB, 2010). For instance, a number of mining projects in LDCs do not benefit the host governments and underprivileged people properly, due to an imbalance in the proportion of profit share contracted by the government and the investors (Lall, 1999; van Wyk, 2010). In fact, LDCs need a strategic framework in order to create or add more value to products and services rather than solely exporting raw materials. So far, many countries have experienced a lack of proper benefits from natural resource projects that have not contributed to the competitiveness of nations.

\subsubsection{Global Integration}

Countries integrate into the global economy in order to enhance NC. Trade liberalisation does not only provide opportunities to enhance economic growth for LDCs, but also provides many challenges to be overcome (Awuah \& Amal, 2011; Lin, et al., 2004; van Wyk, 2010). Under the criteria of the United Nations Development Programme (UNDP), an LDC is defined as a country that has low levels of per capita income (less than US $\$ 1,000$ per capita per year), low levels of HRD, and a lack of economic diversification (UNDP, 2006). During the 1990s, non-globalising countries gained only $1.4 \%$ per capita for economic growth (Dollar \& Kraay, 2004). According to Porter (1990), the prosperity of a country is measured by productivity, thus, all four determinant factors should be enhanced to achieve NC. However, due to many constraints of the four factors in LDCs, trade liberalisation does not promise economic growth (Cho, 1994; Lin, et al., 2004; van Wyk, 2010).

LDCs integrate into the world economy through trade liberalisation as an important route to eliminate poverty and economic inequality (Winters, et al., 2004). In theory, sustained economic growth and stability means poverty alleviation, and this is widely accepted by 
economists and development practitioners. In fact, growth can also increase inequality and poverty gaps (Winters, et al., 2004). This finding also shows that a level of economic growth after opening up an economy does not reflect the income equality of LDCs. However, the roles of trade liberalisation are to reduce barriers to international trade and distribute employment opportunities for the underprivileged (McCulloch, Winters, \& Cirera, 2001). In addition, evidence from poverty reduction programmes in Vietnam found that trade liberalisation was a crucial contribution to improving the standard of living (Heo \& Doanh, 2009).

An international trade agreement is regarded as an opportunity for LDCs to strengthen their position on the international stage. Various literature sources indicate that while the impact of the WTO on trade policy is huge, its impact on economic growth is difficult to measure (e.g. Edwards, 1998; Greenaway, et al., 2002; Sauvé, 2005). For instance, while the investment policy reform of Cambodia and Nepal in line with WTO agreements was useful, it was not efficient enough to attract FDI due to the non-transparency of government institutions on investment policies (Sauvé, 2005). Because of the lack of awareness of cost-effectiveness and competitiveness of socio-economic situations, it seems reasonable to conclude that Cambodia gained less benefit from this organisation (Chea \& Sok, 2005). A study by Pritchett (1996) also illustrates that no significant relationship between trade policy reforms and economic growth has been found in the WTO accession. Some trade reform policies, particularly during the period of preparation for the WTO accession, are not consistent with the real benefits of LDCs, which creates difficult implications for governments to comply with (Pauly, 1999).

While the preferential treatment provided by developed countries to LDCs is useful, it does not stop LDCs' access to markets being hindered by low capacity and weak economic structure. For example, the EU allows all LDC products to be imported without any quantitative restrictions (Brenton, 2003). As a result, the LDCs enjoy export quota and dutyfree access to the EU markets, and can sell their products at the same price as the EU (Panagariya, 2005). This also guarantees certain market access, which helps to attract more investors of a higher quality and a wider range of export products to those markets. LDCs still cannot fully exploit this potential due to domestic constraints such as limited raw material inputs, certain quantity and quality requirements and other specific regulation issues (Brenton, 2003). 
In addition to opportunities, LDCs also encounter disadvantages; for example, the Doha Development Agenda (Scott \& Wilkinson, 2011). After the Doha negotiation on agricultural products, developed countries imposed import barriers in the form of sanitary and phytosanitary measures to protect their domestic farmers, which made it difficult for poorer countries to access their markets (Panagariya, 2005). The agreement also called for further reduction in the tariffs, domestic support and export subsidies of exporting countries, also known as the 'three pillars of agricultural trade reform'. This highlighted the controversial issue of how LDCs can comply with those agreements in the long term.

Trade liberalisation reduces government revenue and expenditure. An LDC government's revenue relies on tariffs and tax collections from import and export activities. According to WTO general agreements on tariffs and trade, all members have to reduce all tariffs to $0 \%$ under the commitments (WTO, 2012). Winter (2004, p. 108) also noted that "although trade liberalisation may not be the most powerful or direct mechanism for addressing poverty in a country, it is one of the easiest to change". Therefore, LDC governments are reluctant to move towards openness because they cannot find any supplementary sources of revenue to spend on government procurement and other social expenditure.

\subsubsection{The Role of Government}

Despite national prosperity and productivity being created by firms, the government has the significant role of creating a competitive environment for business (Porter, Grant, 1991; Hodgetts, 1993; 1990; Porter, et al., 2000; Wu, 2006). Firms invest in more capital, and develop technology and R\&D innovation in order to compete with domestic and international competitors, however, any inconsistent or sensitive economic policies significantly influence their activities (Grant, 1991). It is worth noting that real government decisions in many countries are made by their own adjustments of legalised laws or policies, rather than looking at the perfect theories of the economists (Hämäläinen, 2003).

In general, LDC governments aim to achieve higher economic performance as a way to achieve better NC. A small and single score or rank of NC indices attracts the attention of policy-makers, as well as investors and media, so that they may obtain basic information about a country's economic performance (Berger \& Bristow, 2009). However, NC indices may not be considered an accurate method of predicting the country's future economic sustainability and growth (Krugman, 1994, 1997). The NC indices are only a government 
instrument for promoting a certain political image of the nation. These indices are often preferred over economic growth data, given that they can contain inaccurate data and have methodological weaknesses. (Krugman, 1994).

Government is a very important exogenous factor with huge potential to influence both the positive and negative forces affecting NC (Moon, et al., 1995; Porter, 1990). Generally, governments impose regulations, rules, policies and measures, such as subsidies for infrastructure development, education, healthcare and financial market systems, which affect the production factors of local and foreign markets (Hodgetts, 1993; Rugman \& Verbeke, 1990). Sound policies as well as a politically and economically stable environment also facilitate all types of factor conditions within the Single Diamond model (Porter, 1990).

The institutional capacity of LDCs is relatively low compared with the OECD and other developing countries, which directly affects the economic benefits of factor endowments. Despite the fact that trade openness and economic integration increase the number of FDI flowing into countries, a lack of solid government institutions is the main constraint to enhancing productivity and economic growth (Rodrik, 1994; Wu, 2006). These studies also found that the inadequate performance of government institutions results in unsustainable economic development. For instance, despite mining and hydropower being regarded by NGOs as environmentally unfriendly and unsustainable for development in the long term because of the many physical adverse effects on the underprivileged, governments of LDCs consider both sectors as main sources of income and a way to achieve the millennium development goals (MDGs), such as poverty reduction (WB, 2010).

In addition, Hon (1998) claims that human resources are the main constraint for the public sector in LDCs. According to Michalopoulos (2001), the success of a country's bid to join the WTO depends on human resource factors. For instance, weaknesses in government knowledge in Africa, caused by inefficient civil servants, were considered an obstacle to achieving full benefit from WTO accession (Oyejide, 1990). Due to the limited human resource capacity of LDCs, some specific commitments to the WTO may not be able to be fully implemented (Evenett \& Braga, 2005; Sauvé, 2005). 


\subsection{CHAPTER SUMMARY}

Most literature on NC relates to developed and developing countries, with very little focus on less-developed countries (LDCs). It is clear from Appendix 4 that over $90 \%$ of studies have focused on developed and developing countries. Therefore, an appropriate model should combine, adjust or reduce variables of the model with regard to LDC competitiveness. As the current models and theories do not fit all countries equally well (Berger \& Bristow, 2009; Giedre Staskeviciute, 2010), there is a need to explore what contributes to the competitiveness of LDCs. This chapter proposes three main issues including factor endowments, trade liberalisation and the role of government contributing to LDC's competitiveness. In the case of Lao PDR, the regional (ASEAN) and international economic integration (WTO) encourages countries to be more open, even in the relatively low competitive stage. Consequently, the role of the government is vital in order to exploit all factor endowments and opportunities of the trade liberalisation process to increase productivity and NC. The following section describes the methodology used to achieve the study objectives and explore the NC of Laos. 


\section{CHAPTER 4: RESEARCH METHODOLOGY}

\subsection{INTRODUCTION}

This chapter presents the research methods, design and related procedures in this research project. This research is an exploratory qualitative study aimed at investigating the NC of LDCs, in the context of established theories in Chapter 3. Qualitative research has been used to gather information to understand an area in which there is no widely existing knowledge available (Collis \& Hussey, 2009; Sekaran, 1992). Due to the nature of qualitative research, a description of the phenomenon occurring can be made (Bouma, Ling, \& Wilkinson, 1993). Therefore, a qualitative method is likely to be the most appropriate for this research project. The interviews were guided by the NC literature as discussed in Chapter 3. The next section describes the research design followed by the data collection method. Section 3 discusses data analysis tools and techniques. The final section describes the validation checks and ethical considerations and the last section concludes this chapter.

\subsection{RESEARCH METHODOLOGY}

\subsubsection{The Qualitative Methodology}

A qualitative approach to the research was adopted for several reasons. Qualitative methodology is defined as "a mixture of the rational, explorative and intuitive, where the skills and experience of the researcher play an important role in the analysis of data"(Ghauri \& Gronhaug, 2002, p. 86). It is worth noting that qualitative methods are widely used to understand unexplainable situations in society (Maanen, 1983). Similarly, qualitative research helps a researcher to explore and increase understanding of a phenomenon that is not broadly known (Denscombe, 2007). A popular form of qualitative research is the case study. Case studies can enrich understanding of context, which can then strengthen theoretical concepts being used in the research (Cassell \& Symon, 2004). Therefore, a case study seems to be appropriate to tackle the objectives of this research project. Some additional documents and secondary data provided by the informants were also used.

This research adopts a qualitative methodology to explore the key determinant factors of NC in Laos in the ASEAN context (currently) and further recommendations for the WTO 
accession. In order to have accurate and comprehensive results for these issues, the researcher decided that qualitative methodology should be conducted for several reasons. Firstly, qualitative research is useful when not enough information of the phenomenon exists, because it can provide a clear picture for the researcher during investigation (Symon \& Cassell, 1998). Secondly, a qualitative research method is suitable for investigating social science issues, particularly to understand different aspects of a phenomenon within public and private sector activities (Maanen, 1983). Thirdly, it is essential to conduct research using the qualitative method when the research relates to thoughts, attitudes, perspectives and experience (Miles \& Huberman, 1994). There has been limited research on the NC of Laos. However, there is more emphasis on the regional integration of ten countries under the ASEAN framework, rather than the broader economic integration of the WTO. Most of the findings are in the form of descriptive research dealing with the NC of Laos. The researcher adopted a qualitative methodology to provide greater understanding of these issues by using more in-depth theories on endowment factors on $\mathrm{NC}$, the role of government and the impact of globalisation on $\mathrm{NC}$, as well as to assess future prospects and be able to offer strategies and recommendations for Lao policy-makers, practitioners and professors.

Qualitative methods are flexible and unstructured (Miles \& Huberman, 1994). Qualitative methods also require a smaller number of observations than quantitative methods (Silverman, 2009). A smaller sample size in qualitative methods can help the researcher gain an in-depth understanding of the research. This research method usually produces a more descriptive thesis, which requires more detailed attention by readers instead of just the analysis of numbers in quantitative methods (Ghauri \& Gronhaug, 2002; Patton, 2002). In addition, the expression of informants must also be taken into account to analyse a different level of problems such as flexible, neutral, and strong definite (Miles \& Huberman, 1994).

\subsubsection{The Case Study Method}

According to Yin $(1994,2009)$ and Miles \& Huberman (1994), it is popular for case study methods to use 'how' or 'why' questions to discover answers to a current and uncontrolled phenomenon in a real-life context. This research project applied a variety of 'how' and 'why' questions in the interview guide (see Appendix 5) in order to find a wide range of factors that affect the level of NC of Laos from different clusters' points of view. Multiple sources of information before and during data collection are used in the case study method (Eisenhardt, 
1989). Consequently, these can enrich views and provide different dimensions to the phenomenon of interest (Chetty, 1996). Taking all the above reasons into consideration, they help the researcher to gain a greater understanding of the factors influencing the NC of Laos. Laos is a small and less-developed country with small economic variables compared with other countries both within and outside the region. This implies that the researcher cannot draw conclusions by relying on statistics from field research or from other online sources of data.

\subsubsection{The Single versus Multiple Case Studies}

A single case study can be applied if: i) it is supported broadly by well-formulated theory; ii) the case is critical or unique, with no need for additional comparison among the cases; and iii) it is impossible because of accessibility to investigate the case (Yin,1994, 2009). However, these criteria cannot be applied for the current study.

This research project therefore used a multiple-case studies approach. Many cases from different clusters were studied, in order to compare the phenomenon across different cases to obtain different ways of dealing with the research issues. The multiple-case studies approach seemed to be more appropriate than a single-case study approach because it makes the findings more compelling, and enhances their precision, validity and stability (Eisenhardt (1989); Miles \& Huberman (1994) and Yin (1994, 2009). Therefore, the combination of studies across clusters can show common or distinctive themes and patterns that align with clusters' nationality, age, experience, size and area of the organisations' responsibility.

\subsection{DATA COLLECTION METHOD}

\subsubsection{Primary Data Collection}

The research project employed two techniques during the in-depth interviews: primary data and an analysis of secondary research. The in-depth interviews consisted of open-ended questions in order to obtain comprehensive information. Interview questions progressed from general to more specific in order to sustain logical discussion and progression (see Appendix 5). Questions were formed to suit the respondents' interests, positions and responsibilities. In 
addition, the interview questions and the research information sheet were translated into Lao for better communication and sent to the potential respondents prior to the interview being conducted. This also ensured all questions were easily understood and appropriately worded. All informants were approached and a face-to-face interview was conducted at their office and by appointment. Additional data was collected in the form of responses to interview questions structured specifically for the purpose of this research project.

The data collection occurred during late 2011 after approval was obtained from the Human Ethics Committee. Three weeks before departure to Laos, the proposed respondents were contacted by phone and email, along with a brief interview protocol including a research information sheet (see Appendix 6) and consent form (see Appendix 7). During the first week in Laos, the researcher communicated with all potential respondents regarding their availability for an appointment, as well as the availability of additional contacts that had been made while the interview appointments were not yet confirmed. A few appointments were arranged by senior government officials to facilitate the research in the first week. Thanks to a good personal connection and generous assistance from the senior officials, after three weeks in Laos all proposed respondents had been met. Thus, the last week in Laos allowed the researcher to find more related information from sectors and reflect on what was still missing, as well as ask for more clarification from the participants by phone and email.

This qualitative approach was carried out by conducting 20 interviews with senior staff from four different clusters including government officials, industry representatives, professors from universities and government institutions, and experts from NGOs (see Table 6). Interview participants were recruited via personal connection and recommended participants during the interviews. The specific criterion for these informants was based on their responsibilities and experiences of Lao NC. More than $50 \%$ of the informants work closely with foreign companies in Laos and specialise in import and export activities. The interviewees' profile is provided in Table 6 below. 


\section{Table 6: Profile of Interview Respondents}

\begin{tabular}{|c|c|c|c|c|}
\hline Respondent & Cluster & Organisation & $\begin{array}{l}\text { Experience } \\
\text { (Years) }\end{array}$ & Location \\
\hline 1 & Government official & Prime Minister Office & 34 & Vientiane \\
\hline 2 & Government official & Prime Minister Office & 30 & Vientiane \\
\hline 3 & Government official & Ministry of Industry and Commerce & 20 & Vientiane \\
\hline 4 & Government official & Ministry of Planning and Investment & 13 & Vientiane \\
\hline 5 & Government official & Bank of Lao PDR & 18 & Vientiane \\
\hline 6 & Private Sector & Lao International Freight Forwarder Association & 30 & Vientiane \\
\hline 7 & Private Sector & Lao Wood Processing Association & 21 & Vientiane \\
\hline 8 & Private Sector & Lao ITC Commerce Association & 15 & Vientiane \\
\hline 9 & Private Sector & Lao Textile and Garment Industry Association & 17 & Vientiane \\
\hline 10 & Private Sector & Lao Handicraft Association & 15 & Vientiane \\
\hline 11 & University \& institute & Lao National University & 7 & Vientiane \\
\hline 12 & University \& institute & Lao National University & 25 & Vientiane \\
\hline 13 & University \& institute & Lao National University & 20 & Vientiane \\
\hline 14 & University \& institute & National Economics Research Institute of Laos & 10 & Vientiane \\
\hline 15 & University \& institute & National Economics Research Institute for Trade & 9 & Vientiane \\
\hline 16 & Non-government Org. & World Bank Office & 5 & Vientiane \\
\hline 17 & Non-government Org. & World Bank Office & 7 & Vientiane \\
\hline 18 & Non-government Org. & World Bank Office & 5 & Vientiane \\
\hline 19 & Non-government Org. & ADB Residence Office & 8 & Vientiane \\
\hline 20 & Non-government Org. & UNDP & 7 & Vientiane \\
\hline
\end{tabular}

Note: G: Government Sectors P: Private Sectors; A: Academia and Professors; N: Non-Government Organisations.

The interview protocol was developed and divided into five broad topic areas: general questions about the respondents including age, experience within organisation, size and level of competitiveness of organisations; questions about Lao's competitiveness factors; regional (ASEAN) and globalisation (WTO accession); and recommendations and some additional thoughts that are in the concluding remarks. Only male respondents participated in the research project, which does not have any impact on the quality of the interviews.

All interviews were carried out in Lao with the exception of one native English-speaking interviewee. Follow-up calls, also in Lao, took the form of open-ended questions that related to the NC of Laos. Interviews in this research project took an average time of 30 minutes, and were recorded on audio tape (with the respondents' permission) and then transcribed into English. The reason for speaking Lao in the interviews was because many respondents were not fluent in English, and speaking the local language helped to reduce the possibility of 
misunderstanding and ambiguity. Some of the respondents' technical terms, words and ideas could not be translated into English accurately by translators who are not specialists in this field. Consequently, all transcriptions were made by the researcher. After the interviews, several follow-up phone calls were made to participants for further clarification while the researcher was in Laos and New Zealand.

\subsubsection{Secondary Data Collection}

Before the interviews took place, a relevant literature review on $\mathrm{NC}$ and the impact of globalisation in general was created as background information for the research project. The literature review was conducted to identify all related trade theories, definitions, measurements and concepts of $\mathrm{NC}$, factor endowments, as well as the influence of government. The literature review relied primary on sources from the ASEAN website, the WTO website, organisations in Laos including the World Bank office, ADB residence office, UNDP, UNCTAD, IMF, line ministries, private sectors and industrial associations, as well as both hard and electronic copies of facts and statistics from documents published by universities and institutes, chambers of commerce, Lao industries and NGO representatives while the researcher was in New Zealand and Laos. Some of the material was also retrieved from the database at Victoria University of Wellington and from various internet websites.

\subsection{DATA ANALYSIS}

Differing data analysis techniques were employed, such as thematic analysis and coding development. The coding process allowed the researcher to be able to generate meaning from the primary data (Boyatzis, 1998; Fereday \& Muir-Cochrane, 2006). The researcher also employed the techniques of inductive coding (data driven) and deductive coding (theory driven). A coding set of vertical and horizontal lines was then constructed to synthesise and highlight the most important results. The data analysis set outlined three main stages: withincase analysis, cross-case analysis and comparison with existing literature (Eisenhardt, 1989; Miles \& Huberman, 1994). 


\subsubsection{Within-Case Analysis}

Consistent with the finding by Ghauri and Gronhaug (2002), coding and categorisation systems allow the researcher to interpret data and relate the information to tackle the core research issues. At this stage, coding from data collection was used for each case and classified according to themes relating to the focus of research issues. The coding also indicates the major themes, for example, factors of NC related to endowments, and included natural resources (hydropower and mining) and non-physical factors such as labour productivity. Similarly, 'regional integration' implied the benefits of social and economic development, and a number of rules and regulations that should be revised to comply with ASEAN agreements. These coded patterns were derived from respondents' specific ideas and responses to emergent themes.

As well as coding and categorising the data in the form of themes and patterns, common and contradicting themes in the data were sought to help the researcher to identify relevant themes in line with the research framework. The within-case analysis also allows the researcher to discover relationships between themes (Ghauri \& Gronhaug, 2002). Primary issues from the interviews were grouped into five major themes. Following this method, each case study was interpreted in the form of description, which comprises of four main issues: factor of NC, regional and international economic integration, government role, and strategies and recommendations for policy-makers and practitioners in order to strengthen the NC of Laos. This technique helped to generate insight into the issues and familiarity with the data. As a result, this research project required further analysis in the form of cross-case analysis (Eisenhardt, 1989; Yin, 1994, 2009). The case comparisons and patterns were systematically analysed in Chapter 6.

\subsubsection{Cross-Case Analysis}

In addition to within-case analysis, the researcher discovered common and different themes in the data analysis. Thus cross-case analysis seemed to be an essential method and is subsequently covered in the next section (Eisenhardt, 1989; Miles \& Huberman, 1994). The reasons behind this method were to identify common and different patterns across four clusters. This stage of conducting data analysis provided a broad understanding of NC factors and how government policies were considered vital in the enhancement of NC. 
At this stage, each major theme was vertically illustrated, and the list of clusters was horizontal. The meta-matrix analysis was used to display the respondents' results from four clusters, which were analysed, compared, summarised and synthesised in order to achieve the objectives of the research project. The researcher also found some general agreement among the clusters' case studies, even amongst those from different backgrounds. This method is considered an important analytic technique for the research (Miles \& Huberman, 1994). The results of cross-case analysis can be found in Chapter 6.

\subsubsection{Comparison with Existing Literature}

The literature review in Chapter 3 was compared with the results of the cross-case tabulation or meta-metric (Miles \& Huberman, 1994). The results of the comparison of extant literature review are incorporated with cross-case analysis in Chapter 5. This is similar to the findings of Eisenhardt (1989, p. 544) who found that "an essential feature of theory building research is comparison of the emergent concepts, theory, or hypotheses with the extant literature". This implied that the validity of case study research was enhanced. Thus, the combination of within-case analysis, cross-case analysis and literature review identified implications and recommendations for policy-makers, practitioners and professors in order to strengthen all factors to enhance the NC of Laos.

\subsection{VALIDATION CHECKS}

The researcher attempted to be accurate and avoid any bias in order to maintain a degree of validity and credibility when interpreting information for this research project. According to Miles \& Huberman (1994, p. 262), “qualitative can be evocative, illuminating, masterful and wrong". A similar finding by Dawes (1971) states that statistical judgments are more accurate than human judgments. This means many tactics for testing or confirming findings have to be taken into account. Therefore, the researcher chose senior respondents from four clusters in order to obtain differing sources of secondary data, views and opinions on the same topic and to be able to compare within-case and cross-case analysis. This ensures the credibility and quality of information, as well as the trustworthiness of the respondents. The interview transcriptions and audio records were sent to the respondents for clarification and confirmation and to ensure the accuracy of interpretation from the Lao to English version. 
Different coding techniques, themes and patterns were used in this research in order to categorise the frequencies of respondents' answers to the open-ended set of questions. The researcher used the technique of differentiating and combining data that retrieved and reflected the information from the interviews and categorised various chunks into different themes and patterns so that the researcher could easily investigate the meanings and was able to avoid any potential bias (Miles \& Huberman, 1994).

\subsection{ETHICAL CONSIDERATIONS}

With regard to the ethical issues, the respondents were treated in accordance with the Ethical Research Committee of Victoria University of Wellington. The researcher guaranteed there would be no identifiable risks or exposed identification from participating in this research. The consent form signed by respondents stated the rights to withdraw from the research at any time, should they have felt the need to, and all information given would be destroyed. Only the researcher and the supervisor can identify the respondents through audio records and interview transcriptions. In addition, any further identifying information given by any respondent would have had to be approved by that person before it was used.

Because of some sensitive issues in this research, the researcher assured the respondents of complete confidentiality and that any sensitive information would not be revealed without their prior authorisation. At the end of the interviews, the researcher asked each of the respondents if they required a copy of the audio or transcription both in Lao and English to guarantee the precision and accuracy of the interviews. More than $50 \%$ of the respondents requested a full draft of the transcription and the final report of the research.

\subsection{CHAPTER SUMMARY}

This exploratory research aims to understand the impact of globalisation on the NC of Laos. Because four different clusters were involved in this research, the researcher incorporated a multiple-case study approach in order to gain an in-depth understanding of LDC competitiveness. In regard to data collection, personal connections were used, particularly 
from the public sector, which enabled the researcher to finish the field work in time and facilitated productive interviews with potential respondents. The data analysis techniques, including within-case and cross-case analysis, were used in this research to build an in-depth understanding of the phenomenon from the perspective of different clusters. This research project also used validity check techniques in order to avoid potential bias, recruiting only the most relevant participants for the interviews rather than using arbitrary selection. The researcher took ethical issues into consideration by providing precise protocols and maintaining the rights of the respondents by guaranteeing all responses would be anonymous and there would be no exposure of a respondent's name and identity in the future. 


\section{CHAPTER 5: RESULTS AND ANALYSIS}

\subsection{INTRODUCTION}

This chapter presents the findings from the interviews including four within-cases analyses, cross-case analysis and discussion, with the descriptions systematically organised into the following headings. The first section discusses four factors of the NC of Laos, based on the interview guide, including the key factor endowments of $\mathrm{NC}$, the role of government and impact of regional and global integrations, and future strategies and recommendations for policy-makers and practitioners. The second section uses cross-case analysis to compare and contrast with the same and different factors as the previous section, in order to draw a precise result from the findings. The third section discusses related sub-factors within the four main factors, which influence the national competiveness of Laos. The last section summarises the findings of this chapter.

Each of the case studies highlighted key information and findings in response to the NC of Laos. Each cluster had both diverse and common reasons for the NC of Laos, consisting mainly of endowment factors, the roles of government, as well as regional and international liberalisations, agreements and frameworks. In addition, different clusters proposed strategies, recommendations and thoughts in response to the open-ended questions investigating the $\mathrm{NC}$ of Laos.

\subsection{WITHIN-CASE ANALYSIS}

\section{Case Study 1: Government Officials}

\subsubsection{Factor Endowments}

The respondents from public sectors highlighted several factors that significantly influenced Lao NC. Firstly, Laos has many potential resources such as land, rivers, forests and a cheap labour force; these endowments are being discovered and exploited but less competitively compared with other countries in the region. According to the 7th NSEDP 2010-2015, exploration of hydropower, mining, agriculture and tourism are the top four priorities of the Lao government (NSEDP, 2010). G1 summed up the influence of hydropower and mining sectors by stating: 
The Num Theun II hydropower project will generate electricity to sell to Thailand under the contract of the Lao and Thai government, which could contribute to the economic growth by up to two billion US dollars each year in the first period and would be more in the future. In addition, the mining sector contributes $20 \%$ to GDP and more than $50 \%$ of the total exports of Laos.

Secondly, due to the low price of land and rents, Laos is considered an attractive destination for investors who specialise in agriculture, hard wood furniture and rubber industries. G2 stated "recently, there are many projects under implementation such as wood and wood processing, rubber tree plantation and some organic vegetable agriculture". These projects are not only top priorities for the government, but also solve unemployment problems and generate income for local people. In addition, given the many potentialities of the land, tropical forests, rivers and many unique traditional cultures, Laos is an attractive destination for tourists to discover. The tourism industry has attracted more than a million visitors per year and contributed significantly to the growth of economy.

These endowments factors can create more benefits, however, if more skilled labourers are put in place, which is considered a significant challenge for the Lao economy. Laos is still a country with low wages, with more unskilled labourers than other countries in the region. It is therefore very attractive for the inflow of FDI, particularly for labour-intensive sectors that do not require highly-skilled labourers, such as the garment and textile industries. However, G3 highlighted that low labour cost is not considered an advantage for Laos stating:

The minimum wage of Lao labour in garment and textile industries is approximately US $\$ 0.4$ per hour, which is lower than the other ASEAN countries. However, this advantage may not be convincing for foreign investors because the majority of Lao labour is unskilled and needs additional training, which is very time consuming and expensive. Consequently, many investors are likely to move to other neighbouring countries where labour can create more productivity and profits for them.

\subsubsection{The Role of Government}

Similar to any government, enhancing NC aims to achieve better economic growth, higher industrial sector performance, greater wealth for the nation, and a better standard of living for 
the people. Government plays a significant role in enhancing productivity, growth and NC. Several issues were raised and discussed during the interviews as follow:

The Lao government considers regional and international economic liberalisation as the main force contributing to growth and helping to discard LDC status in 2020 (NSEDP, 2010). As a result, the government has decided to integrate into regional agreements, such as ASEAN Free Trade area (ASEAN-FTA) and ASEAN Economic Community in 2015, and to engage in the trading systems of the WTO as soon as possible. From the time the economic reform and open door policies were reviewed in 1986 until now (the 7th NSEDP 2010-2015), the Lao government has improved many related rules and regulations in order to be consistent within the ASEAN objective of creating and facilitating a favourable investment climate that will attract foreign investment to the country. G2 stated: "Recently Laos has progressed into the final stage of the WTO Accession, which leads to more challenges for Lao economic development in the long-term".

When attracting more foreign investment, Laos' main strength is the stability of its political system. G5 stated: "Laos is controlled by one party so the political system is very stable compared with other countries in the region. This factor increases the credibility and positive attitude of Laos towards foreign investors". As regional and international economic integration processes continue and rules and regulations improve, the numbers of inflow FDI have increased significantly, particularly in hydropower, mining and other labour-intensive sectors. G1 also highlighted the prime focus of government investment policies with a statement: "The Lao government has constantly improved favourable conditions for investors, as well as the improvement of the business climate to attract more foreign investments compared with the period of 1990s".

Key infrastructure, such as transport, electricity and telecommunications, is still in the process of improvement in order to turn the country from land-locked to land-linked. G1 explained that "the major part of less competitiveness for Lao exporting is transport issues". This is evidenced by the cost of transport for one shipment from Laos to neighbouring countries' sea ports being more than US\$1800 per container, compared with half this cost from Vietnam and Thailand. In addition, issues of trade facilitation such as customs clearance, harmonisation, procedures, time clearance and the number of documents at border 
check points remain critical issues and need to be urgently addressed in order to encourage export and transit goods activities. G2 stated:

Even though the East-West and South-North Economic Corridors proposed by the Lao government and the GMS countries under support of the ADB are already implementing, many projects are under construction with an aim to solve all constraints of transport and trade facilitation issues at the border check points.

The scarcity of a skilled human resource component is regarded as the main barrier to the social and economic development of Laos, which also directly hinders the competitiveness of the country. This also implies that there is an insufficient workforce in Laos to participate in the practical activities of the economy. There is also a development gap between urban and rural areas, which affects the rate of tertiary education throughout the country. G4 critiqued the education systems in Laos with this statement:

Despite the government paying great efforts to strengthen education systems in the past few decades, the trend of HRD is not consistent with the real needs of economic development and particularly the needs of the private sector. For instance, while many students graduated from business and management, fewer students did a degree in agriculture and other labour skills, which is considered as the main driver and even backbone of Lao economic growth.

\subsubsection{Regional and Global Integration Issues}

\section{ASEAN Context}

After Laos joined ASEAN in 1997, a number of rules and regulations have been improved, which has contributed to the promotion of a trade and investment environment and increased NC. G5 highlighted:

The government's attitude towards 'free and fair competition' was enhanced, which reduced a level of unfair treatment and discrimination between domestic and foreign companies, as well as sufficient anti-monopoly measures against other countries in the region and other ASEAN dialogue partners.

However, many respondents accepted that Laos' reason for joining the regional and international agreements is more about political aspects than economic benefits. The evidence of the ASEAN-FTA shows that while many member countries are in the process of a tariff 
reduction scheme to adjust all tariff lines for goods and services from 0-5\%, Laos is still lagging behind those countries. Laos still needs more time and resources to improve its internal rules and regulations. G2 also revealed the negative impact of Laos in ASEAN:

Despite the fact that the ASEAN-FTA initiates the region of free flow of trade and investment, import tax is the main income revenue for the central government. Consequently, once we fully implement all tariffs and trade agreements, the Lao government will lose a huge source of income revenue.

Unlike other organisations, ASEAN has a principle of non-interference into any internal business of its members. This is considered a major constraint for economic development in this region, and decreases investors' levels of confidence. There are also differences in economic development levels between the ASEAN countries, and it is not easy for poorer countries to catch up with wealthier countries. G3 stated that "although the ASEAN-FTA has been fully approved by the old ASEAN members, Laos, together with Cambodia, Myanmar and Vietnam (CLMV) do need additional time and resources to make this agreement come into force".

It is worth noting that when the researcher asked about the benefits of joining ASEAN, all five respondents seemed to struggle with their answers. Apart from HRD assistance and political cooperation within ASEAN, the actual economic benefits for Laos from joining this organisation remain unclear. However, G3 and G5 suggested that "we may not see lots of benefits in the first period of joining ASEAN economic cooperation; however, it will expand more opportunities to access foreign markets and its ASEAN dialogue partners such as China, India, the EU, Australia and New Zealand". This comprehensive economic integration within and outside the region indicates potential benefits for Laos in the long term. G5 argued that "no-one can guarantee whether this regional integration will increase or maintain the competitiveness of Laos; it totally depends on our internal efforts to support this integration".

While mining and hydropower are in very high demand for foreign markets, they are considered an unsustainable contribution to the growth of the Lao economy. Even though the Lao GDP has increased significantly in the past ten years, with an average growth of 6-7\% per year, nearly $3 \%$ of GDP was contributed by mining and hydropower, which is set to grow further in the near future. G3 and G5 agreed that "both sectors do not create sufficient jobs 
for people and negatively affect the sustainability of natural resource, biodiversity, replacement of local people and require a huge compensation for people in the affected areas". The respondents also revealed that most of the projects were under long-term concession and shared by foreign companies. Apparently, some projects are 100\% whollyowned by foreign companies, thus, the Lao government receives only a small percentage of the benefits from those projects.

\section{WTO Context}

Progression of the Lao WTO Accession has continued in the past 15 years, highlighting the huge effort by the government to integrate into the world trading systems. Laos submitted its application to the WTO Accession Committee in July 1997. The Working Party was established in February 1998. The Memorandum of Understanding concerning the foreign trade regime was circulated to the members in 2001, and the first set of questions was issued to the Laos WTO Secretariat in October 2003. After this set of questions was circulated to the line ministries and agencies, all answers were revised by the WTO Secretariat and related agencies before submission to the WTO Accession Committee in the First Working Party in October 2004. Several sets of questions and answers were submitted by the Lao contingent and the Eighth Working Party was established in March 2012 (see Appendix 4).

G2 revealed that "insufficient cooperation within the Lao WTO Secretariat did affect the Secretariat's activities". He also called for all line ministries and particularly service sectors to actively cooperate with the Lao WTO Secretariat. G2 also added that "part of the reason behind the delay of joining was a lack of skilled human resources to respond to the tasks from the WTO Accession Committee". On the other hand, a lack of understanding of the costs and benefits of the WTO accession for LDCs in both NGOs' reports and literature resulted in an unwillingness to join the WTO. The G5 stated that "particularly officials at the border check points who are dealing with daily import and export activities should understand about the WTO agreements to strengthen the process".

According to the 7th NSEDP 2010-2015, Lao WTO accession is the main objective of the government, in order to expand opportunities for Lao products to compete in international markets. G3 agreed that "as Laos has experienced an ASEAN framework, we can conclude 
that if any agreements do not contradict with benefits of the country, they are also considered a potential gain for Lao WTO accession”.

G4 also explained that "integrating into a world trading system like the WTO will reduce barriers to trade by trading partners and create more opportunity in international markets; however, many technical barriers are already in place". In comparison, LDCs are allowed to have more time to adjust and some exceptions allow them to compete with others. As a result, LDCs' agricultural products would be able to access international markets without preconditions from importing countries. However, G2 stated: "There are more requirements for agricultural products, such as the agreement on sanitary and phytosanitary (SPS) measures, which exporting countries need to meet".

\subsubsection{Future Strategy and Recommendations}

G5 explained that "the right policy on HRD should be taken into account to increase technical skills". The focus of government policy on education should be on its potential and labour-intensive sectors such as agriculture and tourism. In particular, G5 also added that "more qualified officials will enable government sectors to work effectively and strengthen the performance of the negotiation teams who deal with trade and tariff issues of the Lao WTO accession". In addition, G4 remarked that "even though ASEAN is the model of the WTO, more commitments on tariff and trade issues are broadly anticipated within the WTO framework, rather than political aspects and fewer commitments as in ASEAN".

In addition to the human resource issues, more attention from the government sectors should be paid to improving rules and regulations consistent with ASEAN and the WTO. The majority of respondents emphasised that "Laos is still lagging behind in terms of the implementation of rules and regulations, particularly trade in goods, services, investments and trade in terms of intellectual property rights". Therefore, Laos should urgently increase the speed of reform and remove its constraints in alignment with the regional framework. Moreover, many WTO commitments require more effort from government institutions in order to accelerate this process. 
The impacts of regional and international integration were highlighted by the majority of respondents. At present, Laos has to deliberate on tariff restriction in accordance with the ASEAN economic community in 2015, which would link to a revenue reduction. This issue also directly affects the competitiveness of the nation. G3 remarked: "Even though tariffs reduce from $10 \%$ to $5 \%$ it is still quite large for agricultural products, furthermore, it will increase the agricultural product imports from neighbouring countries. The main broad challenge is that Laos is the importing country". The geographical issue was also mentioned as a key constraint to transport. No access to the sea creates a significant barrier for import and export activities. G3 highlighted the major constraint for export products from Laos to other countries: "Laos has no access to the sea, thus, the cost of transport does affect Lao exporting in comparison with our neighbouring countries".

Even though significant progress has been made by the Lao government to increase NC, Laos still needs more assistance from donors and other neighbouring countries to improve technical skills for human resources. G2 asserted that "without sufficient support from NGOs and other neighbouring countries, the process of regional and international integration would take longer than it should". Constant support from donors is needed for accelerating and ensuring the sustainable growth of the economy. 


\section{Case Study 2: Industries and Entrepreneurs}

\subsubsection{Factor Endowments}

Several insights into NC were gained from within the Lao industrial and private sectors. Apart from I3, the respondents were selected from the private sector in the category of small and medium-sized enterprises (SMEs) that deal with import and export activities.

Textile and garment industries still gain the Generalised System Preferential (GSP) from importing countries; this allows Lao products to compete with other countries. The agreement was signed in the late 1990s with the EU and recently with ASEAN and its dialogue partners, continuously increasing the number of Lao shipments to those countries with an import duty of $0 \%$. However, I3 revealed that "due to a lack of supply and a specific agreement on garment and textile products, Laos still cannot fulfil quantities to meet the quota given by the importing countries". In addition, I3 also added that "the main reason is not only the supply side, but also that the transport costs are higher than others, considering documentation, procedures, as well as insufficiently qualified government officials at the border checkpoints, which all adds to the costs of goods and is time consuming".

With regard to the constraints of doing business, the respondents explained that difficulties to accessing capital are the main issue for the growth of their companies. I2 added:

As a wide range of regional and international integration increases opportunity for enlarging the companies, it is necessary for companies to invest more money in large projects through joint ventures. In fact, the domestic financial institutions do not have sufficient capacity and solutions to assist and enlarge the companies.

Even though low-wage labour is considered a comparative advantage of Laos in terms of economic growth, the insufficient number of workers is taken into consideration. I5 revealed that "while a productive labour force is around 6-800,000 people in a non-agricultural economy, around 2-300,000 people are working in Thailand. Therefore, it is pretty unpleasant for the labour intensive sectors". Garment and textile industries are the main labour incentive sectors. I3 also revealed that "sophisticated and highly-skilled designers who receive a high salary are not Lao citizens. Moreover, trained people are willing to leave and look for companies that can offer them a higher salary and incentives". 


\subsubsection{The Role of Government}

Several issues were raised among the respondents and through the observation of the researcher with regard to improvements in the rules and regulations surrounding doing business in Laos. Despite the Lao government creating favourable conditions to encourage FDI into the country, the respondents revealed that the real implementation still needs to be improved. The majority of respondents revealed that "unexplained fees for import and export activities were collected at border checkpoints, which increased expenses for businesses". In addition, the researcher noticed that many investors considered the Lao business climate ranking as part of their risk management and a factor in deciding whether or not to invest in the country. Even though Laos has made significant progress in the improvement of rules and regulations, the Lao doing business ranking is relatively low, being 172 in 2010 and 165 in 2011, out of 183 countries (see Table 3 ).

Even though many enterprise laws have been drafted and come into force to ensure the transparency of doing business, some flexible cases or personal connections were taken into account in doing business. I2 emphasised that "apparently, Lao exporters are less competitive than domestic entrepreneurs". In fact, many government agencies get involved in documentation and the inspection process at border checkpoints. I4 revealed that "some documents and inspections seem to be duplicated, which causes delays and more expenses for businesses". In addition, I2 and I4 also raised the issue of the inconsistency of the in-land transport agreement with neighbouring countries:

In order to export a container via Thai border checkpoints, the Lao truck drivers need to have a driver license authorised by the Thai authority because of the difference of traffic systems and other road safety issues. In contrast, Thai trucks can operate in Laos without any restrictions. Thus, the Lao exporting companies tend to rent an empty container from Thailand rather than hiring domestic freight forwarding companies.

\subsubsection{Regional and Global Integration Issues}

\section{ASEAN Context}

Skilled human resources remain a challenge for regional integration in Laos. In fact, many companies are struggling with the recruitment of qualified staff. Despite the fact that the government has paid more attention to improving educational systems, particularly for 
agriculture and vocational schools, the respondents were still concerned about the quality of graduate students who would be able to work with them. I3 remarked that "due to the nature of small companies, financial support for upgrading technical skills for labour remains challenging. For example, while firms are struggling with financial issues, more training for new staff is needed".

I1 and I3 responded to the questions regarding challenges of globalisation for their business by saying that "we engaged in international norms before joining ASEAN, so our sector was not seriously impacted when Laos joined ASEAN". However, the remaining respondents confirmed that being a member of the ASEAN economic community reduced their business competitiveness. I3 added "we have gained GSP from the EU since we are not a member of ASEAN; once we become a member all countries will benefits from this common agreement under MFN".

By being part of the ASEAN-FTA, Laos gains benefits from low tariffs to access the rest of the world markets. According to the ASEAN economic community in 2015, all tariffs will be removed for all ten members. I4 remarked: "Having overseas access increases market opportunities for Lao exporters and enhances NC; it does not mean that Laos did anything to do that but rather that it occurred automatically". Similarly, I5 explained:

You can see Lao trade is growing particularly between neighbouring countries. The value of trade between Laos and Thailand and Vietnam has grown about $60-80 \%$ over two years. In addition, the increase of cross-production across the border and supply chain will make Laos business become more integrated into the region.

\section{The WTO Context}

It seemed that the industrial and private sector representatives were not well-informed about the potential costs and benefits of joining the WTO. Due to limited understanding, all questions about the WTO in regard to the challenges and benefits were not responded to effectively, which is considered a limitation of this case study. From observations of each interview, the researcher concluded that the only question the respondents were interested in was how their companies could compete with others if Laos successfully joins the WTO. 
Respondents were generally positive about the WTO accession for Laos however, believing it can help their businesses to be more competitive in the future.

The WTO accession for Laos will not directly affect domestic companies for several reasons. As I3 agreed, their business was operating under the international agreements before joining the WTO. Therefore, they cannot see any disadvantages for their sector. In contrast, it seemed that exporting sectors such as wood and food processing would be less competitive if Laos becomes a member of the WTO because of more requirements based on environmental issues. The reason I2 gave for less competitiveness was that "the main threats for Lao wood and furniture companies are how our products can meet the quality and the standard of international markets, as well as compete with other domestic companies who are more professional".

Intellectual property rights issues, alluded to by the telecommunication representative, also affect the competitiveness of this sector. Several WTO requirements around intellectual property are major constraints for the Lao IT sector. I1 explained:

Lao IT companies experience many difficulties when purchasing full legal software, which is very necessary for meeting the needs of the integrations. However, Lao law on intellectual property is still not strict enough on this issue compared with other countries. Furthermore, if the government liberalises the IT sector and fully engages in the IP agreements under WTO, there will be more difficulties in this sector.

\subsubsection{Future Strategy and Recommendations}

All respondents agreed that HRD is considered an urgent issue for the government to solve in order to increase the capacity of industrial and private sectors. The implementation of the ASEAN single market aims to make this region an attractive destination and promote the free flow of trade and investment. Therefore, it is vital for the government to improve the educational system in alignment with the trend of ASEAN economic development. As a result, competitiveness of domestic companies is very important. I4 also raised the issue of increasing cooperation among government and private sectors:

The government should listen to the requirements of the private sector and propose any challenges and opportunities of the domestic and international markets to the private sector. In fact, the government should pay more attention to helping businesses to increase their 
competitiveness rather than focusing on imposing more regulations, as well as allocating financial resources for the growth of companies.

Furthermore, consistent government support systems for the private sector should be taken into account to enhance business capacity. I1 agreed that "due to the nature of domestic competitiveness, Lao enterprises still need more project identification, national linkage, technology transfer, mentoring and export promotion programmes from the government to reinforce our competitiveness in domestic and international markets". More importantly, I5 suggested that "financial support from the government is not more important than advice and market information to enable them to compete with others in the markets". In addition, the business economic forums held by the government give them opportunities to discuss and contribute their thoughts and concerns about the current issues in business. I1 also added:

Support in the form of training is important for both managers and workers to create more productivity. This means ongoing production should be regularly revised and evaluated to maintain high productivity and risk management. Training also introduces new technology and new ideas, enabling companies to find better solutions for their business issues. 


\section{Case Study 3: Academicians}

\subsubsection{Factor Endowments}

The respondents from the universities and institutes explained that mining and hydropower are the two predominant sectors in Laos' competitiveness. Many mega-projects have been set up and are under construction throughout the country with the aim of exporting under bilateral contracts with neighbouring countries and obtaining hard currency for the country. These two sectors contribute significantly to nearly half of the GDP growth of the country. Because of the increase in the prices of gold and power worldwide, the Lao government considers these sectors to be the right options to help strengthen its social and economic development, as well as to accomplish the millennium development goal of poverty elimination by 2020 . In addition, many agricultural projects such as hard wood, rubber and bio plantations exist throughout the country. A4 stated that "Korean bio-energy plants are under operation with several hectares as an important alternative source of energy. This project enables Laos to be more competitive in the use of clean and green energy in the future".

Secondly, the Lao government has made significant progress in attracting FDI to invest in the priority sectors. In addition to the natural resource sectors, the Lao government encourages all sectors relating to services such as tourism, telecommunications and banking. A1 remarked that "evidence shows that Laos uses high speed internet at a lower price than other countries in the world. High-tech applications such as $3 \mathrm{G}$ and $4 \mathrm{G}$ were already available in Laos at an affordable price to facilitate people's lives and business". A1 also told the researcher that "due to many the government incentives for the telecommunication sectors, Lao people used more high-tech facilities than some countries in the region".

In addition, Lao labour costs are relatively low compared with other countries in the region, which makes Laos more competitive in terms of labour. All five respondents explained that apart from the abundance of natural resources, the main element that makes Laos more competitive and attractive to FDI is the low cost of labour. A1 remarked: "Particularly for textile and garment industries, the combination of labour costs and GSP are an advantage that makes this industry survive, even within the highly competitive environment of neighbouring countries". The reason A1 gave as to why investors chose Laos as the destination for their 
business was that "fewer social welfare conditions were applied to Lao workers, therefore, this encouraged FDI to invest and gain more benefits". In addition, A1 also added:

While the trend of raw labour is increasing, wages also slightly increase; however, it means that this industry would still attract more foreign investors to the country. In fact, this sector still needs to expand because the Lao garment and textile industries cannot yet fulfil the export quota under the GSP.

\subsubsection{The Role of Government}

Poor infrastructure remains a problem for the social and economic development of Laos. It is worth noting that when the researcher asked about the reasons "why has Laos not developed as fast as ASEAN countries", the majority of respondents revealed that inadequate infrastructure systems and the significant damage by wars were contributing to this problem. War not only destroys the infrastructure, but unexploded ordnance still remains under the ground for decades and threatens economic growth. A2 remarked that "the Lao government has invested huge amounts of money and even borrowed from other international financial organisations to improve infrastructure and guarantee a high level of economic development".

A lack of qualified and skilled human resource affects the level of social and economic development of the country. The average tertiary education of Lao people was about $70 \%$ in 2010, which is considered the lowest figure in the region. A3 stated:

There are not enough universities, colleges, vocational and training schools and most of them have limited capacity of science and technological facilities to accommodate the number of students and supply sufficient skills for the needs of labour market.

In addition, A1 revealed that "the education budget was limited to about $12 \%$ of the annual government expenditure in 2010; therefore, many students only finished primary education because of insufficient financial support from their families". Furthermore, the productivity of the Lao education system is not the only aspect affected by a low government budget: teachers in schools and universities also receive an inadequate income. A1 and A2 explain that "there is little salary for teachers; as a result, it also reduces the incentive for researchers and professors to engage in research. Moreover, only a few graduate students desire to 
continue higher education and become dedicated to the improvement of the Lao academic system".

In addition, the difficulties of geographical issues contribute significantly to an increase in production costs. Few countries have the same geographical issues, which create significant physical barriers to import and export activities, as Laos. A4 stated:

Most of Lao shipments are exported through the sea ports of Thailand and Vietnam. Despite the government signing the bilateral transport agreements with these countries under the transport agreement of the Greater Mekong Sub-region (GMS) to facilitate import and export activities, it seems that there are still unnecessary procedures, documentation and bribery issues, which need to be addressed by the line government agencies.

\subsubsection{Regional and Global Integration Issues}

\section{ASEAN Context}

Due to the economic cooperation in the ASEAN framework, the respondents agreed that Laos has increased its management skills and technical knowledge through the assistance of HRD programmes. Particularly for Laos, this is considered the main objective of joining this organisation, due to a deficiency of internal budget support from the government. A4 remarked:

The old ASEAN members actively provide comprehensive assistance for Laos to increase human resource capacity. There are much training sessions, seminars and workshops in related areas with the aim of increasing knowledge and technological skills for government officials, the private sector, professors and students. In addition, much assistance for Laos has also been provided by other ASEAN dialogue partners who are considerably important for HRD.

Laos has adjusted and reformed all rules and regulations to comply with the other members of ASEAN. Even though slow progress has been made, this is considered an important step for Laos to improve itself and move forward, together with other countries in the region. A5 emphasised: "This integration also increases the credibility of Laos on the international stage, which helps enhance its power in the trade negotiation rounds as a group of countries instead of as an individual". The majority of respondents regarded this integration as an important step for Laos to prepare for broader general agreements on tariffs and trade (WTO). 
However, due to the differences in social and economic development, Laos still needs more resources and physical and technical support to implement the ASEAN economic community in 2015. A4 stated that "despite Laos receiving a large amount of technical assistance for improving and accelerating the economic integration process in the region, Laos is still lagging behind both old and new ASEAN members, particularly in the aspect of economic development". As a result, commitments for Laos within ASEAN cannot come into force as automatically as other countries. A4 also suggested that "due to the difficulties of resource and knowledge differences, it is not simple for Laos to gain proper benefits from ASEAN".

Regional trade liberalisation allows free movement of labour from country to country, so while the government is trying to attract more foreign investors to Laos, the internal skilled labour and even the low-skilled labour force are moving out of the country. In contrast, "many skilled construction and agricultural workers from Vietnam and China already exist in Laos. As a result, many unskilled Lao workers would become unemployed because of high competition in the internal labour markets".

\section{WTO Context}

Similar to ASEAN integration, the WTO accession for Laos requires a significant period of time to improve rules and regulations. Much progress has been made over the past ten years by the Lao government with an effort to integrate into the organisation. However, Laos still needs more technical assistance to improve relevant sectors to comply with the WTO agreements. A2 stated:

This integration would not be considered as a political aspect, it requires more efforts and inputs from the Lao side to any commitments under the common umbrella of the general agreement on tariffs and trade. For example, once any bilateral trade agreements have been signed, they will automatically affect the rest of members, which helps to avoid unfair treatment and discrimination among the members. Apparently, small countries would be more affected.

Even though the WTO members provide more flexibility for trade and tariff regimes for LDCs to adapt to world trading systems, some sectors still cannot be liberalised. The costs and benefits of being a member of the WTO were analysed by the respondents. A3 stated that "Laos has to liberalise all tariff and tax barriers on goods and services under the WTO agreements, which means the main income revenue of the government will be reduced. 
Consequently, if the government does not have a good solution to cope with this drawback, less competitiveness in the future is inevitable". A4 also commented that "good evidence shows that import tax accounts for more than $20 \%$ of GDP; liberalising import tax means the loss of the government's main income".

A lack of qualified and skilled human resources is considered a limitation requiring urgent attention in order for Laos to become a member of the WTO. A1 stated: "The WTO is not a charitable organisation, but its focus is on general agreements on trade and tariffs liberalisation, thus, more commitment should be made by the government to ensure benefits from accession". A good example is that it is crucial for negotiation teams to be professional in trade negotiation rounds, otherwise, the benefits of joining the WTO are not guaranteed. A5 emphasised: "We need to know how to play the game properly, if not, we will be in a difficult position".

\subsubsection{Future Strategy and Recommendations}

More effort should be directed into developing consistent human resource programmes within the government, industries, universities and private sector. The majority of respondents explained that a good governance or competitive business person means a qualified and technologically-skilled person. This implies that even though Laos has become a member of ASEAN and of the WTO in the near future, benefits are unforeseeable if all sectors lack knowledge and a skilled workforce. Hence, the focus of the government should be to improve HRD to meet the needs of industry sectors. A3 remarked: "So far there are not enough students studying agriculture and other related skills for industries, while more students are studying business administration and management”.

Government agencies should pay more attention to improving the rank of doing business in Laos to increase the credibility for foreign investments. A2 revealed that the "Lao investment climate for FDI is still lagging behind all countries in the region; this factor is always regarded as a significant component for attracting more investors into the country". Consequently, any inconsistent procedures and documents in alignment with import and export activities should be removed. In addition, urgent attention should be paid to greater transparency within the government in order to reduce bribery and corruption within the public sector. A3 stated: 
The officials who are dealing with documents, procedures, inspections and immigration at the border checkpoints should facilitate instead of hindering import and export activities. According to the reports, a negative action such as bribery still exists. This also creates a harmful image of the Lao business climate to foreign investors.

The government should invest more capital on $R \& D$ to develop existing competitive products. The most important factor for strengthening economic growth, based on existing theories, is sufficient R\&D support from the government to the private sector. A2 stated:

As in many developed countries, the R\&D sector is not only developed by firms, but also by much input from the government. It is a fact that more investment in institutions and laboratories helps investors to make a decision for country-specific advantage. So far the Lao government does not have sufficient resources to invest in this sector, which affects the productivity and appreciation by investors.

In addition, accessibility of capital for entrepreneurs should be simple and transparent to encourage more domestic and foreign investments. Weakness in financial and banking systems reduces the capacity of the private sector to invest in the priority sectors of the government; investment that helps to generate more income and support the essential structures of the economy. A3 stated: "In fact, the banks and financial institutions offer relatively high interest rates for loans for investors and plenty of conditions and assets to be able to borrow the money from the banks, which results in low productivity of business over time". 


\section{Case Study 4: Non-Government Organisations}

\subsubsection{Factor Endowments}

Mining and hydropower are the main factors contributing to NC in Laos. N2 emphasised the significance of hydropower in that "electricity generation from the dams not only supplies the domestic market, but also other neighbouring countries. A target of the Lao government is to turn the country into a battery for the region". N5 revealed: "Mining is the second priority of the Lao government; however, it has been slowing down in the past few years due to adjustments of investment laws. This sector has contributed more than a quarter of GDP, which is mainly owned by China, Vietnam and Australia”.

The endowment factors of low wages attract foreign investors, particularly for garments and textiles under GSP. In general, Southeast Asia is the most attractive destination for foreign investors because of low labour costs and the abundance of natural resources. N3 remarked: "Particularly for the garment and textile industry, there are more than 200,000 workers employed on relatively low wages". In addition, Laos has more comparative advantages in this sector because of the gains of GSP with $0 \%$ import tax. However, due to insufficient resources and certain requirements of local and specific regulation issues, Laos still cannot achieve even half of the total export quantity under the quota.

In addition, the GMS initiated infrastructure development in the so-called East-West and North-South Economic Corridor to turn the country into the centre of transport in the region. The concept of turning land-locked to land-linked was initiated by the Lao government and other non-government organisations. N5 explained: "This significant step encourages more import and export activities and attracts more foreign investment into the region". However, N4 revealed that "in fact, all infrastructures are already there; the volume of import and export of Laos are still not satisfactory". This means the roads are not used by the Lao companies, but by neighbouring countries instead. A different issue was raised by N3: "According to the memorandum of understanding, the Lao government is not allowed to collect any road fees from vehicles or goods, while it has to pay for road maintenance".

After Laos became a member of ASEAN, unnecessary barriers to trade between the country and its dialogue partners have been removed, which increases the opportunities for Laos to 
open to new markets. Ten countries agreed to set up the ASEAN Economic Community (ASEAN-EC) in 2015. N5 emphasised:

This region should have more comprehensive economic cooperation rather than political aspects. In addition, many agreements on trade and services with ASEAN dialogue partners such as China, India, Australia and New Zealand are under negotiation and the free trade area agreements are under implementation. As a result, this cooperation would increase the opportunities for Lao products to access their markets.

\subsubsection{The Role of Government}

The respondents explained that the Lao government should enhance the enforcement of labour laws to maintain its competitiveness in labour-intensive sectors. N5 stated that "Laos does not have the labour surplus of any neighbouring countries so that is not good for economic development in the long run. As ASEAN integrated, the labour-intensive sectors require a more productive labour force to be in place to accommodate the needs of industries. In fact, Lao workers tend to move to neighbouring countries because of higher salary and incentives. Apparently, a shortage of labour in the future is predicted. In addition, N1 remarked: "The issue of brain drain is occurring in both skilled and unskilled labour".

The top two priority sectors of the Lao government are considered fragile and unsustainable for economic development for several reasons. In a survey of many organisations on the impact of hydropower and mining industries, the results found that these two sectors have the potential to decrease $\mathrm{NC}$ in the long term. However, N2 and N3 explained that "the benefits of these projects have been seen by the government to outweigh costs and this is a better alternative for meeting the poverty reduction goal in 2020". N1 remarked:

Firstly, these projects require plenty of land, which contributes to the loss of biodiversity, forests and animals. Secondly, people who are living in the affected areas have to move out to new areas. This creates more problems such as the hardship of resettlement, change of lifestyle and cultivation issues. Thirdly, these projects not only affect people who live in the construction areas, but also people who live downstream of the rivers, because of flooding and erosion. Fourthly, the government still has to spend huge amounts of money on compensation for people who are living in the affected areas. Finally, the international community is concerned that some of the mega hydro power projects will have adverse effects on the people and biodiversity of neighbouring countries. 
Social and economic development requires qualified and skilled people throughout all areas rather than just a few sectors. HRD remains a critical issue for Laos, as the 7th NSEDP 20102015 stated: 'Education always goes one step forward'. In fact, the annual government expenditure on the improvement of educational systems is relatively low. There is a huge gap in educational infrastructure between the urban and rural areas. In addition, educational system development is not consistent with economic development. N4 remarked: "It seems many students with degrees from universities and colleges are not qualified and still need more training in order to satisfy the needs of industries".

Services remain important for the Lao economy; however, most sectors are less competitive than other countries in the region. N2 stated that "apart from telecommunication, many sectors such as financial institutions and the tourism industry have relatively minimal competition". The evidence shows that many investors have found it difficult to get access to capital from banking institutions. In addition, the short and long-term interest rates are not affordable and the banks have complex procedures. As a result, said N3, "More SMEs are willing to borrow money from the local black markets, with higher interest but with fewer procedures, which is considered inappropriate in the financial systems". N2 also added:

The tourism industry is in the top four priority sectors of the Lao economy, however, many middle people from overseas get involved in this industry rather than Lao travel agents. Despite the fact that there are a million tourists visiting Laos every year, a proper profit gain from tourism is not going to local companies and people.

\subsubsection{Regional and Global Integration Issues}

\section{ASEAN Context}

With regard to import and export activities, the majority of respondents revealed that the amount of time, and number of procedures and documents need to be reduced and simplified, particularly at border checkpoints. N3 stated: "The overriding legal framework is already sound, such as investment law, which provides a very good structure for private sector development. However, harmonisation and simplification of rules and regulations can facilitate and reduce the cost of doing business significantly. N5 remarked:

The underlying problem is that there are many more rules, regulations, and procedures to get a seal of approval in business than in other countries in the same region. For example, to get a 
hotel license requires many documents, such as number of staff and business focus, which are not consistent.

Management skill is lagging behind other countries, which adds to the slow progress of ASEAN implementation. Laos still needs to improve its human capital, as do the other new ASEAN members, Cambodia and Myanmar. Good evidence can be seen in the implementation of ASEAN-FTA; Laos still cannot fully participate in all commitments under the agreement. N4 emphasised: "While other ASEAN member countries have bound all tariffs from 5-0\%, these three countries, including Vietnam, still need more time and resources to fulfil the agreements".

In-land transport is considered a critical physical barrier for Lao exporters. Despite the facilities under construction to link countries among the GMS (Cambodia, Laos, Myanmar, Thailand and Vietnam), it seems that these infrastructures do not benefit Laos. In this sense, N3 stated: "Many garment and textiles factories still hire international freight forwarders, mainly from Thailand and Vietnam, and hire local freight forwarders less often". In addition, N4 also revealed that "the Lao Freight Forwarder Association has few trucks that operate domestically. In fact, they also work as the middle person who arranges shipments for Thai and Vietnamese operators". N2 remarked: "The shipment cost per container of both the FOB or CIF of Lao freight forwarders is more expensive than neighbouring countries because of the longer distance of transport".

\section{WTO Context}

The WTO accession process helps Laos to improve rules and regulations in accordance with international trading systems. N4 highlighted:

The benefit for Laos at this stage is to improve any contradictory rules and regulations to comply with the WTO, with regard to any import and export activities with the members. Another benefit should be to increase the transparency issues of public sectors, particularly for line ministries who are becoming involved in tariff and trade.

In fact, the WTO integration is not going to have a massive impact like it did in Singapore, Cambodia or Vietnam. Laos has a large investment in natural resources so the WTO does not impact a lot on Laos. Furthermore, Laos's tariff is relatively low and it is in the reduction 
schedule under the ASEAN framework. Therefore, whether or not Laos is a member of the WTO, it would not have a huge impact to the economy. (N5)

Integrating into regional and international trade agreements does not only remain challenging for government income, but also for the Lao SMEs. N2 revealed:

The nature of the Lao private sector is SMEs with insufficient resources and support from both financial institutions and the government. The concept of SMEs for Laos is different from others with regard to size, experience and capital; in fact, there are many microenterprises with relatively low capacity.

Becoming a member of the WTO for Laos is more challenging than becoming a member of ASEAN. As a result, more effort should be made. N4 remarked:

In contrast, ASEAN members do not push each other much to make a strong economic commitment, for example, the commitment under services is slow to remove tariff barriers. However, once Laos becomes a member of the WTO, all commitments will automatically come into force, which means any commitments of Lao bilateral agreements with other countries will affect the rest of the WTO members. Any trade dispute settlements or adjustments of the agreement will be taken under bilateral and multilateral negotiation rounds.

\subsubsection{Future Strategy and Recommendations}

Several recommendations were given on the NC of Laos. N5 commented that the "Lao currency is relatively constant in the past few years, which is not good for export activities. The appreciation of the kip in the past few years marks the growth of the economy; however, importing countries would not enjoy importing goods from Laos”. N5 also recommended:

If I were the Lao government I would depreciate the kip because the kip now is relatively strong. It is too strong for manufacturing competitiveness. The reason for the strength is the government has a policy of liberalising currency, but I would argue that to increase manufacturing competitiveness, it is important to re-regulate the kip.

HRD should focus on areas of real potential for the country such as agriculture and tourism, instead of a few concentrations in natural resources. The urgent issue for Laos now is to improve both quality and quantity of human capital to serve the elements of economic growth and enhance the competitiveness of the nation. In contrast, N5 stated: "Hydropower and 
mining industries do not create many jobs or generate much income for local people, and may even cause unsustainable problems. There should be more focus on agriculture and services. More vocational and polytechnic schools should be set up in order to accommodate the needs of labour-intensive sectors". In addition, N5 also highlighted:

The Lao education system is not varied; the recent educational systems are not what the private sector needs. Many people are studying business, while the private sector needs people with practical skills, such as engineers and technicians.

Even though low wage labour is very attractive to foreign investors, in fact it is the reason why Laos still has a shortage of labour in many areas. The minimum wage for Lao workers is relatively low, so labourers are willing to find other jobs so they can earn more and will even move to Thailand for a higher wage. Despite the government and industries encouraging students to study more in vocational training and other related skills to meet the needs of industry, more students are interested in management and administration because of the higher wage.

In addition, there should be a focus on more transparency of government institutions. Even though Laos has committed to improving rules and regulations in alignment with ASEAN and the WTO, the progress of implementation is very slow compared with other countries. Thus, more cooperation and integrity are needed, particularly from government institutions in order to maximise the real potential of Laos. In this sense, a transparent environment for business should be strengthened by related sectors of the government, which helps to increase the level of competitiveness of the country over time.

\subsection{CROSS-CASE ANALYSIS}

This section discusses the above results of the within-case analysis. The analysis is based on factors of NC, benefits and challenges of ASEAN and the WTO economic integration on competitiveness, impacts of government policies, and strategies and recommendations for improving NC as a guideline for policy-makers and practitioners. This chapter also highlights the similarities and differences in core issues forth respondents from the four clusters. The results of this analysis were supported by existing research findings presented in the literature 
review. Furthermore, secondary data and information from Laos and other sources was used to examine the findings.

\subsubsection{Factor Endowments}

As discussed in the within-case analysis in Chapter 5 about the factor endowments of the NC of Laos, focus needs to be placed on these issues for Lao to become more competitive: factor endowments, the role of government on improvement of rules and regulations in alignment with the region, opportunities of regional and international economic integrations, as well as other factors (see Table 7).

Table 7: Factor Endowments of Laos

\begin{tabular}{|c|c|c|c|c|}
\hline Competitiveness Factors & $\begin{array}{l}\text { Government } \\
\text { Officials }\end{array}$ & $\begin{array}{l}\text { Industries \& } \\
\text { Entrepreneurs }\end{array}$ & Academicians & NGOs \\
\hline $\begin{array}{l}\text { Mining, hydropower and } \\
\text { agriculture sectors }\end{array}$ & $x$ & $x$ & $x$ & $x$ \\
\hline Regional integration & $x$ & $x$ & $x$ & $x$ \\
\hline Political stability & $x$ & & $x$ & $x$ \\
\hline Government incentives & $x$ & $x$ & $x$ & $x$ \\
\hline Import duty free & $x$ & $x$ & & \\
\hline Cheap labour force & $x$ & $x$ & $x$ & $x$ \\
\hline Infrastructure upgrade & $x$ & & $x$ & $x$ \\
\hline
\end{tabular}

Source: Interview results

Note: The 'cross' $(\mathbf{X})$ represents significant factors that were highlighted by the respondents.

The Lao government encourages sectors such as hydropower, mining, agriculture and other service sectors, by providing investment incentives to investors in the long term. Many foreign companies have chosen Laos as a source of rich natural resources for industries. Several aspects of land and rivers contribute to the competitiveness of Laos and are considered to have the largest potential for social and economic development. This is in line with previous literature on endowment factors to increase NC (Porter, 1980, 1990; Smith, 1937). 
As a member of ASEAN, Laos has implemented many agreements under the framework, at the same time contributing to the improvement of rules and regulations for its trading and dialogue partners. As a result, Laos has developed a reputation as a fair and free business environment in order to attract foreign investors within and outside the region. The four clusters highlighted that regional economic integration is a significant period in which Lao business can catch up with the level of economic development of other ASEAN members and improve the quality and standard of products in line with the requirements of international markets.

In comparison with the rest of the Southeast Asian countries, Laos has gained a reputation for being a peaceful and stable nation, with a stable government. The Lao political system is ruled by only one party; therefore, any decisions are made by the cabinet. Moreover, the stability of the Lao government provides foreign investors with confidence that their assets and production processes will be protected and maintained. For companies that made a decision to invest in Laos, political stability was a key factor over other ASEAN countries. Many projects are following a long-term strategy under a contract with the Lao government, so the credibility remains relatively high.

Since Laos joined ASEAN in 1997, several tariff barriers with regard to import and export activities have been significantly reduced. This enables more opportunities for Lao products to penetrate freely into regional and other ASEAN trading partners' markets. The respondent from the Lao garment and textile association revealed that the ASEAN agreement under the rule of origin allows Lao textile companies to export with $40 \%$ of specific regulation within the ASEAN countries and other countries with $0 \%$ of import tariff. Furthermore, an abundant supply of labour of this sector costs less than other countries in the region, which is considered the main attraction, particularly for labour-intensive sectors such as manufacturing and industries.

Infrastructure support such as good road links under the GMS trade facilitation project provides more opportunity for Laos to turn from a land-locked to a land-linked country. Many findings confirmed the sound infrastructure of a host country as an important factor to attract inward FDI (Dunning, 1993; Garelli, 2003; Ghemawat, 2001; WEF, 2011). The 
combination of low wage labour and richness of natural abundance in the country means an improvement in quality transport, allowing foreign companies to exploit its potential.

The respondents also revealed that the improvement of rules, regulations and a favourable environment for investment since the 1990s have increased Lao competitiveness within ASEAN and its dialogue partners. Despite the region being strongly hit by the 1997 financial crisis, Laos has recovered rapidly and remained competitive in the following years. However, the respondents focused on the level of commitment of Laos within the region, as the key factors of competitiveness are based on major natural resource sectors instead of valueadding activities in industry development, technology and innovation.

\subsubsection{The Role of Government}

Enhancement of NC is helped not only by the wealth of natural resources, but also by significant government input (Moon, et al., 1995, 1998; Porter, 1990). The findings from the interviews suggest that the Lao government has to focus on many constraints to competitiveness (see Table 8), which delay the potential and real benefits gained from those priority sectors and the regional integration process. A number of policy issues were emphasised with respect to constraints of Lao NC: HRD, infrastructures, government transparency, enforcement of law, geographical issues, labour productivity, rules and regulations and support from the government. However, different clusters have responded to these problems differently, as explained below. Table 8 provides a summary of the significant constraints highlighted by the researcher. Although some of these constraints were discussed in the previous section, after comparing and contrasting, additional details were examined. 
Table 8: Major Constraints of Laos

\begin{tabular}{|l|l|l|l|l|}
\hline $\begin{array}{l}\text { Constraints of Lao } \\
\text { competitiveness }\end{array}$ & $\begin{array}{l}\text { Government } \\
\text { Officials }\end{array}$ & $\begin{array}{l}\text { Industries \& } \\
\text { Entrepreneurs }\end{array}$ & Academicians & NGOs \\
\hline Human resource & $\mathbf{X}$ & $\mathbf{X}$ & $\mathbf{X}$ & $\mathbf{X}$ \\
\hline Infrastructure & $\mathbf{X}$ & $\mathbf{X}$ & $\mathbf{X}$ & $\mathbf{X}$ \\
\hline Transparency & & $\mathbf{X}$ & & \\
\hline Enforcement of law & $\mathbf{X}$ & $\mathbf{X}$ & $\mathbf{X}$ & $\mathbf{X}$ \\
\hline Labour productivity & $\mathbf{X}$ & $\mathbf{X}$ & $\mathbf{X}$ & $\mathbf{X}$ \\
\hline Education policy & $\mathbf{X}$ & & $\mathbf{X}$ & $\mathbf{X}$ \\
\hline $\begin{array}{l}\text { Financial \& banking } \\
\text { systems }\end{array}$ & $\mathbf{X}$ & $\mathbf{X}$ & & $\mathbf{X}$ \\
\hline $\begin{array}{l}\text { Government support to } \\
\text { SMEs }\end{array}$ & $\mathbf{X}$ & $\mathbf{X}$ & & \\
\hline Rules and regulations & & & \\
\hline
\end{tabular}

Source: Interview results

Note: The 'cross' $(\mathbf{X})$ represents significant constraints that were highlighted by the respondents.

Most respondents regarded human resources and infrastructure as the main barriers Laos faces in enhancing its competitiveness. These two factors are very common for many countries' competitiveness in the literature (Cho, et al., 2009; Cho \& Moon, 2000; Dunning, 1993; Ghemawat, 2001; Moon, et al., 1995, 1998; Porter, 1990; Rugman \& D'Cruz, 1993). These factors are particularly critical for the labour productivity and add more production costs for manufacturers and industries. A respondent from the industry cluster highlighted that the Lao workforce needs more training in order to be familiar with modern technologies to increase productivity, while the factories do not have enough budget to organise such training for them. In addition, the level of knowhow affects the degree of technology adaptation of the workers. Furthermore, the education system focuses on administration and management skills, which are not consistent with economic development strategies. With regard to infrastructure issues, many findings in the interviews are consistent with previous theories, which suggest that the government is the main driver for managing and improving sufficient infrastructure to facilitate the growth of a country (Garelli, 2003; Ghemawat, 2001; Porter, 1980, 1990; WEF, 2011). Lao infrastructure is considered less competitive than other countries in the region. Even though the North-South and East-West economic corridors have 
improved roads and facilitated import and export activities throughout Laos, turning it into an in-land transit country, it seems that the real benefits are not received by Lao companies but by other neighbouring countries. In addition, transport costs from Laos are higher than any other countries in the region, which makes Lao companies less competitive.

Transparency issues were raised during the interviews. Even though many improvements to rules and regulations were made by government sectors, respondents from the private sector complained about the bribery and corruption of government officials. There are too many unnecessary procedures and too much documentation at border checkpoints. It is worth noting that while the other three clusters have no apparent transparency issues, complaints were raised by the companies. Consistent with the findings in Chapter 3,it was revealed that improvement of government institutions is a key issue for the development of many countries (Easterly, 2001; Garelli, 2003; Ghemawat, 2001; Gugler \& Brunner, 2007; Lee, 2008; Lee, 2010; Liu \& Hsu, 2009; Moon, et al., 1998; North, 1990; Porter, 1980, 1990; WEF, 2011). However, differing opinions from the respondents also suggested that corruption and bribery among government officials is caused by low salaries and a lack of incentives.

The findings also highlighted that as a result of unclear procedures and the insufficient capacity of the Lao financial and banking systems, SMEs found it difficult to access capital. Smaller companies must endure many procedures and much documentation in order to borrow money from the banks. Borrowing firms must comply with various complicated and unaffordable criteria set by the banks, with high interest rates for both short and long-term loans. As a result, Lao SMEs are struggling to access loans, which is not good for business development. Businesses are unwilling to borrow money outside the official financial and banking institutions, because although there are fewer requirements, there are also higher interest rates attached.

The findings emphasised that business support policies from governments help to increase productivity and higher competitiveness (Grant, 1991; Moon, et al., 1998; Porter, 1990; Sauvé, 2005; Wu, 2006). However, respondents from the private sectors accepted that the Lao government support for science and technology (S\&T), R\&D and innovation is not available. As a result, many businesses have to use their own resources to invest in these sectors, as there is even less support for SMEs or none at all for small enterprises. 
Government support does not only develop important infrastructures and facilitate the free flow of trade, but is also beneficial in terms of HRD as mentioned above. None of these are available for the Lao business environment. The majority of support comes from donors and other neighbouring countries, which would not be seen as a comparative advantage or enough to meet the demanding conditions of investors.

Furthermore, despite the fact that Laos is under the implementation of regional and international economic agreements, many inconsistent rules and regulations still exist. The majority of respondents explained during the interviews that even though Laos has been a member of ASEAN for more than a decade, several agreements have not been implemented yet due to a shortage of human capital and the low capacity of the main sectors. Moreover, the country still needs more assistance from international donors rather than the Lao government; therefore, many delays have occurred during the implementation process.

\subsubsection{Regional and Global Integration Issues}

\section{ASEAN Context}

The findings in Table 9 below illustrate the following regional integration issues under the ASEAN context from the respondents: HRD, improvement of rules and regulations, tariff structure under ASEAN-FTA, political stability, an upgrading of standards and quality of products, technical assistance, immigration of labourers in the region and trade facilitation issues, all of which are considered crucial in order for Laos to achieve the goals of the government.

HRD is regarded as the most important factor if Laos is to gain real benefits from regional integration. This finding shows that due to a lack of human resources, Laos is still lagging behind other countries in terms of economic development, labour productivity and competitiveness. Economic integration is the main driver for attracting more FDI to the region as a whole. Recently, ASEAN members assisted Laos to strengthen this sector, particularly in the areas of government and business. Even with this support, Laos still needs more time to implement the full agreements of the ASEAN framework. The rationale behind the assistance given by other members to Laos is that if the members fully implement the free trade agreement, the entire image of the region would also be strengthened. 
The increase in the size of ASEAN economic integration allows more opportunities for immigration to the country, which improves the competition of labour markets and achieves economies of scale for investors. As a result of the free flow of trade liberalisation, the labour market is regarded as both a challenge and an opportunity for the growth of the country's economy. In fact, this integration allows a free flow of neighbouring labour to come and work in the country. In addition, this factor also helps relevant sectors in the market economy solve the problems of non-labour surplus in other countries in the region. Furthermore, this workforce can embed knowledge in the local workforce and help to improve the standard and quality of products, whilst meeting the requirements of the international markets.

With regard to the GMS project, the implementation of an economic corridor such as the trade facilitation helps to improve in-land transport infrastructures, related procedures and documentation, which are needed by ASEAN member countries. The findings confirmed that the objective of the GMS project is to facilitate import and export activities and create an image of Laos as an attractive country for FDI. Whatever the type of infrastructure, improvements can enable and enhance the real capacity of the country to compete with other countries in the region.

\section{WTO Context}

The respondents raised many issues in regard to ASEAN and WTO integration framework, which affect the NC of Laos. Table 10 shows broader issues of the WTO integration, which are different from ASEAN such as cooperation among agencies, reduction of barriers to trade, high competition and the loss of government income. 
Table 9: Major Constraints of Regional Integration of Laos

\begin{tabular}{|l|l|l|l|l|}
\hline $\begin{array}{l}\text { ASEAN economic } \\
\text { integration issues }\end{array}$ & $\begin{array}{l}\text { Government } \\
\text { Officials }\end{array}$ & $\begin{array}{l}\text { Industries \& } \\
\text { Entrepreneurs }\end{array}$ & Academicians & NGOs \\
\hline Human resource development & $\mathbf{X}$ & $\mathbf{X}$ & $\mathbf{X}$ & $\mathbf{X}$ \\
\hline $\begin{array}{l}\text { Improvement of rules and } \\
\text { regulations }\end{array}$ & $\mathbf{X}$ & $\mathbf{X}$ & $\mathbf{X}$ & $\mathbf{X}$ \\
\hline Tariff structure (AFTA) & & $\mathbf{X}$ & $\mathbf{X}$ & \\
\hline Political stability & $\mathbf{X}$ & $\mathbf{X}$ & \\
\hline $\begin{array}{l}\text { Improvement of standard \& } \\
\text { quality of products }\end{array}$ & & $\mathbf{X}$ & $\mathbf{X}$ & $\mathbf{X}$ \\
\hline Technical assistance & $\mathbf{X}$ & $\mathbf{X}$ & $\mathbf{X}$ & $\mathbf{X}$ \\
\hline Immigration of labour & & $\mathbf{X}$ & $\mathbf{X}$ \\
\hline Trade facilitation & & & & \\
\hline
\end{tabular}

Source: Interview results

Note: The 'cross' $(\mathbf{X})$ represents significant factors that were highlighted by the respondents.

Table 10: Major Issues of Global Integration of Laos

\begin{tabular}{|c|c|c|c|c|}
\hline $\begin{array}{l}\text { Global economic integration } \\
\text { issues }\end{array}$ & $\begin{array}{l}\text { Government } \\
\text { Officials }\end{array}$ & $\begin{array}{l}\text { Industries \& } \\
\text { Entrepreneurs }\end{array}$ & Academicians & NGOs \\
\hline $\begin{array}{l}\text { Awareness of costs and } \\
\text { benefits }\end{array}$ & $x$ & & & $x$ \\
\hline $\begin{array}{l}\text { Improvement of rules and } \\
\text { regulations }\end{array}$ & $x$ & $\mathbf{x}$ & $\mathbf{x}$ & $\mathbf{x}$ \\
\hline Reduction of barriers to trade & $x$ & $x$ & $\mathbf{x}$ & $x$ \\
\hline $\begin{array}{l}\text { Improvement of standard \& } \\
\text { quality of products }\end{array}$ & $x$ & $x$ & $x$ & $x$ \\
\hline Transparency & $x$ & $x$ & $x$ & $x$ \\
\hline Technical assistance & $x$ & & & \\
\hline High competition & $x$ & $\mathbf{x}$ & $\mathbf{x}$ & $\mathbf{x}$ \\
\hline Loss of government income & & & $x$ & $x$ \\
\hline
\end{tabular}

Source: Interview results

Note: The 'cross' $(\mathbf{X})$ represents significant factors that were highlighted by the respondents. 
A number of concerns about the awareness of costs and benefits among agencies in Laos toward the WTO accession were highlighted, particularly from the public sector. As mentioned in within-case analysis in Chapter 4, the WTO Secretariat includes several government agencies who are dealing with a number of preparation issues. In addition, due to insufficient technical staff, budget restrictions and the degree of integrity of the public sector, the integration process is being affected. A part of the problem raised during the interviews is that Laos still cannot see a clear benefit or even envisage products that can compete with other members, so there appeared to be considerable scepticism on the part of the respondents around the advantages of the WTO accession for Laos. Even though the government is trying to accelerate this process so it can become a reality as soon as possible, little awareness of the gains within global integration reduces the efficiency of the process.

Similar to ASEAN, joining the WTO means all barriers to trade will no longer exist to delay import and export activities. The respondents were more confident about the enforcement of trade and tariffs of the WTO, which are more practical than those of ASEAN. It seems the country will enjoy the code of Most Favoured Nation (MFN), which helps to reduce any discrimination or unfair treatment in international trade. As an LDC, Laos can gain from the preferential treatment, which allows the country to have more time and flexibility compared to some developed and developing countries in order to adjust any inconsistent rules and regulations.

\subsubsection{Future Strategies and Recommendations}

A number of strategies and recommendations for Lao NC were expressed by the clusters interviewed. Table 11 summarises major strategies initiated by clusters, as well as specific recommendations that the respondents mentioned to improve Lao competitiveness. Based on the interviews, the following specific issues are considered important by the four clusters: HRD, improvement of rules and regulations, educational system, government support to SMEs, improvement of the doing business rank, a focus on $R \& D$, accessibility to capital, and transparency. 
Table 11: Strategies and Recommendations for Lao Competitiveness

\begin{tabular}{|l|l|l|l|l|}
\hline $\begin{array}{l}\text { Strategy and } \\
\text { recommendations }\end{array}$ & $\begin{array}{l}\text { Government } \\
\text { Officials }\end{array}$ & $\begin{array}{l}\text { Industries \& } \\
\text { Entrepreneurs }\end{array}$ & Academicians & NGOs \\
\hline Human resource development & $\mathbf{X}$ & $\mathbf{X}$ & $\mathbf{X}$ & $\mathbf{X}$ \\
\hline Infrastructure development & $\mathbf{X}$ & $\mathbf{X}$ & $\mathbf{X}$ & $\mathbf{X}$ \\
\hline $\begin{array}{l}\text { Improvement of rules and } \\
\text { regulations (ASEAN \& WTO) }\end{array}$ & $\mathbf{X}$ & $\mathbf{X}$ & $\mathbf{X}$ & $\mathbf{X}$ \\
\hline Education system & $\mathbf{X}$ & $\mathbf{X}$ & $\mathbf{X}$ & $\mathbf{X}$ \\
\hline Government support to SMEs & & $\mathbf{X}$ & $\mathbf{X}$ & $\mathbf{X}$ \\
\hline $\begin{array}{l}\text { Improvement of doing business } \\
\text { rank }\end{array}$ & & $\mathbf{X}$ & $\mathbf{X}$ \\
\hline $\begin{array}{l}\text { Research and development } \\
\text { (R\&D) }\end{array}$ & & & $\mathbf{X}$ & $\mathbf{X}$ \\
\hline Accessibility to capital & $\mathbf{X}$ & $\mathbf{X}$ & $\mathbf{X}$ & $\mathbf{X}$ \\
\hline Transparency & & & $\mathbf{X}$ \\
\hline
\end{tabular}

Source: Interview results

Note: The 'cross' $(\mathbf{X})$ represents significant factors that were highlighted by the respondents.

As discussed in Chapter 4, the human resource capacity of Lao is limited, particularly during the period of regional and international trade liberalisation. The four clusters expressed concerns that education systems in Laos are not sufficiently cohesive for real economic development potential of the country. In addition to the existing skills in hydropower, mining, agriculture and tourism, practical skills such as mechanics and engineering need to be developed. The needs of Lao manufacturing and industries are based on the technical skills of the workforce so education should focus more on vocational schools and training skills for workers. While the needs of the labour-intensive sectors are very high compared with the rest of the region, many Lao workers are working in neighbouring countries. At the same time, Laos does not have a surplus of labour in industry as do many countries in the region, which makes is less easy to attract foreign investors and enhance the competitiveness of the country.

The ease of doing business in Laos in regard to fairness, clarity and transparency were raised by the respondents during the interviews. There is considerable potential in the sectors within the doing business environment in Laos for investors to explore and exploit. The doing 
business rank in Laos is the lowest in the region, according to the annual reports of the International Financial Cooperation (IFC) on the Ease of Doing Business. Despite some progress after efforts made by the government, foreign investors seem to be unimpressed by the rank of 165 out of 183 in 2011. The respondents considered that, compared with domestic companies, the export companies are not competitive, and this is a problem that Laos must solve as soon as possible. This means transparency of the environment of doing business still needs to be improved.

R\&D capacity was indicated as the most critical area that the Lao government should pay immediate attention to. As more foreign investors are moving to Laos, R\&D needs to be speedily established to increase productivity, as well as the effectiveness of labour skills and technologies. In this regard, unless the Lao government can allocate a budget to invest in $\mathrm{R} \& \mathrm{D}$, it may find it increasingly difficult to attract further FDI compared with other countries in the region. Moreover, a lack of scientific and technological sophistication is considered the key reasons for poor economic performance. The findings also found that the government puts insufficient investment into $\mathrm{R} \& \mathrm{D}$, due to a lack of budget support. This results in minimal science and technology development, which will directly affect the level of competitiveness of the country in the long term.

Surprisingly, the respondents from the textile and garment industry and the Lao freight forwarder were positive about the economic integration of both the ASEAN and the WTO frameworks, due to the fact that regional and international integration would promote a degree of competition among rivals. These two sectors above are confident that whether or not Laos joins the WTO, the competitiveness of the companies would not be affected. The respondents also revealed that these sectors in particular experienced strong competition among their international rivals before the country's integrations. Many experts have indicated that the Lao economy would not be heavily affected by joining ASEAN or even the WTO. In contrast, some Lao export sectors would be vulnerable because of being less competitive in the quality and standard of products, particularly in agriculture and food processing industries. 


\subsection{PROPOSED COMPETITIVENESS MODEL AND DISCUSSION}

The proposed conceptual framework was derived from the result and analysis section, which identifies the nature of the NC of Laos. Because fewer economic variables were found in LDCs' competitiveness, compared with the status of other countries' economic development (Berger \& Bristow, 2009; Cho \& Moon, 2005; Lall, 2001; Lin, et al., 2004; Thompson, 2004), this model proposed to develop an understanding of the NC of Laos. The elements in this conceptual framework include the role of government, factor endowments and the impacts of globalisation, such as ASEAN and the WTO. More detail is provided as follows:

The NC of Laos depends mainly on the interaction of the role of government, global integration and factor endowments. As a result, the strong relationship between global integration and the improvement of government roles has been investigated in the findings. The results also show that regional and international economic integration helps Laos by improving government rules and regulations as trade is liberalised and tariffs are reduced in the region (ASEAN) and preparations are made for the accession of Laos into the WTO. In addition, these institutions help to improve productivity and the value-adding activities of all factor endowments, which lead to an improvement in the NC of Laos.

Although factor endowments are considered its main competitiveness feature, Laos still lacks most of the important elements such as qualified human resources, knowledge and technology development in order to increase the value of products and services. It is widely understood that knowledge is power and the main source of competitiveness of many countries and industries, thus, with little input into the number of qualified and skilled workers, the rest of the endowment factors cannot be developed properly. Despite mining and hydropower generating more than half of the Lao government income, these sectors are still not considered by the respondents as sustainable for economic development in the long term. In contrast, the key economic growth strategies for Laos should be focused on the agricultural and tourism sectors, which contribute to better living standards and poverty reduction. These sectors need to be constantly developed in parallel with the improvement of human resources.

The role of government has been found to be critical for competitiveness and productivity, particularly for the development of the industrial and private sectors because they are the 
main actors who contribute to economic growth (Gugler \& Brunner, 2007; Lee, 2008; Lee, 2010; Liu \& Hsu, 2009; Moon, et al., 1998; Porter, 1990). According to the analysis and discussion above, there is a significant link between government policies on education systems and an insufficient level of knowledge in the human capital in Laos, so the needs of industry, the private sector, and even the public sector, are not met. In addition, there are still many unnecessary government documents, procedures and fees involved in import and export activities at border checkpoints, which reduce the competitiveness of businesses. Furthermore, the ease of doing business in Laos in the past two decades has only minimally improved, which reflects the investment environment and the ability of both the Lao government and domestic suppliers to increase the confidence of foreign investors. To sum up, the above issues show that, contrary to all other countries, Lao exporters are less competitive than domestic entrepreneurs.

Particularly for Laos, globalisation provides both opportunities and challenges for improving NC. Becoming a member of ASEAN brings greater opportunities for Laos to trade with countries in the region and with other ASEAN dialogue partners, as well as opportunities to receive plentiful assistance in the development human resources. However, due to differences in the social and economic development of ASEAN members, Laos still requires more resources, assistance, flexibility and time to fully achieve the requirements of rules and regulations that comply with international frameworks. In fact, the interviews emphasised that the benefit of integration for Laos was not based solely on economics, but also on gaining a greater voice on the world stage. In addition, because Laos does not perform well in ASEAN agreements, the question of how it will be able to compete with other countries in the WTO was raised by many respondents. 
Figure 7: Conceptual Model of the National Competitiveness Model of Laos

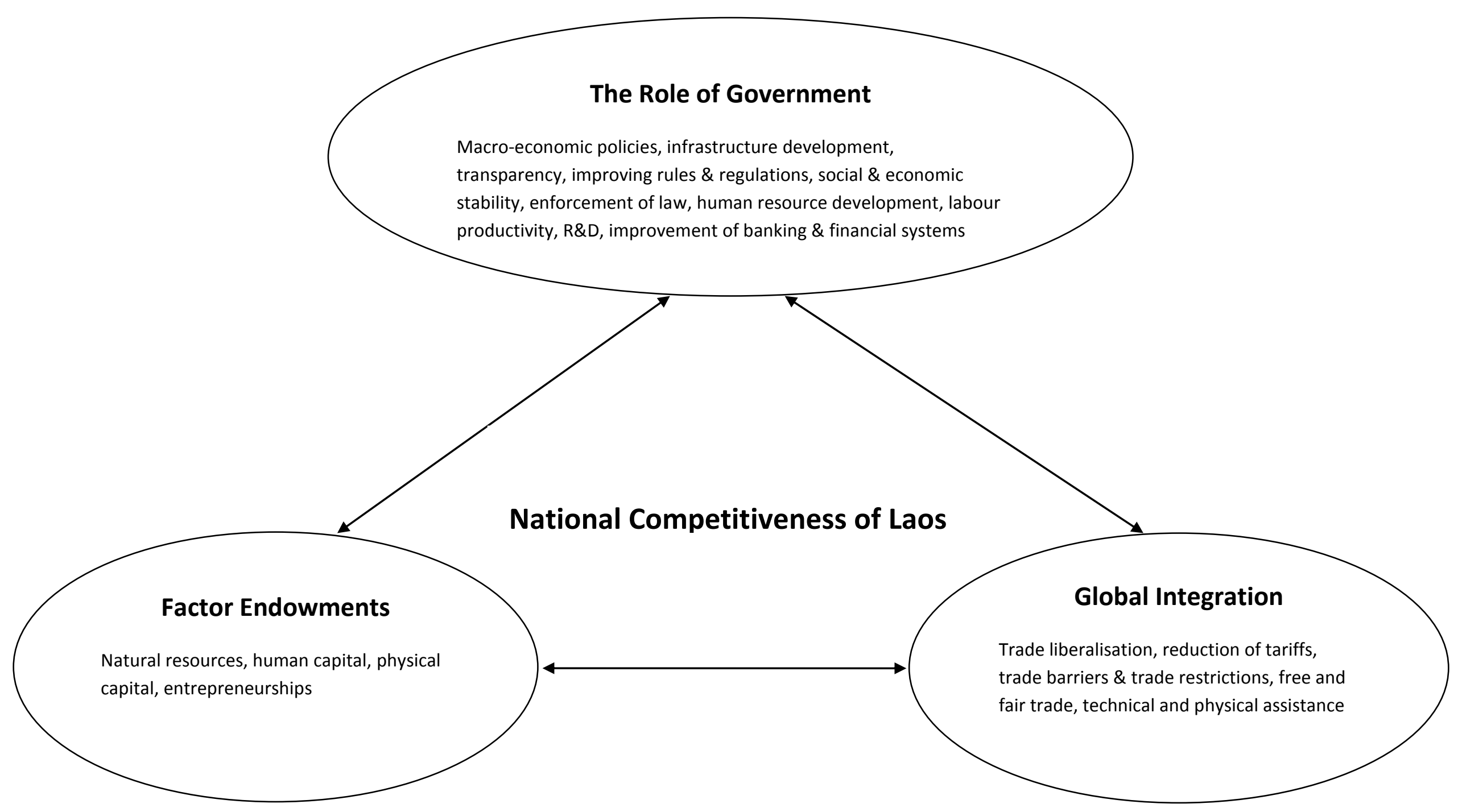


To sum up, this conceptual model is considered appropriate for identifying and understanding the competitiveness of Laos and argues that the role of factor endowments, government institutions and the impact of global integration are correlated with the NC of Laos.

\subsection{DISCUSSION}

The above findings were consistent with trade and competitiveness theories that competitiveness of nations is derived from factor endowments (Porter, 1990, 1998; Smith, 1937). Lao government priority focuses on the richness of the country's natural resources, which contribute to higher economic performance and NC. Some theories also suggested that the only way to increase wealth and eradicate poverty is to trade with the rest of the world (Grant, 1991; Hsiao \& Hsiao, 2006). However, due to the nature of small and limited economic variables (Cho, et al., 2009; Moon, et al., 1998), small economies are less competitive than larger countries with varied economic alternatives. Comprehensive and sophisticated models used to measure the NC of OECD or developing countries were not applicable to LDCs. The results found that at this stage Laos cannot apply the economic models discussed in Chapter 3 to measure productivity and competitiveness, but also highlighted how the factor endowments can be enhanced through government policies, consistent with regional and international economic integrations.

However, these factor endowments would enhance productivity and economic development of the countries more if they were incorporated with domestic and international human factors (Cho, et al., 2009; Cho \& Moon, 2000; Rugman \& D'Cruz, 1993). Most inflow FDI takes advantage of labour-intensive sectors such as textile and garment industries, which require the development of knowledge and technological skills provided by the host country to increase productivity, rather than advancing knowledge and training for labourers using internal resources. The study of competitiveness of nations by Porter (1990) confirmed that human capital is regarded as the determinant factor contributing significantly to the growth of economies. This finding suggested that it is necessary to increase knowledge of human capital in order to increase competitiveness and productivity.

Furthermore, sound government policies create a favourable climate for investments and affect a high degree of NC. It is well known that while firms are the main actor enhancing the 
economic growth of a country, the role of government helps to improve all four forces of competitiveness (Porter, 1990). Thus, the four factors cannot be achieved without productive government intervention policies. The findings in the literature review chapter also support that government plays a significant role in the improvement of rules and regulations to facilitate all potential factors of economic growth (Gugler \& Brunner, 2007; Krugman, 1994; Lee, 2008; Lee, 2010; Liu \& Hsu, 2009; Luo, 2001; Moon, et al., 1998; Porter, 1990). In contrast, these studies also found that inconsistent policies by local government reduce the productivity of firms and the competitiveness of a country.

Infrastructure development is a particularly urgent problem for Laos to address in order to enhance competitiveness, as domestic companies still find it difficult to cope with a competitive environment. The findings in Chapter 4 are consistent with the literature review in Chapter 2 that there is a strong relationship between a degree of infrastructure development and the competitiveness of countries (Dzeng \& Wang, 2008; Easterly, 2001; Garelli, 2003; Porter, 1990; WEF, 2011). The implementation of trade facilitation under the GMS development programmes assists Laos to overcome the constraint of being land-locked and to become land-linked throughout the region. However, geographical difficulty and distance both contribute to the costs of transport and increase production costs, preventing firms from competing internationally, and having a negative impact on NC. In addition, even though roads and bridges have been built throughout the country, it is obvious that many shipments are undertaken by foreign companies, instead of Lao companies. Therefore, it is not clear that Laos would benefit from infrastructure development that would transform it into a major country for inland transporting the region.

More importantly, HRD remains the key constraint for Lao NC since the 1980s. Studies found that sophisticated education and training systems help workers to be able to adapt faster to new knowledge and technological skills (Moon, et al., 1995, 1998; Rugman \& D'Cruz, 1993). It is a fact that inward FDI brings along with it sophisticated knowledge and advanced technology to be embedded in the host countries. However, a less educated and unskilled workforce struggles with learning and adapting to new knowledge and technologies. Consequently, the trend of Lao education systems and vocation training programmes should be consistent with the level of economic growth and the international climate of investment. Moreover, Lao people still distinctly prefer to work in an office with a 
high salary rather than being a labourer with a low income; as a result, most students choose not to work in industry when they finish university.

In addition, the accessibility of domestic firms to the capital seems to be a significant barrier for the development of Lao businesses. The analysis in Chapter 4 reveals weaknesses in the financial and banking systems of Laos. As a result, many large projects are owned by foreign investors, particularly mining and hydropower, which reduces the competitiveness of the domestic firms when competing within the country and within the international environment. This is also burdensome for financial institutions because of unnecessary procedures and requirements around the accessibility of capital.

Despite Laos having experienced economic growth in the past few decades, the majority of growth is still too reliant on the abundance of natural resources, and places less emphasis on economic development factors such as health and education. The analysis in Chapter 4 shows misunderstanding and confusion among the respondents about the concepts of economic growth and economic development. While many respondents appreciate the average growth of GDP as a significant achievement, other essential economic development factors such as environmental sustainability, social inclusion, health, safety, literacy and the improvement of living standards are less emphasised.

Services and industry sectors have increased as the country develops; however, the agricultural sector has slightly decreased. Even though more than $70 \%$ of the Lao workforce is in the agricultural sector, services and industries have become the most important sectors to contribute to the growth of the economy. The findings are consistent with the theory of Perkins, Radelet, \& Lindauer (2006). Many large projects are shared and owned by foreign rather than local companies. As a result, these sectors do not create adequate jobs for people and even increase the environmental issues of the country. In addition, Lao workers are unskilled and still receive relatively low wages, which does not contribute significantly to the MDG of poverty reduction by 2020. Furthermore, many local workers are moving to the labour-intensive sectors of neighbouring countries. 
Globalisation not only provides opportunities, but also significant challenges for the Lao economy. The findings in Chapter 4 note the first issue that requires consideration: the degree of commitment by Laos to the agreements. Because of physical infrastructure and human capital limitations, only slow progress has been made during regional and international economic integrations. Evidence shows that a degree of openness of countries in regional and international economic integrations strengthens the competitiveness of those countries over time (Frankel \& Romer, 1999; Greenaway, 1998; Greenaway, et al., 1997; Greenaway, et al., 2002; Greenaway \& Sapsford, 1994; Krugman, 1994; Sachs \& Warner, 1995). Consistent with these findings, it seems logical for Laos to liberalise its trade regime and integrate into international trade in order to boost productivity and NC.

The ASEAN regional agreement helps Laos to increase its access to regional and international markets. The free trade agreement among ASEAN and other trading partners increases the capacity of Laos to compete with others without significant barriers. In addition, member countries provide technical assistance to overcome any domestic constraints and join the economic community and free flow of trade in the region. However, there are various levels of economic development within ASEAN member countries. This influences the implementation of tariff reduction from $0-5 \%$ in accordance with ASEAN-FTA, and is considered a concern for Laos. Tariffs contribute to $20 \%$ of the government income, thus reducing tariffs means the loss of government income. As a result, the process of comprehensive trade liberalisation in ASEAN has not been fully implemented.

Moreover, Laos is in the process of joining the WTO and more commitments on trade and tariffs are challenging. The respondents noted both the constraints and opportunities that WTO accession could bring to the Lao economy. The WTO is not considered to be as political an organisation as ASEAN and consists of unilateral, bilateral and multilateral agreements on trade and tariffs. Consequently, winning or losing depends on how the country can develop its productivity to compete with others. The MFN principle allows countries to compete with each other fairly and non-discriminatorily. This also emphasises that once countries integrate into the organisation, more effort should be made to compete and gain benefits from others. 


\subsection{CHAPTER SUMMARY}

As discussed above, the findings in this chapter emphasised the significant relationship between these three factors in the improvement of the NC of Laos. Overall, the results and analysis and the literature review in Chapter 3 confirm how significant the interactions of factor endowments, government role and global integration are for enhancing the $\mathrm{NC}$ of LDCs. Appropriate government policies were found to facilitate all aspects of existing endowment factors and at the same time accelerate the process of global integration. However, due to a lack of physical support from the Lao government, industries and entrepreneurs are struggling with limited resources to improve competitiveness. The findings suggest that it is crucial for the Lao government to continue improving rules and regulations and solving any existing issues, including education policies and the sustainability of investment projects, during the period of regional and international economic integration. 


\section{CHAPTER 6: SUMMARY, CONCLUSION AND IMPLICATIONS}

\subsection{INTRODUCTION}

This chapter summarises the study. The dissertation summary is provided in section 6.2, followed by the implications of the study in section 6.3. Section 6.4 provides the contributions and limitations of the study. And finally, concluding remarks are provided in section 6.5.

\subsection{DISSERTATION SUMMARY}

$\mathrm{NC}$ can be understood as the ability of a country to make good use of all factor endowments in the most effective way. It is important for countries to identify the strengths and weaknesses of the important components of the economy, which help to enhance NC. The government plays a significant role in enhancing all factor endowments and increasing productivity with the right social and economic development policies. In addition, integrating into the world economy raises more opportunities for countries to engage in import and export activities, and knowledge and technology transfers. However, these aspects of NC in relation to LDCs are different from those of other countries. Due to relatively weak government participation, bargaining power and level of commitment to international trade agreements, it seems that LDCs still gain fewer benefits than they should. Thus, this research project aims to address these gaps by investigating the determinants of the NC of Laos.

There are many reasons why the researcher is interested in studying the NC of Laos. Firstly, although Laos has the advantages of cheap wages and an abundance of natural resources, these factors have not really contributed to social and economic development. Secondly, despite the government making significant effort throughout the three phases of the NEM in the past three decades to strengthen its $\mathrm{NC}$ and eradicate poverty, Laos remains in the category of LDC. Thirdly, even though the government has engaged in regional economic integration (ASEAN) for over 15 years and been attempting to join the WTO since 1997, few benefits have been identified; questions have even been raised by the experts as to how Laos can compete with global integration. This exploratory research is conducted in order to understand the factors contributing to the NC of LDCs, with a focus on Laos. 
The main research objective of the study is to explore the factors that contribute to the NC of Laos. This helps understanding of the question: 'How can the national competitiveness of LDCs be enhanced?' The study found that three main factors influence the NC of Laos: factor endowments, government role and global integration. As a small, less developed and land-locked country in the middle of five neighbouring countries including the strong economic development of China, Thailand and Vietnam, regional integration for Laos is considered to be the best way to increase its economic performance and get rid of poverty by 2020 (NSEDP, 2010). However, more than $80 \%$ of FDI from these countries focuses on the natural resource sectors, with the much smaller percentage focusing on agriculture, industry and service development being a major contribution to the employment issue in Laos (WB, 2009).

The researcher selected qualitative methods as the most appropriate tool to address the research topic, due to the nature of the phenomenon. This exploratory qualitative research was conducted in both within-case and cross-case analysis in order to gain a deeper understanding from the interviews within the four clusters. Firstly, the within-case analysis helps the researcher to understand the relationship between the different themes used in the study (Ghauri \& Gronhaug, 2002). Secondly, it also helps the researcher to become accustomed to the extent of the data and gain a better understanding from the interview responses. Thirdly, the cross-case analysis allows the researcher to identify the commonalities and differences in patterns among the interviews. In addition, common issues were analysed in the interviews and transposed into tables, which helped the researcher to establish the outstanding issues in the NC of Laos by the frequency of the responses to the research questions.

The study argues that it is the interaction of three factors, namely factor endowments, global integration and government's role that is likely to enhance the NC of Laos. Government plays an important role in developing factor endowments and enhancing global integration, which in turn helps to enhance factor endowments. The findings are summarised in Table 10 and discussed below. 
Table 12: Summary of the Main Findings

\begin{tabular}{|c|c|}
\hline $\begin{array}{l}\text { The Lao } \\
\text { NC factors }\end{array}$ & The \\
\hline & $\begin{array}{l}\text { - There are fewer sophisticated factor endowments existing in Laos than other } \\
\text { countries. } \\
\text { - Natural resource sectors are the main contribution to Lao economic growth, but } \\
\text { are still less value-adding, create fewer jobs and are unsustainable in the long } \\
\text { term. } \\
\text { - No advanced factors such as S\&T, R\&D, and innovation activities - all of which } \\
\text { are necessary for competitiveness - exist in the components of Lao economy. } \\
\text { - Infrastructure issues are considered critical for Lao economic development. } \\
\text { - Banking and financial institutes are not competitive and accessible for } \\
\text { entrepreneurs. }\end{array}$ \\
\hline $\begin{array}{l}\text { Gove } \\
\text { role }\end{array}$ & $\begin{array}{l}\text { - A transparent and productive government is needed to manage and monitor the } \\
\text { advantages of the natural sectors. } \\
\text { - Consistency in rules and regulations should be improved in the period of global } \\
\text { integration. } \\
\text { - The trend of HRD of Laos is not consistent with the needs of the industries. } \\
\text { - Industrial and private sector development can be achieved by improving } \\
\text { consistency in government policies for the education system. } \\
\text { - The development of transport infrastructures under the GMS development } \\
\text { projects did not, on the whole, benefit Laos. } \\
\text { - Complicated procedures and laws within the banking and financial sectors hinder } \\
\text { the development of Lao SMEs. }\end{array}$ \\
\hline & $\begin{array}{l}\text { - The trade liberalisation process helps to shape consistent rules and regulations. } \\
\text { - Global integration provides more physical and technical assistance for social and } \\
\text { economic development. } \\
\text { - ASEAN membership and WTO accession for Laos are no longer considered } \\
\text { political issues, but have become economic issues. } \\
\text { - Global integration allows the country to engage in the region (ASEAN) and } \\
\text { creates more economic opportunities with dialogue partners. } \\
\text { - Laos still needs more physical and technical assistance, time and flexibility to } \\
\text { strengthen its NC in alignment with ASEAN and WTO accession. }\end{array}$ \\
\hline
\end{tabular}




\subsubsection{Factor Endowments}

Laos possesses rich natural resources; however, Lao export products are mainly unprocessed materials with no value-added elements. In particular, hydropower and mining projects are shared by foreign companies and $100 \%$ of the mining sector has been exporting primary material without adding any value. Thus, it is important for the Lao government to consider adding value activities to these sectors. Evidence shows that Laos has still not received enough benefits from these projects (WB, 2010). As a result, hydropower and mining projects were revised and assessed by the government, which resulted in fewer projects and would contribute to a lower economic growth in the next few years (MOPI, 2012).

In addition, agriculture and tourism are important for Lao economic development. Due to an increase in the price of food in world markets, Laos has more comparative advantage for the development of the agricultural sector. Given its LDC status, it is not only important for Laos to produce enough food for domestic consumption, but also to export both within and outside the region. However, the findings revealed that the government must urgently invest in S\&T and $\mathrm{R} \& \mathrm{D}$ in order to improve productivity and add value to products. In addition, due to the unique traditions and beautiful landscapes, tourism could enhance economic growth and should be considered a significant alternative for Laos. From 2000, more than one million visitors have come to Laos each year to discover its natural beauty, and have consequently contributed significantly to the Lao economy.

Although there is an abundance of natural resources, a lack of skilled and qualified human capital affects the level of economic development of the country. The study found that it is difficult for the private sectors to find employees who have the skills and knowledge that they are looking for. The implication for institutions such as universities, colleges, vocational schools and training centres, therefore, is to urgently improve the skills of the workforce relevant to the needs of industries. The findings also suggest that the other main reasons for a deficiency inhuman capital, particularly in the labour-intensive sectors, are the low salaries and minimal incentives in the industrial sector, which are not attractive for the local workforce. Consequently, trained and skilled workers choose to move out of Laos to find better opportunities in neighbouring countries. 


\subsubsection{The Role of Government}

The interviews highlighted the need for consistent and transparent policies in the public sector, particularly those policies that deal with import, export and investment activities, in order to increase NC. Firstly, the complexity of import and export procedures, documentation, and the unclear costs of doing business are overwhelming for foreign investors and exporters. While exporters must deal with a variety of documents and regulatory burdens, local importers are more competitive because of smuggling and bribery. These are regarded as significant physical barriers to trade and hinder the ASEAN-FTA initiative of the free flow of trade and investment agreements in 2015. Furthermore, the approved projects, such as hydropower and mining, paid little attention to sustainability issues, which resulted in environmental degradation and affected biodiversity and the lifestyle of the local people.

Secondly, while the aim of ASEAN is to achieve a regional economic community by 2015 for the six original members and 2020 for the rest, known as CLMV, Laos is still lagging behind this in this implementation. In fact, the government has imposed more rules and regulations with regard to tariffs and taxed of import commodities. The findings revealed that import taxes on some commodity products are significant for economic stability and an important source of adjustment for the balance of central government trade deficits. Therefore, fully liberalised trade means the reduction of government revenue, which also affects the speed of the integration process.

In order to strengthen Lao NC, it was necessary for the government to establish a national productivity and competitiveness body, which consists of all four main clusters: the government, private companies, universities and institutes, and NGOs. This organisation identifies competitiveness issues then seeks solutions to the problems by making submissions to the government. So far this initiative has been supported by government agencies, the private sector and other NGOs; however, due to budget and human resource difficulties, the initiative has made only slow progress.

At present, no proper research institutes in S\&T, R\&D or innovation exist in Laos. These institutes are very significant for the enhancement of productivity and the competitiveness of industries and the country. Despite this, the government has incorporated the above initiatives 
into policies under the $6^{\text {th }}$ and $7^{\text {th }}$ NSEDP in order to improve productivity and NC step by step, and help to achieve the MDG of poverty eradication by 2020. Direction for the implementation of the proposals and policies has been sketchy and delayed, however, due to insufficient human resources, poor infrastructure and a lack of financial support from the government.

\subsubsection{Global Integration}

Due to Laos' attempts to integrate globally, the trade liberalisation process has contributed to sustainable increases in the volume of imports, exports, GDP growth and FDI in the past decades (see Figure 2); however, many constraints still need to be overcome. Even though Laos became a member of ASEAN in 1997, all trade, investment and service agreements have only slowly come into force. It is important that the skills and integrity of government officials who are involved in maximising the real benefits of integration are developed. As the full implementation of the ten members on ASEAN Economic Community in 2015, the benefits of joining ASEAN would be no longer be considered only from a political standpoint.

The benefits and challenges of global integration were highlighted by the interviewees. More commitment to trade and tariff agreements would be necessary as Laos engaged in regional and international trade agreements. Like the WTO agreement, this would include further opportunities and challenges for the Lao economy. Unlike the ASEAN framework, however, Laos is required to commit to trade and tariff agreements with more than 150 nations worldwide, compared with only ten ASEAN countries. Therefore, it would create more challenges for economic development if Laos is not well-prepared in human resources, as well as in the related rules and regulations on trade, services and investment. Thus, it requires even more effort and commitment, particularly from the public and private sectors, as well as universities, institutes and NGOs, to cooperate more to enhance benefits and mitigate any potential harm to the economy.

In addition, the findings found a strong relationship between global integration and the improvement of government roles. The results show that regional and international economic integration assists Laos to improve government institutions, and to develop consistent rules and regulations in accordance with trade liberalisation and tariff reductions within the region 
(ASEAN) and the preparation for WTO accession. The role of institutions helps to improve productivity and the value-adding activities of all factor endowments, which leads to the improvement of the NC of Laos.

\subsection{IMPLICATIONS}

\subsubsection{Implications for Policymakers}

The key implications for policy-makers relate to developing human resource, natural resources, infrastructures, banking and financial institutions, business environment and social welfare.

Firstly, Laos needs to focus on improving the quality of the education system in order to be consistent with the needs of domestic industries and foreign investors. As the literature shows, advanced education is important as it increases the level of sophisticated customers and leads to NC (see, for example, Porter (1990); Moon, et al. $(1995,1998)$ and Cho, et al. (2009)). As the researcher noted in the interviews, the capabilities of the Lao workforce to add value are still limited, and need to be improved. By focusing on labour productivity and providing students with more vocational training schools, instead of management and administration skills, outputs would be increased and proper benefits from regional and international integration would be gained. It is also necessary to strengthen the collaboration between industries and universities so that students are aware of the practical knowledge and skills required by industries. Moreover, practically-oriented joint projects between students and researchers should be enhanced to increase knowledge levels of students.

Secondly, even though Laos is rich in natural resources, the country still remains poor. The country needs to develop the natural resource sector with a value addition on exports to achieve economic growth and become a middle-income country by 2020 . The government should focus more on the degree of sustainability of investment projects. Tighter quality control and greater monitoring of projects to ensure the speed of economic growth is consistent with sustainable natural resource development would help mitigate any drawbacks. Poverty reduction requires proactive policies and should be more about the development of S\&T, R\&D and innovation activities than the exploitation of natural resource sectors. Although the natural resource sectors have helped to improve economic growth over the past 
decade, this has not significantly increased the living standard of the poor. Evidence shows that resource-rich countries are likely to be $15 \%$ less developed in manufacturing and agriculture sectors than other countries (Brahmbhatt, Canuto, \& Vostroknutova, 2010).

Thirdly, an upgrade in infrastructure and supporting services was strongly recommended by the interviewees. The government needs to continue developing the necessary supporting infrastructure such as roads, bridges and highways to facilitate economic development. The GMS trade facilitation plans within the East-West and North-South Economic Corridors have already connected transport and other investment activities in the region. As a result, Laos represents an inland transit country, which could create many opportunities for the expansion of the Lao economy. However, it is worth noting that while foreign goods and services were represented in this project, few Lao entrepreneurs made good use of these facilities. Furthermore, the government is obliged to pay for the maintenance of the roads when, in the main, they have not been used by local business.

Fourthly, with regard to the natural resource sectors and the sustainability of Lao economic development, it is essential for policymakers to integrate corporate social responsibility (CSR) principles into the government's policies in order to mitigate the potential risks of hydropower and mining projects. The government should regulate the investment law and reinforce CSR as a compulsory criterion for foreign companies who are interested in investing in the hydropower and mining industries. Recently, some large mining projects have implemented CSR and not only achieved high profits but also contributed to the sustainable economic development of the country (WB, 2010).

Furthermore, the government should enhance the capacity of the private banking sector to become involved in the Lao financial market, in order to facilitate the development of the local business environment. It is essential that the government regulates financial and banking laws, including bankruptcy laws and loan screening procedures, to support the accessibility of loans for Lao SMEs. This would help to reduce the negative influence of black market finance, which is not appropriate for NC in the long-term.

Finally, it is imperative that the government strengthens the competitiveness of Lao exporters compared with local importers, by reducing complicated and unnecessary documentation and procedures. Effectiveness and consistency of government policies is also needed to enhance 
economic performance. Many issues, including the transparency of government policies, were highlighted during the interviews. It appears that some government agencies are unwilling to cooperate with each other and drive the integration process, due to misunderstandings about the costs and benefits of joining, and the fear of losing group and personal benefits. Furthermore, Lao preparation for WTO accession requires the active participation of line ministries and agencies because of a greater economic commitment than was required for ASEAN membership. The government should also introduce sophisticated IT systems at border checkpoints to reduce any negative elements, including corruption and unnecessary documentation, fees and procedures during import and export activities.

\subsubsection{Implications for Academics}

This study provides academics with further understanding of the NC of LDCs and raises questions for future researchers. Even though richness in natural resources helps to strengthen the NC of countries (Porter, 1990, 1998; Smith, 1937), few benefits from natural resource sectors have been received by LDCs, which is one of the main reasons they remain poor (Lall, 1999; van Wyk, 2010). Due to a lack of sophisticated factor endowments such as human capital, infrastructures and technology development, LDCs gain less profit from the natural sectors (Lall, 1999; van Wyk, 2010). At the same time, many developed countries, particularly in the Asia-Pacific region, rely on importing raw material from LDCs but pay little attention to investing in other sectors. Thus, further research could focus on how nonnatural resource sectors can increase the NC of LDCs.

Further research should also pay attention to how advanced education enhances the NC of LDCs. The literature found that consumption by sophisticated domestic consumers increases the productivity of industries and also helps to compete with others (Moon, et al., 1995, 1998; Porter, 1990; WB, 2009). Hence, due to differing levels of HRD in LDCs, compared with those of OECD countries and other developing countries, it is worth researching how the human capital development of LDCs affects NC.

In addition, the lower competitiveness of LDCs is caused by a lack of transparency by governments. The findings reveal that the government imposes rules and regulations with regard to imports, exports and FDI activities, rather than focusing on reducing and helping businesses to solve problems. Industries and the private sector require more technical 
assistance and other market information from the government to gain advantages in business. Therefore, more research should establish how to enhance the transparency of LDCs' governments in order to contribute to productivity and NC.

Despite global integration for LDCs being consistent with the economic development policies of governments and the enhancement of $\mathrm{NC}$, it also depends heavily on how productive countries can become. Regional and international economic integration provides opportunities for LDCs to improve rules and regulations and enhance import and export activities among international trade partners, which usually contributes to an increase of knowledge and technology transfer to host countries through FDI. However, more emphasis should be placed on whether the level of commitments has a negative impact on local business. It has been found that excessive policies under international trade agreements have a negative effect on local business (Bhagwati, et al., 1995; Helleiner, 1996); therefore, further research should concentrate on the negative impacts of global integration for LCDs' competitiveness.

\subsubsection{Implications for Entrepreneurs}

Most sectors, apart from hydropower, mining, the garment industry and a few service sectors are relatively uncompetitive. The main implications for entrepreneurs include collaborating with government for effective global integration, improving productivity of their labour force, optimal utilisation of factor endowments and adding value to the resources before exporting them. It is critical for exporting firms to prepare themselves to adapt to new and highly competitive environments in regard to the improvement of quality and the standard of products once the country succeeds in joining the WTO.

\subsubsection{Implications for NGOs}

Consistent support from NGOs is significant for the improvement of Lao NC. Due to the difficulties caused by limited financial support from the government, it is necessary for donors and related agencies to take this issue into account as follows:

Firstly, both technical and physical support can strengthen the level of competitiveness of Laos. In general, the organisations do not only play an important role in Lao social and economic development strategies, but also help to solve the in-depth issues of NC. Therefore, 
there should be more focus on the enhancement of factor endowments during Laos' global integration.

Secondly, assistance from donors should focus on the establishment of an NC body to identity the strengths and weaknesses of both government institutions and the private sector. This would help to accelerate productivity and the sustainable economic development of natural resources, and also help to gain proper benefits from global integration.

Thirdly, the NGOs should continue to identify the problems of Lao business sectors - mainly import and export enterprises - as well as the ability of development projects to increase the capacity of domestic firms in the long term.

Fourthly, even though many projects to increase the NC of Laos have been implemented, only a few projects have helped to identify the problems behind the NC of Laos, particularly when assessing the benefits of the global integration process.

Finally, more emphasis should be placed on building capacity at the local level. Most of the projects are focused on the capacity building of related sectors in the main cities, but less emphasis was placed on rural areas.

\subsection{CONTRIBUTIONS AND LIMITATIONS OF THE STUDY}

The study contributes to the NC literature on three ways:

Firstly, it provides understanding of the NC of LDCs, and specifically Laos. It adds to the current competitiveness literature, which primarily focuses on the NC of high-income countries. Understanding the NC of LDCs is important as their competitiveness factors are not the same as those of developed countries. Thus the study adds to the competitiveness literature by providing an understanding of the NC of LDCs.

Secondly, the findings provide a conceptual model for the NC of Laos, which is examined further in the study. The study finds that it is the interaction of government role, global integration and factor endowments that contributes to NC. An active government role with enhanced global integration is likely to result in improved factor endowments and thus enhanced competitiveness. 
Thirdly, as the area of study in this context is less well-researched, the exploratory findings provide a base for future researchers to be able to test the findings. The exploratory research undertaken provides a more comprehensive understanding by the use of within-case and cross-case analysis of informants from multiple sectors, which could help to provide a better overall picture of the economic environment in Laos. Lastly, this research project is considered a source of reference for further studies in this area.

However, as is usual in any research, the study suffers from some limitations. Firstly, the findings are exploratory in nature and should be quantitatively tested in order to make generalisations. Secondly, a single-country study is not enough to explain the entire NC of LDCs; therefore, further research should focus on a comparison of the different perspectives from different LDCs. Ideally, a multi-country comparison using quantitative techniques is needed for enhanced understanding of the already-explored factors of the NC of LDCs.

\subsection{CONCLUDING REMARKS}

This exploratory study of Lao NC provides a contribution to the understanding of the NC of LDCs in general and the Lao case in particular. As a result, several factors were considered including the improvement of factor endowments, the role of government and global integration. A number of conclusions can now be made regarding the NC of Laos. The current success of Lao economic development, together with implications for policymakers from all four clusters, indicates that an improvement in NC is important for Laos.

However, several challenges still exist. If Laos desires to strengthen its level of NC, Laos should consider the following:

(1) Hydropower and mining projects should be managed and monitored closely by both government agencies and NGOs to enhance proper benefits and reduce any potential risks to the economy and the degradation of the environment in the long term.

(2) HRD should be promoted correctly, with an emphasis on increasing more skilled labour and engineers to serve the needs of industries, which adds more value to products.

(3) More emphasis on economic development should be placed on its potential sectors including agriculture and tourism, which in turn would increase the employment levels of the Lao workforce. 
(4) Infrastructure development requires urgent attention in order to help Laos to be the centre of transport (land-link) in the region; however, it is essential to encourage the improvement of export sectors in order to make a good use of the facilities.

(5) Inconsistent rules and regulations should be adjusted in accordance with regional and international frameworks.

(6) Cooperation between the four clusters should be enhanced in order to update and provide adequate information among the clusters.

(7) Integrity and productivity among public sectors are considered the main source of NC.

(8) Transparency is a significant issue for improving the environment of doing business in Laos. However, improving the quality and standard of Lao products is very challenging at this stage.

The issue of most concern for the Lao economy is the poverty level of the country, meaning the government has great difficulty investing in advanced factors such as S\&T, R\&D and product innovation. In addition, the HDI indicates it is necessary for the government to invest more in public healthcare and higher education throughout the country. Furthermore, the lowest rank of doing business does not attract a productive and quality inflow of FDI. Moreover, the major income of the country is mainly from the natural resource sector and less about value adding, unlike other countries in the region. These factors make the Lao economy fragile and unsustainable, meaning it cannot compete with other countries.

Nevertheless, the Lao government has a strong policy to promote economic growth and reduce poverty to $0 \%$ by 2020 , and the goal is not considered impossible. According to the economic performance figures (see Figure 2), Laos is on the right track for industrialisation to eradicate poverty. In addition, more than 50\% of the GDP growth of Laos relies on the export of natural resources and the country has to retain its strengths and competitiveness in the future based on this factor. The conclusion appears to be that the NC of Laos is vulnerable, and it is difficult to predict whether Laos can maintain its strengths in the future. At the same time, natural resources are the only source that the government uses to sustain competitiveness and drive domestic industry beyond its current stage. However, the study suggests that the active role being taken by the government to develop factor endowments and enhance global integration is also likely to enhance the NC of Laos. 


\section{APPENDICES}

\section{Appendix 1: World Bank List of Economies (April 2012)}

\begin{tabular}{|c|c|}
\hline $\begin{array}{l}\text { High } \\
\text { income } \\
(70)\end{array}$ & $\begin{array}{l}\text { Andorra, Aruba, Bahamas, Bahrain, Barbados, Bermuda, Brunei Darussalam, Cayman Islands, Channel } \\
\text { Islands, Croatia, Curacao, Cyprus, Equatorial Guinea, Faeroe Islands, French Polynesia, Gibraltar, } \\
\text { Greenland, Guam, Hong Kong SAR, China, Isle of Man, Kuwait, Liechtenstein, Macao SAR, China, Malta, } \\
\text { Monaco, New Caledonia, Northern Mariana Islands, Oman, Puerto Rico, Qatar, San Marino, Saudi, Arabia, } \\
\text { Singapore, Sint Maarten (Dutch part), St. Martin (French part), Trinidad and Tobago, Turks and Caicos } \\
\text { Islands, United Arab Emirates, Virgin Islands (U.S.), Australia, Austria, Belgium, Canada, Czech Republic, } \\
\text { Denmark, Estonia, Finland, France, Germany, Greece, Hungary, Iceland, Ireland, Israel, Italy, Japan, Korea, } \\
\text { Rep., Luxembourg, Netherlands, New Zealand, Norway, Poland, Portugal, Slovak Republic, Slovenia, } \\
\text { Spain, Sweden, Switzerland, United Kingdom, United States }\end{array}$ \\
\hline $\begin{array}{l}\text { Upper } \\
\text { middle } \\
\text { income } \\
(54)\end{array}$ & $\begin{array}{l}\text { Albania, Algeria, American Samoa, Antigua and Barbuda, Argentina, Azerbaijan, Belarus, Bosnia and } \\
\text { Herzegovina, Botswana, Brazil, Bulgaria, Chile, China, Colombia, Costa Rica, Cuba, Dominica, Dominican } \\
\text { Republic, Ecuador, Gabon, Grenada, Iran, Islamic Rep., Jamaica, Jordan, Kazakhstan, Latvia, Lebanon, } \\
\text { Libya, Lithuania, Macedonia, FYR, Malaysia, Maldives, Mauritius, Mayotte, Mexico, Montenegro, } \\
\text { Namibia, Palau, Panama, Peru, Romania, Russian Federation, Serbia, Seychelles, South Africa, St. Kitts and } \\
\text { Nevis, St. Lucia, St. Vincent and the Grenadines, Suriname, Thailand, Tunisia, Turkey, Uruguay, } \\
\text { Venezuela, RB }\end{array}$ \\
\hline $\begin{array}{l}\text { Lower } \\
\text { middle } \\
\text { income } \\
(57)\end{array}$ & $\begin{array}{l}\text { Angola, Armenia, Belize, Bhutan, Bolivia, Cameroon, Cape Verde, Congo, Rep., Côte d'Ivoire, Djibouti, } \\
\text { Egypt, Arab Rep., El Salvador, Fiji, Georgia, Ghana, Guatemala, Guyana, Honduras, India, Indonesia, Iraq, } \\
\text { Kiribati, Kosovo, Lao PDR, Lesotho, Marshall Islands, Mauritania, Micronesia, Fed., Sts., Moldova, } \\
\text { Mongolia, Morocco, Nicaragua, Nigeria, Pakistan, Papua New Guinea, Paraguay, Philippines, Samoa, São } \\
\text { Tomé and Principe, Senegal, Solomon Islands, South Sudan, Sri Lanka, Sudan, Swaziland, Syrian Arab } \\
\text { Republic, Timor-Leste, Tonga, Turkmenistan, Tuvalu, Ukraine, Uzbekistan, Vanuatu, Vietnam, West Bank } \\
\text { and Gaza, Yemen, Rep., Zambia }\end{array}$ \\
\hline $\begin{array}{l}\text { Low } \\
\text { income } \\
\text { (35) }\end{array}$ & $\begin{array}{l}\text { Afghanistan, Bangladesh, Benin, Burkina Faso, Burundi, Cambodia, Central African Republic, Chad, } \\
\text { Comoros, Congo, Dem. Rep., Eritrea, Ethiopia, Gambia, The, Guinea, Guinea-Bissau, Haiti, Kenya, Korea, } \\
\text { Dem. Rep., Kyrgyz Republic, Liberia, Madagascar, Malawi, Mali, Mozambique, Myanmar, Nepal, Niger, } \\
\text { Rwanda, Sierra Leone, Somalia, Tajikistan, Tanzania, Togo, Uganda, Zimbabwe }\end{array}$ \\
\hline
\end{tabular}

Source: Adapted from World Bank Website, retrieved 05 May 2012 (www.worldbank.org)

Note: This table classifies all World Bank member economies and all other economies with populations of more than 30,000. For operational and analytical purposes, economies are divided among income groups according to 2010 gross national income (GNI) per capita, calculated using the World Bank Atlas method. The groups are: low income, $\$ 1,005$ or less; lower middle income, $\$ 1,006-3,975$; upper middle income, $\$ 3,976-12,275$; and high income, $\$ 12,276$ or more. Other analytical groups based on geographic regions are also used. 
Appendix 2: LDCs and WTO Membership (52 countries)

\begin{tabular}{|c|c|c|}
\hline Observer countries & Member countries & Non-member countries \\
\hline $\begin{array}{l}\text { Afghanistan, Bhutan, Comoros, } \\
\text { Ethiopia, Lao PDR, Iraq, Liberia, } \\
\text { Sao Tome and Principe, South, } \\
\text { Sudan, Syrian Arab Republic, } \\
\text { Tajikistan, Uzbekistan, Vanuatu, } \\
\text { Yemen, Rep. }\end{array}$ & $\begin{array}{l}\text { Angola, Bangladesh, Benin, Burkina } \\
\text { Faso, Burundi, Cambodia, Central } \\
\text { African Republic, Chad, Congo, } \\
\text { Djibouti, Haiti, Gambia, Guinea, } \\
\text { Guinea-Bissau, Madagascar, } \\
\text { Malawi, Mali, Mauritania, } \\
\text { Mozambique, Myanmar, Nepal, } \\
\text { Niger, Rwanda, Senegal, Sierra } \\
\text { Leone, Solomon Islands, Tanzania, } \\
\text { Togo, Uganda, Zambia }\end{array}$ & $\begin{array}{l}\text { Eritrea, Kenya, Kiribati, North } \\
\text { Korea, Somalia, Timor-Leste, } \\
\text { Tuvalu, Zimbabwe }\end{array}$ \\
\hline
\end{tabular}

Source: Adapted from WTO Website, retrieved 16 May 2012 (www.two.org) 
Appendix 3: Summary of the Literature

\begin{tabular}{|c|c|c|c|}
\hline $\begin{array}{l}\text { Authors/ } \\
\text { year }\end{array}$ & $\begin{array}{l}\text { Sample of } \\
\text { countries }\end{array}$ & Key findings & Summary of empirical literature on NC \\
\hline $\begin{array}{l}\text { Scott \& } \\
\text { Lodge } \\
(1985)\end{array}$ & $\begin{array}{l}\text { The United } \\
\text { States }\end{array}$ & $\begin{array}{l}\text { Strengthening endowment } \\
\text { factors and international } \\
\text { activities enhance NC }\end{array}$ & 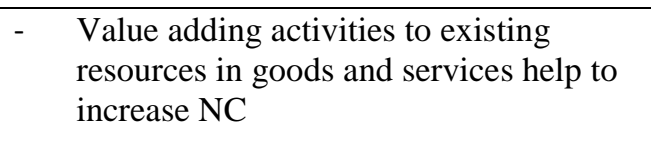 \\
\hline $\begin{array}{l}\text { Porter } \\
(1990)\end{array}$ & $\begin{array}{c}\text { OECD } \\
\text { countries }\end{array}$ & $\begin{array}{l}\text { Improving domestic factors } \\
\text { increase productivity and } \mathrm{NC}\end{array}$ & $\begin{array}{ll}\text { - } & \text { Sophisticated customers lead to better } \\
\text { performance of industries. } \\
\text { - } \\
\text { Government policies affect } \\
\text { competitiveness of industries. } \\
\text { - } \quad \text { Improvement of technology and labour } \\
\text { force skills add to high productivity }\end{array}$ \\
\hline $\begin{array}{l}\text { Grant } \\
(1991)\end{array}$ & $\begin{array}{c}\text { OECD } \\
\text { countries }\end{array}$ & $\begin{array}{l}\text { The role of international trade } \\
\text { and MNEs influence NC }\end{array}$ & $\begin{array}{l}\text { Good governance is an essential element } \\
\text { for domestic industries and international } \\
\text { competitions }\end{array}$ \\
\hline $\begin{array}{l}\text { Cartwright } \\
(1993)\end{array}$ & $\begin{array}{c}\text { New } \\
\text { Zealand }\end{array}$ & $\begin{array}{l}\text { The roles of MNEs are } \\
\text { important for small and open } \\
\text { economies }\end{array}$ & $\begin{array}{l}\text { International competitiveness advantage } \\
\text { of industries in small economies depends } \\
\text { on export-dependent and resource-base }\end{array}$ \\
\hline $\begin{array}{l}\text { Rugman \& } \\
\text { D’ Cruz } \\
\text { (1993) }\end{array}$ & Canada & $\begin{array}{l}\text { Domestic physical factors are } \\
\text { influenced significantly by the } \\
\text { triad MNEs }\end{array}$ & $\begin{array}{l}\text { - } \text { A specific modification of original single } \\
\text { diamond model is needed for countries } \\
\text { with smaller diamond factors to measure } \\
\text { NC } \\
\text { - } \quad \text { International competitiveness shapes a } \\
\text { degree of NC rather than a great deal of } \\
\text { weak home country diamond }\end{array}$ \\
\hline $\begin{array}{l}\text { Dunning } \\
\text { (1993) }\end{array}$ & $\begin{array}{c}\text { OECD } \\
\text { countries }\end{array}$ & $\begin{array}{l}\text { Both domestic and international } \\
\text { factors influence NC }\end{array}$ & $\begin{array}{l}\text { MNEs contribute significantly to the } \\
\text { dynamic grow of the countries' } \\
\text { economies }\end{array}$ \\
\hline $\begin{array}{l}\text { Hodgetts } \\
(1993)\end{array}$ & Mexico & $\begin{array}{l}\text { The competitiveness of Mexican } \\
\text { cluster relies on the regional } \\
\text { agreement (NAFTA) }\end{array}$ & $\begin{array}{ll}\text { - } & \text { Appropriate role of government } \\
\text { improves the determinants of NC } \\
\text { - } \\
\text { Internationalisations help to accelerate } \\
\text { technical change, compress product life } \\
\text { cycles, and increase geographical } \\
\text { concentration of industries }\end{array}$ \\
\hline Cho (1994) & South Korea & $\begin{array}{l}\text { Porter's single diamond model } \\
\text { does not explain dynamic } \\
\text { changes of economies in LDCs } \\
\text { and developing countries. }\end{array}$ & $\begin{array}{l}\text { Four main forces of human factors for } \\
\text { economic growth: entrepreneurs, } \\
\text { professionals, politicians and workers } \\
\text { strengthen diamond factors in the } \\
\text { international competitiveness }\end{array}$ \\
\hline $\begin{array}{l}\text { Rodrik } \\
(1994)\end{array}$ & $\begin{array}{l}\text { South Korea } \\
\text { \& Taiwan }\end{array}$ & $\begin{array}{l}\text { Sophisticated education of } \\
\text { human capital has a significant } \\
\text { effect to a high quality labour } \\
\text { force and always strengthen } \\
\text { productivity }\end{array}$ & $\begin{array}{ll}\text { - } & \text { Effective government intervention is } \\
\text { essential for economic growth. } \\
\text { - } \\
\text { Export oriented lead countries to succeed } \\
\text { globally } \\
\text { - Coordinating and encouraging private } \\
\text { and public investments within modern } \\
\text { sectors lead to economic growth }\end{array}$ \\
\hline $\begin{array}{l}\text { Moon, } \\
\text { Rugman \& } \\
\text { Verbeke } \\
(1998)\end{array}$ & $\begin{array}{l}\text { South Korea } \\
\& \text { Singapore }\end{array}$ & $\begin{array}{l}\text { Globalisation and the role of } \\
\text { multinational activities are very } \\
\text { significant for small economies }\end{array}$ & 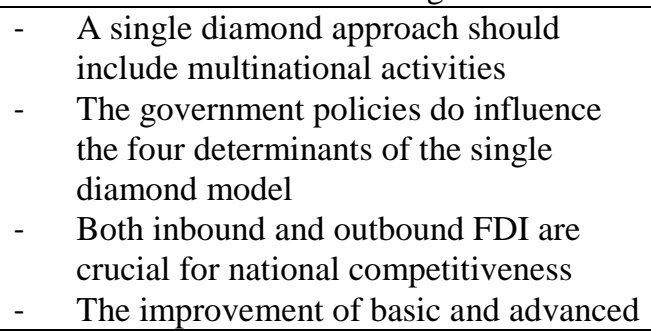 \\
\hline
\end{tabular}




\begin{tabular}{|c|c|c|c|}
\hline & & & factors increases $\mathrm{NC}$ \\
\hline Lall (1999) & $\begin{array}{c}\text { Sub-Saharan } \\
\text { Africa }\end{array}$ & $\begin{array}{l}\text { Because of a lack of sufficient } \\
\text { technological upgrading, rapid } \\
\text { liberalisation leads to massive } \\
\text { destruction of industrial } \\
\text { capacity }\end{array}$ & $\begin{array}{l}\text { - The readiness of technology } \\
\text { development enhances productivity of } \\
\text { industries }\end{array}$ \\
\hline $\begin{array}{l}\text { Jonsson \& } \\
\text { Subramania } \\
\mathrm{n}(2000)\end{array}$ & South Africa & $\begin{array}{l}\text { Trade liberalisation is in } \\
\text { accordance with an increase of } \\
\text { total factor productivity }\end{array}$ & $\begin{array}{l}\text { - Trade liberalisation has a positive impact } \\
\text { on plant-level productivity of } \\
\text { manufacturing sectors }\end{array}$ \\
\hline $\begin{array}{l}\text { Porter, } \\
\text { Takeuchi, \& } \\
\text { Sakakibara } \\
(2000)\end{array}$ & Japan & $\begin{array}{l}\text { Vigorous competitions in } \\
\text { supportive environment and free } \\
\text { government involvement shape } \\
\text { the success of industries } \\
\text { Strengthening factor conditions } \\
\text { and sound government policies } \\
\text { are first priority for success of } \\
\text { industries }\end{array}$ & $\begin{array}{ll}\text { - } & \text { Less intervention of government } \\
\text { industrial policies are considered as } \\
\text { sources of success } \\
\text { - } & \text { Improvement of human capital and R\&D } \\
\text { increases NC } \\
\text { - } \quad \begin{array}{l}\text { Export is a driving force of economic } \\
\text { growth and prosperity } \\
\text { - }\end{array} \\
\text { Management skills are considered as } \\
\text { main force of success } \\
\text { - Integration into the internationalisation } \\
\text { enhance productivity and success }\end{array}$ \\
\hline Lall (2001) & $\begin{array}{c}\text { Developing } \\
\text { countries }\end{array}$ & $\begin{array}{l}\text { Measurement of national } \\
\text { competitiveness index of } \\
\text { developing countries are vague }\end{array}$ & 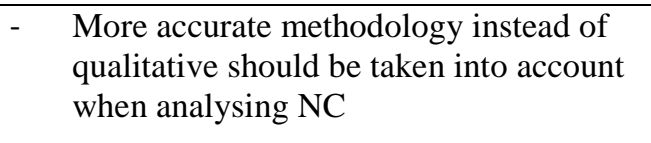 \\
\hline Oz (2002) & Turkey & $\begin{array}{l}\text { Despite Porter's model is } \\
\text { appropriate in developing } \\
\text { countries, domestic rivalry and } \\
\text { the role of government are } \\
\text { inconsistent }\end{array}$ & $\begin{array}{l}\text { The diamond framework does not } \\
\text { comply with competitive advantage of } \\
\text { industries in developing countries } \\
\text { because of low wages and cost of raw } \\
\text { materials }\end{array}$ \\
\hline $\begin{array}{l}\text { Ferreira \& } \\
\text { Rossi } \\
(2003)\end{array}$ & Brazil & $\begin{array}{l}\text { There is a strong relationship } \\
\text { between productivity growth } \\
\text { and trade liberalisation }\end{array}$ & 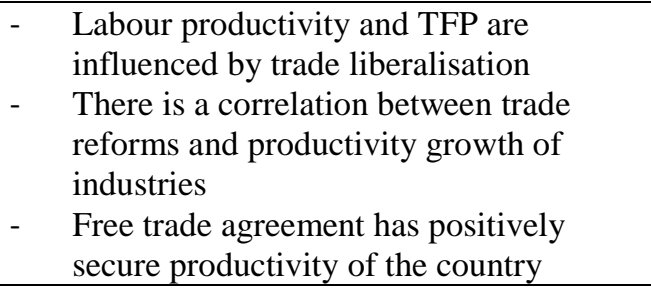 \\
\hline $\begin{array}{l}\text { Winters } \\
(2004)\end{array}$ & $\begin{array}{c}\text { Developing } \\
\text { countries }\end{array}$ & $\begin{array}{l}\text { Trade liberalization increases } \\
\text { economic growth and } \\
\text { productivities }\end{array}$ & $\begin{array}{l}\text { - A benefit of trade liberalisation depends } \\
\text { on the role of productive government } \\
\text { policies and institutions } \\
\text { - Trade liberalisation contributes } \\
\text { positively to an improvement of } \\
\text { economic performance }\end{array}$ \\
\hline $\begin{array}{l}\text { Lin, Hsieh, } \\
\text { Yuok, } \\
\text { Savary, \& } \\
\text { Sum (2004) }\end{array}$ & Cambodia & $\begin{array}{l}\text { Economic performance, } \\
\text { technology development, human } \\
\text { resources and management are } \\
\text { critical for NC }\end{array}$ & $\begin{array}{l}\text { The previous and recent trade, } \\
\text { competitiveness theories and other } \\
\text { studies of NC are based on OECD and } \\
\text { developing countries. } \\
\text { Social stability, upgrading the } \\
\text { workforce, free and fair trade } \\
\text { environment to either foreign or } \\
\text { domestic businesses are needed for } \\
\text { enhancing NC } \\
\text { Low cost of labour, but low skills, } \\
\text { knowledge and technology hinder the }\end{array}$ \\
\hline
\end{tabular}




\begin{tabular}{|c|c|c|c|}
\hline & & & economic growth \\
\hline $\begin{array}{l}\text { Porter } \\
\text { (2005) }\end{array}$ & Vietnam & $\begin{array}{l}\text { Existing endowment factors are } \\
\text { no longer considered as } \\
\text { comparative advantages, but } \\
\text { labour productivity and business } \\
\text { climate development }\end{array}$ & 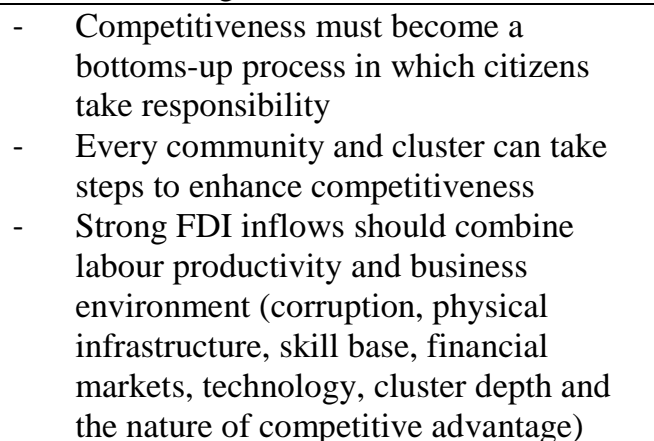 \\
\hline $\mathrm{Wu}(2006)$ & China & $\begin{array}{l}\text { Central government policies } \\
\text { play a very significant role to } \\
\text { enhance NC in the period of } \\
\text { market economies }\end{array}$ & $\begin{array}{l}\text { Internationalisation, efficient supports } \\
\text { from the government and human } \\
\text { resource development help to improve } \\
\text { competitiveness of industries } \\
\text { An improvement of R\&D increases } \\
\text { productivity of Chinese auto industries }\end{array}$ \\
\hline $\begin{array}{l}\text { Moon } \\
\text { (2006) }\end{array}$ & $\begin{array}{l}\text { South Korea } \\
\text { \& Japan }\end{array}$ & $\begin{array}{l}\text { Culture differences reinforce } \\
\text { NC structures }\end{array}$ & $\begin{array}{l}\text { Both physical and human factors in both } \\
\text { domestic and international contexts are } \\
\text { significant for NC }\end{array}$ \\
\hline $\begin{array}{l}\text { Snowdon \& } \\
\text { Stonehouse } \\
\text { (2006) }\end{array}$ & $\begin{array}{l}\text { The United } \\
\text { State of } \\
\text { America }\end{array}$ & $\begin{array}{l}\text { Microeconomic foundation is } \\
\text { the key issue of global } \\
\text { competitiveness }\end{array}$ & $\begin{array}{l}\text { Macroeconomic stability, sound politics } \\
\text { and legal institutions influence } \\
\text { productivity } \\
\text { - Geography is a significant issue which } \\
\text { contributes to the success of the firms } \\
\text { - Economic development levels affect } \\
\text { innovation of the firms. } \\
\text { There is a link between national culture } \\
\text { and economic performance of nations }\end{array}$ \\
\hline $\begin{array}{l}\text { Kao et al. } \\
\text { (2008) }\end{array}$ & $\begin{array}{l}\text { Southeast } \\
\text { Asian } \\
\text { countries }\end{array}$ & $\begin{array}{l}\text { There is a huge different } \\
\text { economic performance of the } \\
\text { countries within the region }\end{array}$ & $\begin{array}{l}\text { Improvement of technology and R\&D } \\
\text { increase productivity among Southeast } \\
\text { Asian countries }\end{array}$ \\
\hline $\begin{array}{l}\text { Cho, Moon, } \\
\& \text { Kim } \\
(2009)\end{array}$ & South Korea & $\begin{array}{l}\text { The DDD model is more } \\
\text { comprehensive than the GDD } \\
\text { and NF models, particularly } \\
\text { when assess country specific } \\
\text { advantages (CSAs) of countries } \\
\text { with high international } \\
\text { connectivity and high human- } \\
\text { factor dependency }\end{array}$ & $\begin{array}{l}\text { Domestic physical and human factors are } \\
\text { the most significant for national } \\
\text { competitiveness. } \\
\text { - Different statuses of countries need } \\
\text { different models to measure national } \\
\text { competitiveness than existing models. } \\
\text { - DDD approach provides a } \\
\text { comprehensive analysis of national } \\
\text { competitiveness for MNCs. }\end{array}$ \\
\hline $\begin{array}{l}\text { van Wyk } \\
(2010)\end{array}$ & Botswana & $\begin{array}{l}\text { Economic diversification is } \\
\text { important for long term stability } \\
\text { and growth }\end{array}$ & $\begin{array}{l}\text { Economies solely based on natural } \\
\text { resources are not considered as } \\
\text { sustainable economic development, but } \\
\text { more diversification on manufacturing } \\
\text { and financial market. }\end{array}$ \\
\hline $\begin{array}{l}\text { Khandelwal } \\
\text { \& Topalova } \\
\text { (2011) }\end{array}$ & India & $\begin{array}{l}\text { Lower import-tariffs in trade } \\
\text { liberalisation to increase firms' } \\
\text { productivity level }\end{array}$ & $\begin{array}{l}\text { Increasing trade liberalisation and reduce } \\
\text { input-tariffs reforms are correlated with } \\
\text { higher productivity of the firms. }\end{array}$ \\
\hline
\end{tabular}


Appendix 4: Status of the WTO Accession for Laos

\begin{tabular}{|c|c|c|}
\hline 1. & Application Received & 16 July 1997 \\
\hline 2. & $\begin{array}{l}\text { Working Party Established } \\
\text { Chairperson: H.E. Yi Xiaozhun (China, Jul } 2011 \text { - ) } \\
\text { Dr. Zhang Xiangchen (China, May 2009 — Jul 2011) } \\
\text { H.E. Bruce Gosper (Australia, Jul } 2006 \text { - May 2009) } \\
\text { Mr. T. Groser (N. Zealand, May } 2004 \text { — Jul 2006) } \\
\text { Mr. G. Raby (Australia, Apr } 1998 \text { - May 2004) }\end{array}$ & 19 February 1998 \\
\hline 3. & Memorandum & 28 March 2001 \\
\hline 4. & Questions and Replies & 2 October 2003 \\
\hline 5. & Meetings of the Working Party & $\begin{array}{l}28 \text { October 2004; } 30 \text { November 2006; } 15 \\
\text { November 2007; } 4 \text { July 2008; } 14 \text { July } \\
\text { 2009; } 24 \text { September 2010; } 29 \text { June 2011; } \\
16 \text { March } 2012\end{array}$ \\
\hline \multirow[t]{7}{*}{6.} & Other Documentation & \\
\hline & (a) Additional Questions \& Replies & 24 January 2012 \\
\hline & (b) Information on agriculture (WT/ACC/4) & 6 May 2008 \\
\hline & (c) Information on services (WT/ACC/5) & \\
\hline & (d) SPS/TBT checklists (WT/ACC/8) & 23 January 2012 \\
\hline & (e) TRIPS checklist (WT/ACC/9) & 23 January 2012 \\
\hline & (f) Legislative Action Plan & $\begin{array}{l}23 \text { January } 2012 \text { (General) } \\
23 \text { January } 2012 \text { (Customs Valuation) } \\
\text { 23 January } 2012 \text { (SPS) } \\
\text { 23 January } 2012 \text { (TBT) } \\
23 \text { January } 2012 \text { (TRIPS) }\end{array}$ \\
\hline \multirow[t]{3}{*}{7.} & Market Access Negotiations & \\
\hline & $\begin{array}{ll}\text { Goods Offer } & \text { (a) initial } \\
& \text { (b) latest }\end{array}$ & $\begin{array}{l}3 \text { November } 2006 \\
10 \text { August } 2010\end{array}$ \\
\hline & $\begin{array}{ll}\text { Services Offer } & \text { (a) initial } \\
& \text { (b) latest }\end{array}$ & $\begin{array}{l}16 \text { October } 2007 \\
27 \text { July } 2010\end{array}$ \\
\hline 8. & Factual Summary (revision) & $\begin{array}{l}29 \text { October } 2007 \\
3 \text { June } 2009\end{array}$ \\
\hline 9. & Draft Working Party Report (latest revision) & $\begin{array}{l}27 \text { August } 2010 \\
16 \text { February } 2012\end{array}$ \\
\hline
\end{tabular}

Source: Adapted from WTO Website, retrieved 10 May 2012 (www.wto.org) 


\section{Interview Guide}

\section{How Can National Competitiveness of Less Developed Countries be Enhanced? :} A Case Study of Laos

\section{General information about the respondent:}

- Job Title:

- Organisation:

- Experience with the Organisation:

- A brief overview of the organisation including age, size, and relative standing

\section{Lao's competitiveness factors}

- What are the key factors that determine Lao national competitiveness (Enhancing productivity, growth, foreign direct investment)?

- Discussion follows on each of the identified factors

- Why has Laos not developed as fast as other ASEAN countries?

\section{Regionalization and Lao's National Competitiveness}

- Has Laos competitiveness increased by joining ASEAN? Why do you think so?

- What benefits has Laos realised by joining ASEAN?

- What challenges have Laos faced in ASEAN context?

\section{Globalisation and Lao's National Competitiveness}

- What can Laos learn from ASEAN experience while embracing globalisation (i.e. joining the WTO)?

○ Do you see any additional benefits of joining the WTO? What are those benefits?

- What challenges do you see Laos may face in a globalised environment?

\section{Concluding Remarks}

- If you are given the power and control to enhance Lao competitiveness, what three things will you do? Why?

- Are there any additional thoughts that you would like to share on Lao's competitiveness?

- Can you recommend anyone I can talk to about the competitiveness of Laos? 
Appendix 6

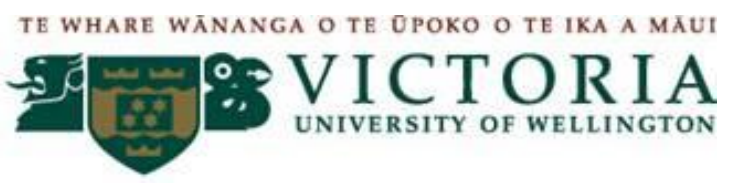

Research Information Sheet

\section{How Can National Competitiveness of Less Developed Countries be Enhanced? : A Case Study of Laos}

My name is Phoxai Inthaboualy and I am a Master's student at Victoria University of Wellington, New Zealand. I would like to invite you to participate in an interview (approximately 30 minutes) for my research project.

This study aims to explore and assess the determinants of national competitiveness of Laos. It investigates the changes in national competitiveness of Laos during its globalisation journey. Most of the literature to date relates to industrialised developed countries and competitiveness of LDCs is less understood. This study aims to fill this gap in research.

Your participation will add significant value to this research particularly for Laos and other LDCs on competitiveness. The benefits of this project are primarily academic, but may have both policy and practical implications. The study is expected to contribute to academic literature on competitiveness of LDCs and provide policy guidelines to the Lao government for enhancing its competitiveness.

Following strict procedures, for research involving human subjects at Victoria University of Wellington, this research has been assessed and approved by the Human Ethics Committee. The participants' confidentiality is assured throughout the research process. Neither your name nor your organization will be identifiable to people other than the researcher. The data will only be used for the purposes of the master's thesis and other possible academic publications.

If you agree to participate in this study, please reply via e-mail with a signed copy of the consent form which you will find attached. The researcher will contact you by phone or e-mail and arrange a time convenient to you to conduct the interview.

Thank you for your time and assistance in making this research possible. If you are interested in the findings of this research, you can contact me or my supervisor (by phone or e-mail) and request a copy of the thesis by the end of June 2012. For further information about this research, please do not hesitate to contact me or my supervisor.

Kind regards,

Phoxai Inthaboualy (inthabphox@myvuw.ac.nz),

Masters Student, School of Marketing and International Business, Victoria University of Wellington, New Zealand, Mobile phone: +64 22 6474229; Home: +64 043829698

Dr. Revti Raman (revti.raman@vuw.ac.nz)

Lecturer in International Business, School of Marketing and International Business, Victoria University of Wellington, New Zealand, Telephone: +64 04 463-7452 
Appendix 7

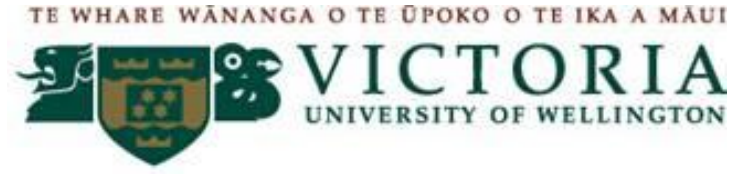

\section{Consent Form}

This consent form outlines the rights I have as a participant in the research entitled 'How Can National Competitiveness of Less Developed Countries be Enhanced? : A Case Study of Laos' conducted by Phoxai Inthaboualy, (Masters Student, School of Marketing and International Business, Faculty of Commerce and Administration, Victoria University of Wellington, New Zealand).

This interview will take approximately 30 minutes, and I understand that:

- I have been provided with adequate information relating to the nature and objectives of this research project.

- I have understood this information and have been given the opportunity to seek further clarification or explanations.

- I understand that I will be participating in an audio-recorded interview.

- I understand I may withdraw from the project at any time during the interview, or within two weeks of the interview taking place, without providing a reason; and all related data will be destroyed.

- I understand that the researcher, supervisors and the transcribers will have access to the audio recordings.

- I understand that any information or opinions I provide will be kept confidential and reported only in an aggregated/non-attributable form.

- I understand that the results may be published in academic journals, and/or conference papers but my name will have been changed, and no identifiable information that is traceable to me will be included.

- I understand the information will be used only for the purpose indicated, and any other use would require my written consent.

- I understand that when this research is completed the raw data obtained will be destroyed after two years.

Name of interviewee:

Signature of interviewee:

Date:

Please tick the box if you would like a written summary of the results at the end of the project, and provide your contact details below.

$$
\square \text { Yes }
$$

Postal address: 


\section{REFERENCES}

ADB. (2008). Lao People's Democratic Republic: Preparing the strengthening higher education project. Vientiane: Asian Development Bank.

ADB. (2009). Country report on the impact of the global economic slowndown on poverty and sustainable development in Lao PDR. Vientiane.

Ades, A., \& Di Tella, R. (1997). National champions and corruption: some unpleasant interventionist arithmetic. The Economic Journal, 107(443), 1023-1042.

Ades, A., \& Di Tella, R. (1999). Rents, competition, and corruption. The American Economic Review, 89(4), 982-993.

Andersson, M., Engvall, A., \& Kokko, A. (2007). Regional development in Lao PDR: Growth patterns and market integration. EIJS Working Paper Series.

Andersson, M., Engvall, A., \& Kokko, A. (2009). In the shadow of China: Trade and growth in Lao PDR. Working Paper Series.

Arbache, J. S., Dickerson, A., \& Green, F. (2004). Trade liberalisation and wages in developing countries. The Economic Journal, 114(493), 73-96.

ASEAN. (2009). ASEAN economic community blueprint. Jakarta: The ASEAN Secretariat.

Awuah, G. B., \& Amal, M. (2011). Impact of globalization: The ability of less developed countries'(LDCs') firms to cope with opportunities and challenges. European Business Review, 23(1), 120-132.

Barro, R. J. (1991). Economic growth in a cross section of countries. The Quarterly Journal of Economics, 106(2), 407-443.

Berger, T., \& Bristow, G. (2009). Competitiveness and the benchmarking of nations-A critical reflection. International Advances in Economic Research, 15(4), 378-392.

Bhagwati, J., \& Srinivasan, T. (1999). Outward-orientation and development: are revisionists right? Yale University Economic Growth Center Discussion Paper, 806.

Bhagwati, J. N., Krueger, A. O., \& Ebrary, I. (1995). The dangerous drift to preferential trade agreements: AEI Press.

Bird, K., \& Hill, H. (2010). Tiny, poor, land-locked, indebted, but growing: lessons for late reforming transition economies from Laos. Oxford Development Studies, 38(2), 117-143.

Bolaky, B., \& Freund, C. (2005). Trade, regulations, and growth. World.

Boltho, A. (1996). The assessment: international competitiveness. Oxford review of economic policy, 12(3), 1.

Bouma, G. D., Ling, R., \& Wilkinson, L. (1993). The research process: Oxford University Press Oxford.

Bourdet, Y. (2000). The economics of transition in Laos: From socialism to ASEAN integration: Edward Elgar Publishing.

Boyatzis, R. E. (1998). Transforming qualitative information: Thematic analysis and code development: Sage Publications, Inc.

Brahmbhatt, M., Canuto, O., \& Vostroknutova, E. (2010). Dealing with Dutch disease. World BankEconomic Premise(16), 1-7.

Brenton, P. (2003). Integrating the least developed countries into the world trading system: The current impact of European Union preferences under" Everything But Arms". Journal of World Trade, 37(3), 623-646.

Cantwell, J. (2005). Innovation and competitiveness (pp. 543-567): Oxford University Press, Oxford.

Cartwright, W. R. (1993). Multiple linked" diamonds" and the international competitiveness of export-dependent industries: the New Zealand experience. MIR: Management International Review, 55-70.

Cassell, C., \& Symon, G. (2004). Essential guide to qualitative methods in organizational research: Sage Publications Ltd. 
Chea, S., \& Sok, H. (2005). Cambodia's accession to the WTO:'Fast track'accession by a least developed country. Managing the Challenges of WTO Participation, 45, 120-134.

Chetty, S. (1996). The case study method for research in small-and medium-sized firms. International small business journal, 15(1), 73.

Cho, D. S. (1994). A dynamic approach to international competitiveness: The case of Korea. Asia Pacific Business Review, 1(1), 17-36.

Cho, D. S. (1998). From national competitiveness to bloc and global competitiveness. Competitiveness Review: An International Business Journal incorporating Journal of Global Competitiveness, 8(1), 11-23.

Cho, D. S., \& Moon, H. C. (2005). National competitiveness: Implications for different groups and strategies. Framework, 1(1), 1-11.

Cho, D. S., Moon, H. C., \& Kim, M. Y. (2009). Does one size fit all? A dual double diamond approach to country-specific advantages. Asian Business \& Management, 8(1), 83-102.

Cho, T., \& Moon, H. C. (2000). From Adam Smith to Michael Porter: evolution of competitiveness theory: World Scientific Pub Co Inc.

Clark, J., \& Guy, K. (1998). Innovation and competitiveness: A review. Technology Analysis \& Strategic Management, 10(3), 363-395.

Collis, J., \& Hussey, R. (2009). Business research: A practical guide for undergraduate and postgraduate students: Palgrave Macmillan.

Crafts, N. (2004). Globalisation and economic growth: a historical perspective. The World Economy, 27(1), 45-58.

Davis, D. R. (1996). Trade liberalization and income distribution: National Bureau of Economic Research Cambridge, Mass., USA.

Dawes, R. M. (1971). A case study of graduate admissions: Application of three principles of human decision making. American Psychologist, 26(2), 180.

Denscombe, M. (2007). The good research guide: for small-scale social research projects: Open University Press.

Dollar, D. (1992). Outward-oriented developing economies really do grow more rapidly: evidence from 95 LDCs, 1976-1985. Economic development and cultural change, 40(3), 523-544.

Dollar, D., \& Kraay, A. (2004). Trade, Growth, and Poverty*. The Economic Journal, 114(493), F22F49.

Dunning, J. H. (1992). The competitive advantage of countries and the activities of transnational corporations. Transnational Corporations, 1(1), 135-168.

Dunning, J. H. (1993). Internationalizing Porter's diamond. MIR: Management International Review, 7-15.

Dunning, J. H., \& Narula, R. (2004). Multinationals and industrial competitiveness: A new agenda: Edward Elgar Publishing.

Dzeng, R. J., \& Wang, S. S. (2008). An analysis of infrastructure development based on national competitiveness perspectives. Construction Management and Economics, 26(1), 47-61.

Easterly, W. (2001). The elusive quest for growth. Economists' Adventures and.

Easterly, W. (2005). National policies and economic growth: a reappraisal. Handbook of Economic Growth, 1, 1015-1059.

Edwards, S. (1992). Trade orientation, distortions and growth in developing countries* 1 . Journal of Development Economics, 39(1), 31-57.

Edwards, S. (1993). Openness, trade liberalization, and growth in developing countries. Journal of Economic Literature, 31(3), 1358-1393.

Edwards, S. (1998). Growth: What do we really know. Economic Journal, 108(3), 383-398.

Edwards, S. (1998). Openness, productivity and growth: what do we really know? The Economic Journal, 108(447), 383-398.

Eisenhardt, K. M. (1989). Building theories from case study research. Academy of management review, 532-550. 
Evenett, S., \& Braga, C. (2005). WTO accession: lessons from experience. World Bank Trade Note, 22.

Fane, G. (2006). Trade liberalization, economic reform and poverty reduction in Lao PDR. Journal of the Asia Pacific Economy, 11(2), 213-226.

Farra, F., Burgio, C., \& Cernov, M. (2011). The competitiveness potential of central Asia: OECD.

Feinberg, R., \& Weymouth, S. (2011). National competitiveness in comparative perspective: Evidence from Latin America.

Fereday, J., \& Muir-Cochrane, E. (2006). Demonstrating rigor using thematic analysis: A hybrid approach of inductive and deductive coding and theme development. International Journal of Qualitative Methods, 5(1), 1-11.

Ferreira, P. C., \& Rossi, J. L. (2003). New evidence from Brazil on trade liberalization and productivity growth. International Economic Review, 44(4), 1383-1405.

Fischer, S. (2000). Lunch address given at the conference on promoting dialogue: Global challenges and global institutions. American University, Washington, $D C$.

Foster, N. (2008). The impact of trade liberalisation on economic growth: Evidence from a quantile regression analysis. Kyklos, 61(4), 543-567.

Frankel, J. A., \& Romer, D. (1999). Does trade cause growth? The American Economic Review, 89(3), 379-399.

Garelli, S. (2003). Competitiveness of nations: the fundamentals. South Korea: International Institute for Management and Development.

Ghauri, P., \& Gronhaug, K. (2002). Research methods in business studies, essex: Pearson Education Limited.

Ghemawat, P. (2001). Distance still matters. Harvard Business Review, 79(8), 137-147.

Giedre Staskeviciute, R. T. (2010). The evaluation of the national competitiveness: analysis of existing means. Business and Management. doi:10.3846/bm.2010.066

Grant, R. M. (1991). Porter's 'Competitive advantage of nations': an assessment. Strategic management journal, 12(7), 535-548.

Greenaway, D. (1998). Does trade liberalisation promote economic development? Scottish Journal of Political Economy, 45(5), 491-511.

Greenaway, D., Leybourne, S., \& Sapsford, D. (1997). Modeling growth (and liberalization) using smooth transitions analysis. Economic Inquiry, 35(4), 798-814.

Greenaway, D., Morgan, W., \& Wright, P. (2002). Trade liberalisation and growth in developing countries. Journal of Development Economics, 67(1), 229-244.

Greenaway, D., \& Sapsford, D. (1994). What does liberalisation do for exports and growth? Review of World Economics, 130(1), 152-174.

Gugler, P., \& Brunner, S. (2007). FDI effects on national competitiveness: A cluster approach. International Advances in Economic Research, 13(3), 268-284.

Hämäläinen, T. J. (2003). National competitiveness and economic growth: The changing determinants of economic performance in the world economy: Edward Elgar Publishing.

Hanson, G. H., \& Harrison, A. (1999). Trade liberalization and wage inequality in Mexico. Industrial and Labor Relations Review, 52(2), 271-288.

Harrison, A. (1996). Openness and growth: A time-series, cross-country analysis for developing countries. Journal of Development Economics, 48(2), 419-447.

Hay, D. A. (2001). The Post 1990 Brazilian trade liberalisation and the performance of large manufacturing firms: Productivity, market share and profits. The Economic Journal, 111(473), 620-641.

Helleiner, G. K. (1996). Why small countries worry: neglected issues in current analyses of the benefits and costs for small countries of integrating with large ones. The World Economy, 19(6), 759-764.

Heo, Y., \& Doanh, N. K. (2009). Trade liberalisation and poverty reduction in Vietnam. The World Economy, 32(6), 934-964. 
Hodgetts, R. M. (1993). Porter's diamond framework in a Mexican context. MIR: Management International Review, 33, 41-54.

Hon, L. (1998). Demonstrating effectiveness in public relations: Goals, objectives, and evaluation. Journal of Public Relations Research, 10(2), 103-135.

Hsiao, C., \& Shen, Y. (2003). Foreign direct investment and economic growth: the importance of institutions and urbanization. Economic development and cultural change, 883-896.

Hsiao, F. S. T., \& Hsiao, M. C. W. (2006). FDI, exports, and GDP in East and Southeast Asia--Panel data versus time-series causality analyses. Journal of Asian Economics, 17(6), 1082-1106.

IMF. (2011). Lao People's Democratic Republic-staff report; stuff supplement; public information notice on the executive board discussion; and statement by the executive director of Lao P.D.R. Washington: International Monetary Fund.

Jin, B., \& Moon, H. C. (2006). The diamond approach to the competitiveness of Korea's apparel industry: Michael Porter and beyond. Journal of Fashion Marketing and Management, 10(2), 195-208.

Jonsson, G., \& Subramanian, A. (2000). Dynamic gains from trade: Evidence from South Africa: International Monetary Fund.

Jönsson, K. (2000). Policymaking in transitional economies: poverty reduction and health care in Cambodia and Laos. Health and social protection: experiences from Cambodia, China and Lao PDR.

Kao, C., Wu, W. Y., Hsieh, W. J., Wang, T. Y., Lin, C., \& Chen, L. H. (2008). Measuring the national competitiveness of Southeast Asian countries. European Journal of Operational Research, 187(2), 613-628.

Kawai, H. (1994). International comparative analysis of economic growth: trade liberalization and productivity. The Developing Economies, 32(4), 373-397.

Khandelwal, A., \& Topalova, P. (2011). Trade liberalization and firm productivity: The case of india.

Kim, E. (2000). Trade liberalization and productivity growth in Korean manufacturing industries: price protection, market power, and scale efficiency. Journal of Development Economics, 62(1), 55-83.

Kneller, R., Morgan, C. W., \& Kanchanahatakij, S. (2008). Trade liberalisation and economic growth. The World Economy, 31(6), 701-719.

Kneller, R., \& Pisu, M. (2007). Industrial linkages and export spillovers from FDI. The World Economy, 30(1), 105-134.

Krueger, A. (1998). Why trade liberalisation is good for growth. The Economic Journal, 108(450), 1513-1522.

Krueger, A. O. (1997). Trade policy and economic development: how we learn: National Bureau of Economic Research Cambridge, Mass., USA.

Krugman, P. (1994). Competitiveness: a dangerous obsession. Foreign affairs, 73(2), 28-44.

Krugman, P. (1997). Pop internationalism: the MIT press.

$\mathrm{Ku}, \mathrm{S}$. C. Y. (2002). The political economy of regime transformation: Taiwan and Southeast Asia. World Affairs, 165(2), 59-78.

Lall, S. (1999). The technological response to import liberalisation in SubSharan Africa: Macmillan.

Lall, S. (2001). Competitiveness indices and developing countries: an economic evaluation of the Global Competitiveness Report. World Development, 29(9), 1501-1525.

Lee, C. (2008). An Institutional Perspective of National Competitiveness. The Singapore Economic Review, May.

Lee, J. W. (1993). International trade, distortions, and long-run economic growth. Staff PapersInternational Monetary Fund, 40(2), 299-328.

Lee, J. W. (1996). Government interventions and productivity growth. Journal of Economic Growth, 1(3), 391-414. 
Lee, J. W. (2010). Foreign direct investment, exchange rate, and their roles in economic growth of developing countries: Empirical evidence from Kazakhstan. Journal of International Business Research, 9(2).

Levine, R., \& Renelt, D. (1992). A sensitivity analysis of cross-country growth regressions. The American Economic Review, 82(4), 942-963.

Lewis, D. (2008). Integration of landlocked countries into the global economy and domestic economic reforms: The case of Lao People's Democratic Republic. Working Papers.

Lin, C., Hsieh, H., Yuok, N., Savary, C., \& Sum, V. (2004). Evaluating the competitiveness of leastdeveloped countries - the example of Cambodia. Asia Pacific Management Review, 9(2), 205-227.

Liu, D. Y., \& Hsu, H. F. (2009). An international comparison of empirical generalized double diamond model approaches to Taiwan and Korea. Competitiveness Review: An International Business Journal incorporating Journal of Global Competitiveness, 19(3), 160-174.

Liu, X., \& Song, H. (1997). China and the multinationals--A winning combination. Long Range Planning, 30(1), 74-83.

Luo, Y. (2001). Determinants of entry in an emerging economy: a multilevel approach. Journal of management Studies, 38(3), 443-472.

Maanen, J. V. (1983). Qualitative methodolody. Beverly Hills: Sage Publications.

Mbekeani, K. (2007). The Role of Infrastructure in Determining Export Competitiveness: Framework Paper. AERC Research Project on Export Supply Response Capacity Constraints in Africa, Paper No. ESWP_05. Available at http://www. aercafrica. org/documents/export_supply_working_papers/KMbekeanilnfrastr8DB3B. pdf.

McCulloch, N., Winters, L. A., \& Cirera, X. (2001). Trade liberalization and poverty: A handbook: Centre for Economic Policy Research.

Melitz, M. J., \& Ottaviano, G. I. P. (2008). Market size, trade, and productivity. Review of Economic studies, 75(1), 295-316.

Menon, J. (1999). Transitional economies in free trade areas: Lao PDR in the ASEAN free trade area. Journal of the Asia Pacific Economy, 4(2), 340-364.

Menon, J. (2008). Dealing with multiple currencies: What options for the transitional economies of Southeast Asia? Journal of the Asia Pacific Economy, 13(92), 131-146.

Michael, P. (1990). The competitive advantage of nations. Harvard Business Review, 90(2), 73-93.

Michalopoulos, C. (2001). Developing countries in the WTO: Palgrave Macmillan.

Miles, M., \& Huberman, A. (1994). Qualitative data analysis: An expanded sourcebook: SAGE publications, Inc.

Miles, M. B., \& Huberman, A. M. n. e. (1994). Qualitative data analysis: An expanded sourcebook. 1994. Beverly Hills: Sage Publications.

Milner, C., \& Wright, P. (1998). Modelling labour market adjustment to trade liberalisation in an industrialising economy. Economic Journal, 509-528.

MOIC. (2012). Import and export statistic by countries. Retrieved 30th March 2012, from http://www.moic.gov.la/statistic.asp

Moon, Rugman, A. M., \& Verbeke, A. (1995). The generalized double diamond approach to international competitiveness.

Moon, Rugman, A. M., \& Verbeke, A. (1998). A generalized double diamond approach to the global competitiveness of Korea and Singapore. International Business Review, 7(2), 135-150.

Moon, H. C. (2006). Competition and Cooperation between Korea and Japan: A Business perspective.

Moon, H. C., Rugman, A. M., \& Verbeke, A. (1995). The generalized double diamond approach to international competitiveness.

MOPI. (2012). Public and foreign investment statistic of Laos. Retrieved 25th May 2012, from http://www.nsc.gov.la/index2.php?option=com content\&view=article\&id=34\&ltemid=35

Myint, H. (1977). Adam Smith's theory of international trade in the perspective of economic development. Economica, 44(175), 231-248. 
Narula, R. (1993). Technology, international business and Porter's "diamond": Synthesizing a dynamic competitive development model. MIR: Management International Review, 33, 85107.

North, D. C. (1990). A transaction cost theory of politics. Journal of Theoretical Politics, 2(4), 355.

NSEDP. (2010). Executive Summary of the Seventh National Social and Ecnomic Development Plan 2011-2015. Vientiane.

OECD. (1998). Open markets matter: The benefits of trade and investment liberalisation. Paris.

Ohlin, B. G. (1933). Interregional and international trade (Vol. 39): Harvard University Press.

Onphanhdala, P., \& Suruga, T. (2007). Education and earnings in Lao PDR: Further results.

Oyejide, T. (1990). The participation of developing countries in the Uruguay Round: An African perspective. World Economy, 13(3), 427-444.

Oz, O. (2002). Assessing Porter's framework for national advantage: the case of Turkey. Journal of Business Research, 55(6), 509-515.

Panagariya, A. (2005). Agricultural liberalisation and the least developed countries: six fallacies. The World Economy, 28(9), 1277-1299.

Patton, M. Q. (2002). Qualitative research and evaluation methods: Sage Publications, Inc.

Pauly, L. (1999). Good governance and bad policy: the perils of international organizational overextension. Review of International Political Economy, 6(4), 401-424.

Peng, G. C., \& Nunes, M. (2009). Using PEST analysis as a tool for refining and focusing contexts for information systems research.

Perkins, D. H., Radelet, S., \& Lindauer, D. L. (2006). Economics of development: Norton New York.

Phouphet, K. (2009). Evaluation of macroeconomic policy in Laos. Economic Research.

Porter. (1980). Competitive strategy: techniques for analyzing industries and competitors: with a new introduction. New York: Free Press.

Porter. (1990). The competitive advantage of nations: Macmillan.

Porter. (1998). Competitive advantage: creating and sustaining superior performance: with a new introduction: Free Pr.

Porter, M. E., Takeuchi, H., \& Sakakibara, M. (2000). Can Japan compete? : Basic Books.

Pritchett, L. (1996). Measuring outward orientation in LDCs: Can it be done? Journal of Development Economics, 49(2), 307-335.

Qi, L. (2007). The relationship between growth, total investment and inward FDI: evidence from time series data. International Review of Applied Economics, 21(1), 119-133.

Rigg, J. (2005). Living with transition in Laos: Market integration in Southeast Asia (Vol. 5): Psychology Press.

Rodriguez, F., \& Rodrik, D. (2001). Trade policy and economic growth: a skeptic's guide to the crossnational evidence: MIT PRess.

Rodrik, D. (1994). Getting interventions right: how South Korea and Taiwan grew rich: National Bureau of Economic Research Cambridge, Mass., USA.

Rodrik, D. (1997). Trade strategy, investment and exports: another look at East Asia. Pacific Economic Review, 2(1), 1-24.

Romer, P. (1994). New goods, old theory, and the welfare costs of trade restrictions. Journal of Development Economics, 43(1), 5-38.

Rose, A. (2004). Do we really know that the WTO increases trade? American Economic Review, 94(1), 98-114.

Rosser, A. (2006). Lao People's Democratic Republic. IDS Bulletin, 37(2), 27-39.

Rugman, A. M., \& D'Cruz, J. R. (1993). The" double diamond" model of international competitiveness: The Canadian experience. MIR: Management International Review, 17-39.

Rugman, A. M., \& Verbeke, A. (1990). Global corporate strategy and trade policy: Psychology Press.

Rugman, A. M., \& Verbeke, A. (1993). Foreign subsidiaries and multinational strategic management: an extension and correction of Porter's single diamond framework. MIR: Management International Review, 33, 71-84. 
Sachs, J. D., \& Warner, A. (1995). Economic convergence and economic policies: National Bureau of Economic Research Cambridge, Mass., USA.

Santos Paulino, A., \& Thirlwall, A. P. (2004). The impact of trade liberalisation on exports, imports and the balance of payments of developing countries. The Economic Journal, 114(493), F50F72.

Sauvé, P. (2005). Economic impact and social adjustment costs of accession to the World Trade Organisation: Cambodia and Nepal. Asia-Pacific Trade and Investment Review, 1(1), 27-49.

Scott, B. R., \& Lodge, G. C. (1985). US competitiveness in the world economy. The International Executive, 27(1), 26-26.

Scott, J., \& Wilkinson, R. (2011). The poverty of the Doha Round and the least developed countries. Third World Quarterly, 32(4).

Sekaran, U. (1992). Research methods for business: A skill building approach: Taylor \& Francis.

SGreenaway, D. (1998). Does trade liberalisation promote economic development? Scottish Journal of Political Economy, 45(5), 491-511.

Silverman, D. (2009). Doing qualitative research: Sage Publications Ltd.

Smith, A. (1937). An inquiry into the nature and causes of the wealth of nations,(1776): Methuen.

Snowdon, B., \& Stonehouse, G. (2006). Competitiveness in a globalised world: Michael Porter on the microeconomic foundations of the competitiveness of nations, regions, and firms. Journal of International Business Studies, 37(2), 163-175.

Sokoloff, K. L., \& Engerman, S. L. (2000). History lessons: Institutions, factors endowments, and paths of development in the new world. The Journal of Economic Perspectives, 14(3), 217-232.

Stiglitz, J. E. (1998). Towards a new paradigm for development: strategies, policies, and processes. UNCTAD.

Stokey, N. L. (1991). The volume and composition of trade between rich and poor countries. The Review of Economic Studies, 58(1), 63-80.

Symon, G. E., \& Cassell, C. E. (1998). Qualitative methods and analysis in organizational research: A practical guide: Sage Publications Ltd.

Thompson, E. R. (2004). National competitiveness: a question of cost conditions or institutional circumstances? British Journal of Management, 15(3), 197-218.

Topalova, P., \& Khandelwal, A. (2004). Trade liberalization and firm productivity: The case of India. The Review of Economics and Statistics (0).

Tummala, V. M. R., Lee, H. Y. H., \& Yam, R. C. M. (2000). Strategic alliances of China and Hong Kong in manufacturing and their impact on global competitiveness of Hong Kong manufacturing industries. Integrated Manufacturing Systems, 11(6), 370-384.

Tybout, J. R. (1992). Linking trade and productivity: New research directions. The World Bank Economic Review, 6(2), 189.

UNCTAD. (2002). Trade and development report 1999. Geneva.

UNCTAD. (2010). An investment guide to the Lao People's Democratic Republic Opportunities and Conditions 2010. New York: UNCTAD.

UNDP. (2006). International trade and human development. Vientiane: United Nations Development Programme.

UNDP. (2006). National Human Development Report: International Trade and Human Development, Lao PDR 2006.

UNDP. (2011). Human development report 2011. New York: United Nations Development Program.

UNIDO. (2003). Technology needs assessment in the Lao PDR. Vientiane: United Nations Industrial Development Organisation.

van Wyk, J. (2010). Double diamonds, real diamonds: Botsawana's national competitiveness. Academy of Marketing Studies Journal, 14(2).

Vernon, R. (1966). International investment and international trade in the product cycle. The Quarterly Journal of Economics, 80(2), 190-207. 
Ward, D. (2005). An Overview of Strategy Development Models and the Ward-Rivani Model. Economics Working Papers, June, 1-24.

WB. (2006). Building export competitiveness in Laos: Summary report. Washington, DC: World Bank. WB. (2006). Lao PDR: Diagnostics trade integration study for Lao PDR. Washington DC: World Bank.

WB. (2008). Lao PDR economic monitor. Vientiane: The World Bank.

WB. (2009). Lao PDR recent economic developments Vientiane: The World Bank.

WB. (2010). Natural resource management for sustainable development: Hydropower and mining. Vientiane: The World Bank.

WEF. (2011). The global competitiveness report 2010-2011. Geneva: World Economic Forum.

Wei, S. J. (2000). Natural openness and good government: National Bureau of Economic Research Cambridge, Mass., USA.

Wilson, J. (2008). Territorial competitiveness and development policy. Orkestra, Basque Institute of Competitiveness. Basque Country, Spain, 31.

Winters, L. A. (2004). Trade liberalisation and economic performance: an overview. The Economic Journal, 114(493), 4-21.

Winters, L. A., McCulloch, N., \& McKay, A. (2004). Trade liberalization and poverty: the evidence so far. Journal of Economic Literature, 42(1), 72-115.

Wood, A. (1997). Openness and wage inequality in developing countries: the Latin American challenge to East Asian conventional wisdom. The World Bank Economic Review, 11(1), 33.

WTO. (2012). 10 benefits of the WTO trading system. Retrieved 13th March 2012, from http://www.wto.org/english/res e/doload e/10b e.pdf

WTO. (2012). What is the WTO? Retrieved 03rd March 2012, from http://www.wto.org/english/thewto e/whatis e/whatis e.htm

Wu, D. (2006). Analyzing China's automobile industry competitiveness through Porter's diamond model: Lethbridge, Alta.: University of Lethbridge, Faculty of Management, 2006.

Yao, S., \& Wei, K. (2007). Economic growth in the presence of FDI: The perspective of newly industrialising economies. Journal of Comparative Economics, 35(1), 211-234.

Yin, R. K. (1994). Case study research, design, and methods. Applied social research method series (5): Sage: London.

Yin, R. K. (2009). Case study research: Design and methods (Vol. 5): Sage publications, INC.

Zhuang, J., \& Dowling, J. M. (2002). Causes of the 1997 Asian Financial Crisis: What Can an Early Warning System Model Tell Us? Retrieved 23rd December 2011, from http://www.adb.org/Documents/ERD/Working Papers/wp026.pdf 